Linköping Studies in Science and Technology

Thesis No. 1793

\title{
Introducing New Materials in the Automotive Industry \\ Managing the Complexity of Introducing New Materials in Existing Production Systems
}

\section{Fredrik Henriksson}

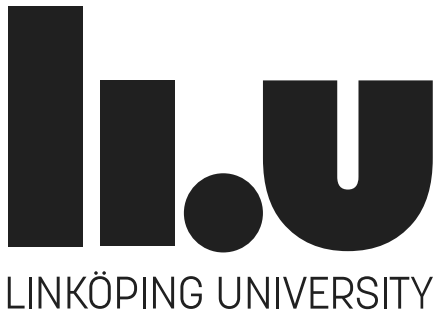

Division of Machine Design

Department of Management and Engineering Linköping University, SE-581 83, Linköping, Sweden

Linköping 2017 
Copyright (C) Fredrik Henriksson, 2017

Introducing New Materials in the Automotive Industry - Managing the Complexity of Introducing New Materials in Existing Production Systems

ISBN 978-91-7685-397-9

ISSN 0280-7971

Distributed by:

Division of Machine Design

Department of Management and Engineering

Linköping University 


\section{A true thing badly expressed becomes a lie}

Stephen Fry 



\section{Du vet att verkligheten är inte alltid så verklig}

Lars Winnerbäck - Dom Tomma Stegen 



\section{ABSTRACT}

Passenger vehicles are central to Western society, and contribute to a significant part of our greenhouse gas emissions. In order to reduce emissions, the automotive industry as a whole is working to reduce mass in passenger vehicles in order to reduce energy consumption. One way to reduce mass is to introduce lightweight materials in the body of the vehicle. This research aims to explore the relationship between product and production system when introducing new materials.

Besides a theoretical review and an industry-centered technological mapping, four case studies have been conducted during the course of this licentiate thesis. Two case studies were conducted with engineering design students working as development teams, one case study with the author as the developer and finally one case study in an industrial environment at a product owning company with in-house production. The goal of the case studies has been to increase the collective knowledge of how product development decisions affect production development decisions, and vice versa, when developing passenger vehicles in new materials.

In the following analysis of case study outcomes, a number of factors important for introducing new materials are discussed. The relationship between product and production is investigated, both in terms of how the production system affects the product and how the product affects the production system. The outcome from this analysis is a mapping of important factors for automotive industry companies to understand and identify when looking at introducing new materials in existing production systems. Finally, a suggestion for future research efforts is presented. 



\section{ACKNOWLEDGEMENTS}

Linköping, October 2017

The research presented in this thesis was performed at the Division of Machine Design, Department of Management and Engineering (IEI) at Linköping University. The research was performed within the Vinnova-funded Produktion 2030 strategic innovation program.

I am grateful for all the support and help that I have received during the time of writing this thesis, I really have been standing on the shoulders of giants in order to see as far as possible. I would like to express this gratitude to several people, for several different reasons.

Firstly, I want to express my gratitude towards my main supervisor, Docent Kerstin Johansen, for discussions about what actually constitutes integrated product and production development, how material, product and production are interconnected and how to present my ideas in a way for others to understand what I am talking about.

My former main supervisor and the person who employed me at Machine Design, Professor Johan Ölvander, for giving me the chance to pursue my doctoral education, giving advice, support and guidance as well as proofreading my efforts during this endeavor.

My second supervisor, Jonas Detterfelt, for active advise regarding research methodology in engineering design, knowledge of the historical progress of the field and advice during the writing of this thesis. 
I would also like to thank all interviewees, industry contacts and students who have put up with my ideas and research efforts. The data you contributed with when performing your work was fundamental in this research, and without your ideas and insights this thesis would not have been what it is right now. Thanks to all my colleagues, current and former, at the Division of Machine Design for supporting me while researching and writing my thesis as well as creating an environment where I've looked forward to coming into work (almost) every day.

Finally, I would like to thank my family: My parents for putting up with my ramblings about research projects, deadlines, interview questions and all other things that have filled my head the last years. Thanks to my sister Frida, for helping me make this thesis look at least semi-decent. Your help and support has meant a lot.

Fredrik Henriksson 


\section{APPENDED PUBLICATIONS}

The appended papers are the basis of this thesis, and referred to as papers $\mathrm{A}-\mathrm{C}$ in the text. The papers are printed as they were originally published except for format changes.

\section{Paper A}

Henriksson, F. \& Johansen, K., 2016. An Outlook on Multi Material Body Solutions in the Automotive Industry - Possibilities and Manufacturing Challenges. In: SAE 2016 World Congress and Exhibition. Detroit, United States, 12 - 14 April 2016.

\section{Paper B}

Henriksson, F. \& Johansen, K., 2016. On Material Substitution in Automotive BIWs-From Steel to Aluminum Body Sides. In: 26th CIRP Design Conference, Stockholm, Sweden, 15 - 17 June 2016.

\section{Paper C}

Henriksson, F. \& Johansen, K., 2016. Including Student Case Projects in Integrated Product and Production Development Research - Methodology Description and Discussion. In: 7th Swedish Production Symposium, Lund, Sweden, 25 - 27 October 2016. 



\section{ADDITIONAL PUBLICATIONS}

Following additional publications were published during the course of the research, but are not included or discussed in this licentiate thesis.

Henriksson, F. \& Johansen, K., 2014. Towards Applying The Boothroyd, Dewhurst and Knight Methodology for Cost Estimation on Fibre Composite Manufacturing - A Theoretical Approach. In: Proceedings of The 6th International Swedish Production Symposium 2014, Gothenburg, Sweden, 16-18 September 2014.

Henriksson, F. \& Johansen, K., 2015. Product development in the Swedish Automotive industry: Can design tools be viewed as decision support systems? In: The 23rd International Conference on Production Research, Manila, Philippines, 2 - 5 August 2015.

Henriksson, F.; Johansen, K.; Wever, R. \& Berry, P., 2016. Student-developed laboratory exercises - An approach to cross-disciplinary peer education. In: NordDesign 2016 - Highlighting the Nordic approach, Trondheim, Norway, 10 - 12 August 2016.

Kurdve, M.; Henriksson, F.; Wiktorsson, M.; Denzler, P.; Zachrisson, M. \& Bjelkemyr, M., 2017. Production System And Material Efficiency Challenges For Large Scale Introduction Of Complex Materials. In: Advanced Materials Proceedings, Volume 2 Issue 8 (492 - 499), 2017. 



\section{ABBREVIATIONS}

\begin{tabular}{|l|l|l|}
\hline Abbreviation & Meaning & Unit \\
\hline CFRP & Carbon Fiber Reinforced Polymer & - \\
\hline ABS & Acrylonitrile Butadiene Styrene (polymer) & - \\
\hline DFMA & Design for Manufacturing and Assembly & - \\
\hline PDP & Product development process & - \\
\hline FC & Vehicle's fuel consumption & $\mathrm{L} / \mathrm{km}$ \\
\hline $\mathrm{b}_{\mathrm{e}}$ & Engine's specific fuel consumption & $\mathrm{L} / \mathrm{kWh}$ \\
\hline $\mathrm{t}$ & Time & $\mathrm{s}$ \\
\hline $\mathrm{v}$ & Instantaneous vehicle speed relative to ground & $\mathrm{m} / \mathrm{s}$ \\
\hline $\mathrm{F}_{\mathrm{t}}$ & Tractive effort & $\mathrm{kN}$ \\
\hline $\mathrm{n}$ & Drivetrain efficiency & $\mathrm{N}$ \\
\hline $\mathrm{F}_{\mathrm{ROLL}}$ & Rolling resistance & $\mathrm{N}$ \\
\hline $\mathrm{F}_{\text {ACC }}$ & Acceleration resistance & $\mathrm{N}$ \\
\hline $\mathrm{F}_{\mathrm{DRAG}}$ & Aerodynamic drag & $\mathrm{N}$ \\
\hline $\mathrm{F}_{\mathrm{CLMB}}$ & Climbing resistance & $\mathrm{N}$ \\
\hline $\mathrm{f}$ & Rolling resistance coefficient & - \\
\hline $\mathrm{m}$ & Vehicle payload mass & $\mathrm{kg}$ \\
\hline $\mathrm{g}$ & Gravitational acceleration & $\mathrm{m} / \mathrm{s} 2$ \\
\hline $\mathrm{a}$ & Vehicle acceleration & $\mathrm{m} / \mathrm{s} 2$ \\
\hline $\mathrm{C}_{\mathrm{D}}$ & Drag coefficient & - \\
\hline$\rho_{\text {AIR }}$ & Air density & $\mathrm{kg} / \mathrm{m} 3$ \\
\hline $\mathrm{A}$ & Vehicle frontal area & $\mathrm{m} 2$ \\
\hline $\mathrm{v}$ & Instantaneous vehicle speed relative to air & $\mathrm{m} / \mathrm{s}$ \\
\hline$\alpha$ & Slope angle from horizontal & $\mathrm{degrees}$ \\
\hline & & \\
\hline
\end{tabular}





\section{CONTENTS}

Part 1 - Introducing the work

1.1 Introduction

3

1.2 Background

3

1.3 Aims and objectives 11

1.4 Research questions 12

$\begin{array}{ll}\text { Part } 2 \text { - Frame of Reference } & 15\end{array}$

2.1 Theoretical overview $\quad 17$

2.2 Research methodology 30

Part 3 - Technology Mapping 39

3.1 Material Properties $\quad 41$

3.2 State of the Industry $\quad 48$

3.3 A general model for passenger vehicle production $\quad 59$

Part 4 - Contribution 63

4.1 Industrial problem analysis $\quad 65$

$\begin{array}{ll}4.2 \text { Case studies } & 70\end{array}$

4.3 Analysis and discussion $\quad 85$

4.4 Conclusions 101

4.5 Future research 104

$\begin{array}{ll}\text { References } & 107\end{array}$ 



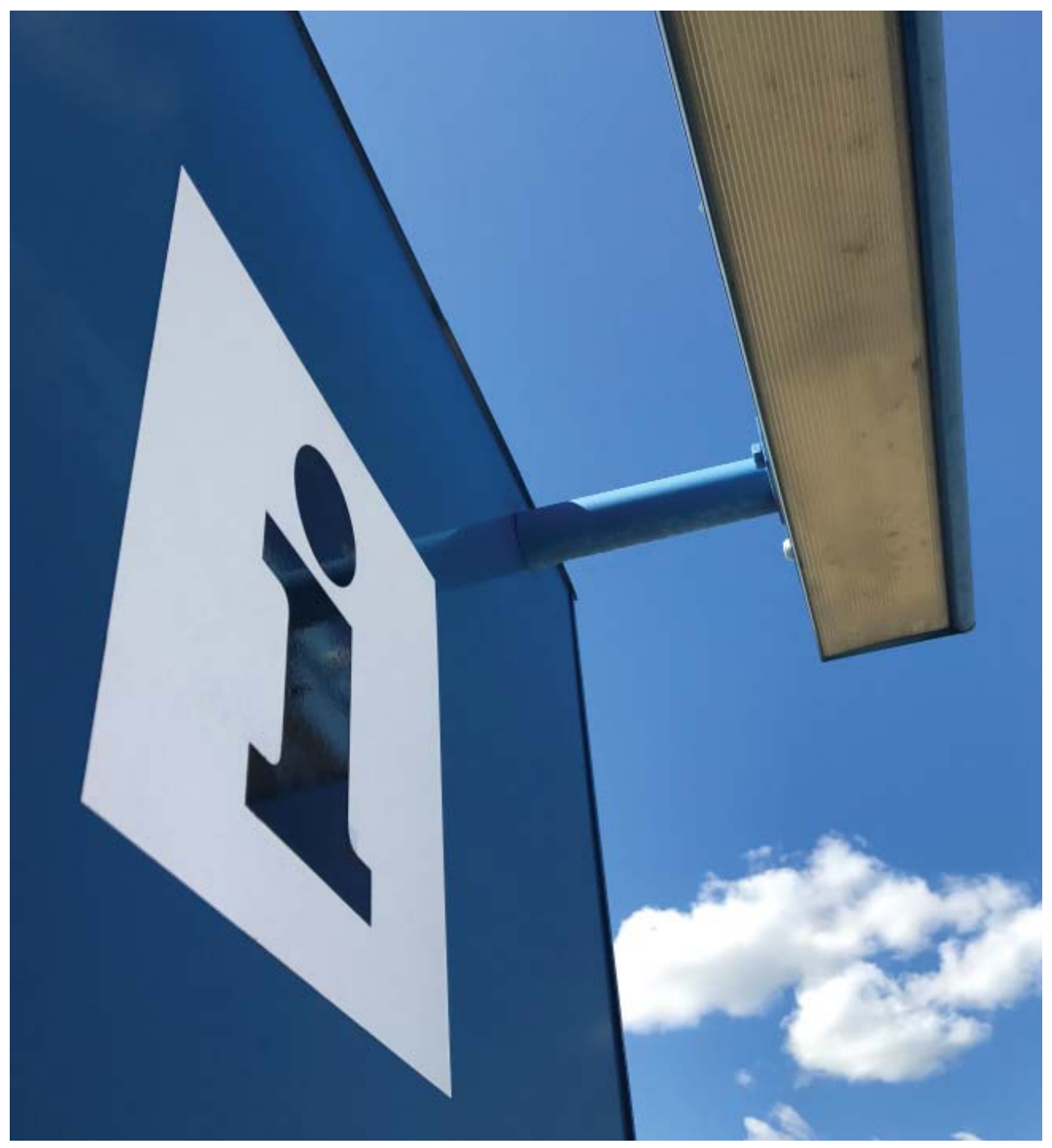

\section{PART 1 - INTRODUCING THE WORK}




\section{PART 1 - INTRODUCING THE WORK}

In Introducing the work, the introduction to and background for the work performed are presented. This part should be read as an introduction to the research performed and presented in the thesis, explaining the academic and industrial need for research within the area of integrated product and production development as well as providing an understanding of the research questions posted.

Picture on previous page courtesy of author. 


\subsection{INTRODUCTION}

"Why can’t we just switch the material?"

The question might seem valid, and we have probably all said it to ourselves at one point in time during some project. Moreover, while it might seem easy to change material in a product, there is a certain risk that the product would come out significantly worse than before - if it were even possible to manufacture the product, that is. Switching the material of a product or component is much more than changing a drop-down menu in a CAD software application; instead, it necessitates further evaluation of both product and production properties to become a viable engineering design decision. Is it possible to create the selected geometry in the new material? Is it economically viable? These are just some of the questions that need to be answered.

\subsection{BACKGROUND}

In 2015, the United Nations signed the Global Goals for Sustainable Development [1]. These goals focus, among other things, on economic growth and environmental sustainability [2], and a possible way of achieving these goals is to introduce more sustainable materials in products that are distributed to the public in order to reduce 
environmental impact while enabling economic growth.

Looking at the possible challenge of introducing new materials into products produced in existing production infrastructure, a significant amount of research has been done in the underlying research fields that form the basis of this field; product development research, materials and structural engineering and production engineering research. This can be seen in different applications, as academic and industry-based research has covered the design of specific components in lightweight materials [3], material selection methodologies [4, 5], mass optimization [6] and production development for new materials [7], but there is a research gap when looking at the introduction of new materials in an existing production system. The situation defined by introducing new materials in products produced in existing production infrastructure is general, and can be seen in the automotive industry as well as aerospace industry, consumer product industry and others. Looking at the impact of mass reduction and multi-material design in the automotive industry, the research was applied to this specific industry sector.

\section{Automotive industry challenges}

Personal transport, and the transport sector of the industry, are vital components in Western society, where Sweden could be a suitable example. The transport sector in Sweden contributes to $33 \%$ of the total greenhouse gas emissions (measured in C02 equivalents) in the country, with road transports contributing to $93 \%$ of these emissions; out of these $93 \%$, passenger cars contribute to $64 \%$ of the emissions [8]. This means that passenger cars contribute to approximately $19.6 \%$ of the total greenhouse gas emissions in Sweden. These numbers will differ from country to country, but it becomes evident that personal transport and passenger cars have a significant impact on emissions.

With a predicted growing middle class globally $[9,10]$, and thus an increased 
availability of personal transportation (sources indicate a slight shift from work-related transport to leisure-related transport in Sweden [11, 12]), along with tightened regulations on pollution and energy consumption, the automotive industry needs to increase energy efficiency in the vehicles it produces. One way of achieving this is to reduce weight, or in some cases to keep weight at the present level while introducing new functionality in the vehicle (to keep up with market demands). This could be seen as increasing the "functionality over mass quota" for the product, or creating a higher mass efficiency in the product.

Increasing mass efficiency could be solved by a more diverse choice of materials for components and products, and this is a current trend in the automotive industry with the multi-material design of many components (see the "State of The Industry" section for further information). This increased diversity can be seen in figure 1, showing material decomposition in American automobiles over the latest 40 years $[13,14]$. Notably, the plastic and plastic composites as well as aluminum content have grown with time, while regular steel proposes a smaller portion of the materials with each year (from $\sim 54$ per cent to $\sim 35$ per cent) $[13,14]$. Looking at this shift for the industry, it seems like advances in material and manufacturing technology, along with increased demands on sustainability, enable new materials to be introduced and used increasingly in mass-produced vehicles.

This material diversification poses questions regarding the development of new products: How can new materials be introduced more effectively, and how is the material distribution managed when developing a new vehicle? If it is possible to reduce the implementation time and effort of introducing new materials the industrial and environmental gain could be significant, since more effective products could be launched to market earlier.

To summarize, the automotive industry needs to introduce new materials to 
reduce mass in their products, without sacrificing functionality or increasing the cost outside the customer's prize range. This also needs to be done continuously, and with short lead time in order to be able to follow market trends as well as legal requirements.

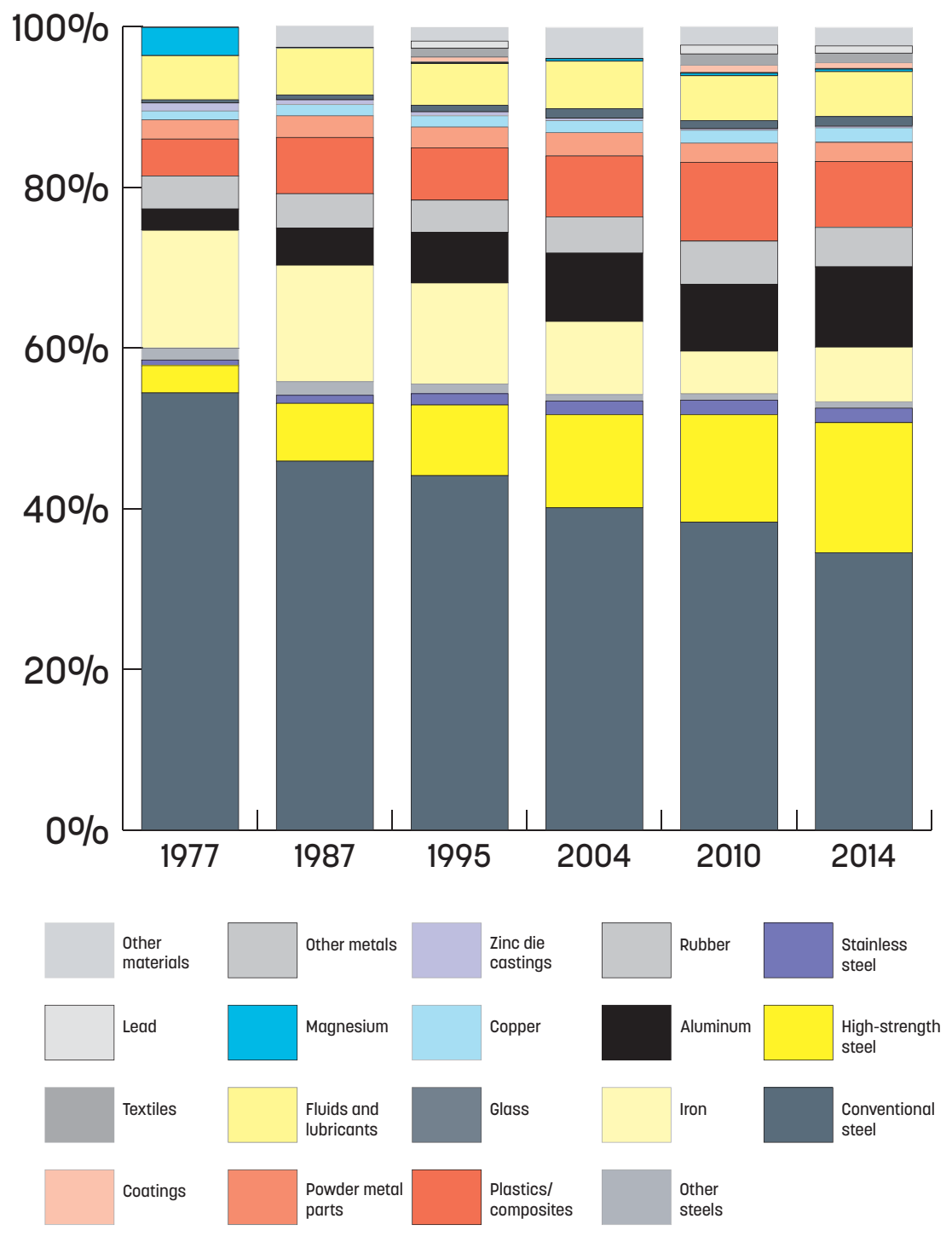

Figure 1. Material distribution (in \%) of an average American car by year (adapted from [13] and [14]). 


\section{Production system challenges}

To be able to introduce new materials, the production system needs to be taken into account. The production system can be defined as "the people, equipment, and procedures that are organized for the combination of materials and processes that comprise a company's manufacturing operations" [15]. The development of such a system is called production development. Automotive production systems are complex, complicated systems of systems that many times manage many different products simultaneously, and do not necessarily have the same life cycle (neither in time span nor place in time) as the products managed within the production system. In dialogue with engineers working in the Swedish automotive industry, it has been brought forward that the development of a production system is often more incremental than that of a product, due to the size and complexity of the system; greenfield production development (that could be compared to new product development) in this field is rare and very resource demanding. This means that the development time for a production system is longer than that of a product, since design decisions from earlier production system development are carried over in the physical configuration of the production system.

To summarize, the challenge for the production system is to enable both existing and new materials, in future and present products, at an acceptable cost and without the need for costly downtime while reconfiguring or investing in the infrastructure (buildings, electricity, water, waste treatment, etc.) or production equipment.

\section{Product development challenges}

Before a product is introduced into production, a significant amount of work is put into developing it. Product development is, as defined by Krishnan and Ulrich, "the transformation of a market opportunity and a set of assumptions about product technology into a product ready for sale" [16]. Product development processes are 
therefore the sequencing of methods that companies use to bring new products to a demanding market [17] where the goal is to "create a 'recipe' for producing a product" [18].

A product development project can be described as a way of going from a scope (market opportunity and assumptions about product technology in Krishnan's and Ulrich's definition) through using data, tools and knowledge in a process to creating a result (as described in figure 2). Figure 2 explains how the factors scope, data, knowledge and result in some way create boundaries for the process. The process here would be the sequencing of tasks and decisions in order to move towards the best possible solution (the result) given the scope, tools, knowledge and data at hand.
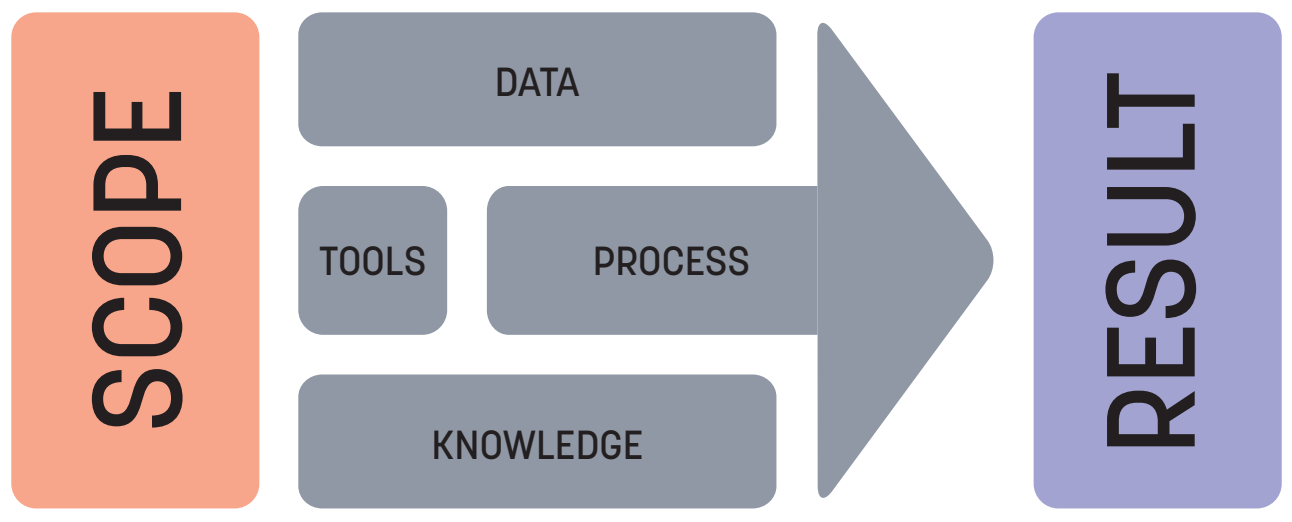

Figure 2. A generic model of a product development project.

Changing the material in the product would typically correspond to a change of scope and result, as well as lower levels of data and knowledge regarding these new product technology assumptions. Changing the material in the product while keeping the same (or a very similar) production system would correspond to a partially changed scope, a changed result, and lower levels of data and knowledge regarding these new product technology assumptions due to path dependency as well as lost or forgotten knowledge about decisions regarding the kept production system segments. 
To summarize, product development engineers need to develop new and interesting products, creating value for customers while still keeping production cost (both in terms of unit cost and investment needs) within company profitability margins. This needs to be done more efficiently, since product life cycles are decreasing while product functionality is increasing.

\section{An Industrial example}

As an example of an industrial context, Volvo Cars $\mathrm{AB}$ is a company that needs to manage the aforementioned challenges of the introduction of new materials in the automotive industry, along with a change in product development work and in production development work at its Torslanda plant in Gothenburg, Sweden.

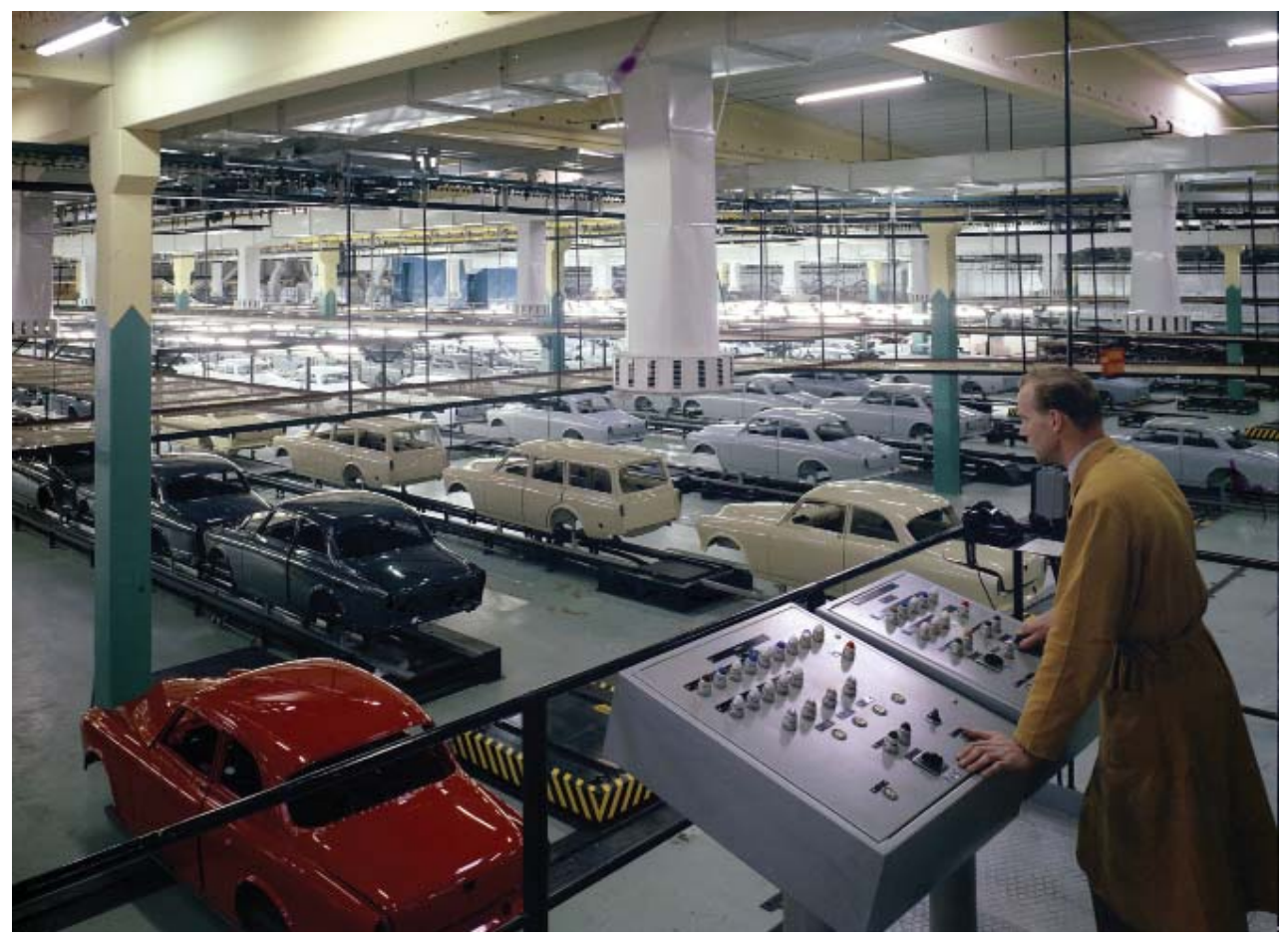

Figure 3. Historic picture from Volvo Cars Torslanda [picture courtesy of Volvo Cars AB]. 
Volvo Cars AB have been a vehicle manufacturer since 1927, and have since then been producing cars in Gothenburg, Sweden. The current plant in Gothenburg, Volvo Cars Torslanda, was opened in 1964 [19] and has been developed and expanded since. figure 3 shows how the plant looked in the late 1960s, while figure 4 shows a more recent example of production at Volvo Cars Torslanda.

Volvo Cars Torslanda uses mixed-model assembly lines, which means that multiple models with different assembly requirements are assembled on the same production line and with units of different models mixed in sequencing [20]. As of May 2017, four models were assembled at Volvo Cars Torslanda: the S90 II, V90 II, XC90 II and XC60 II, all built on the SPA platform [21, 22, 23]. When the first model built on the SPA platform, XC90 II [21], was introduced, models built on earlier platforms were still made at Volvo Cars Torslanda. This meant that the mixed-model assembly lines had to accommodate both different models and platforms.

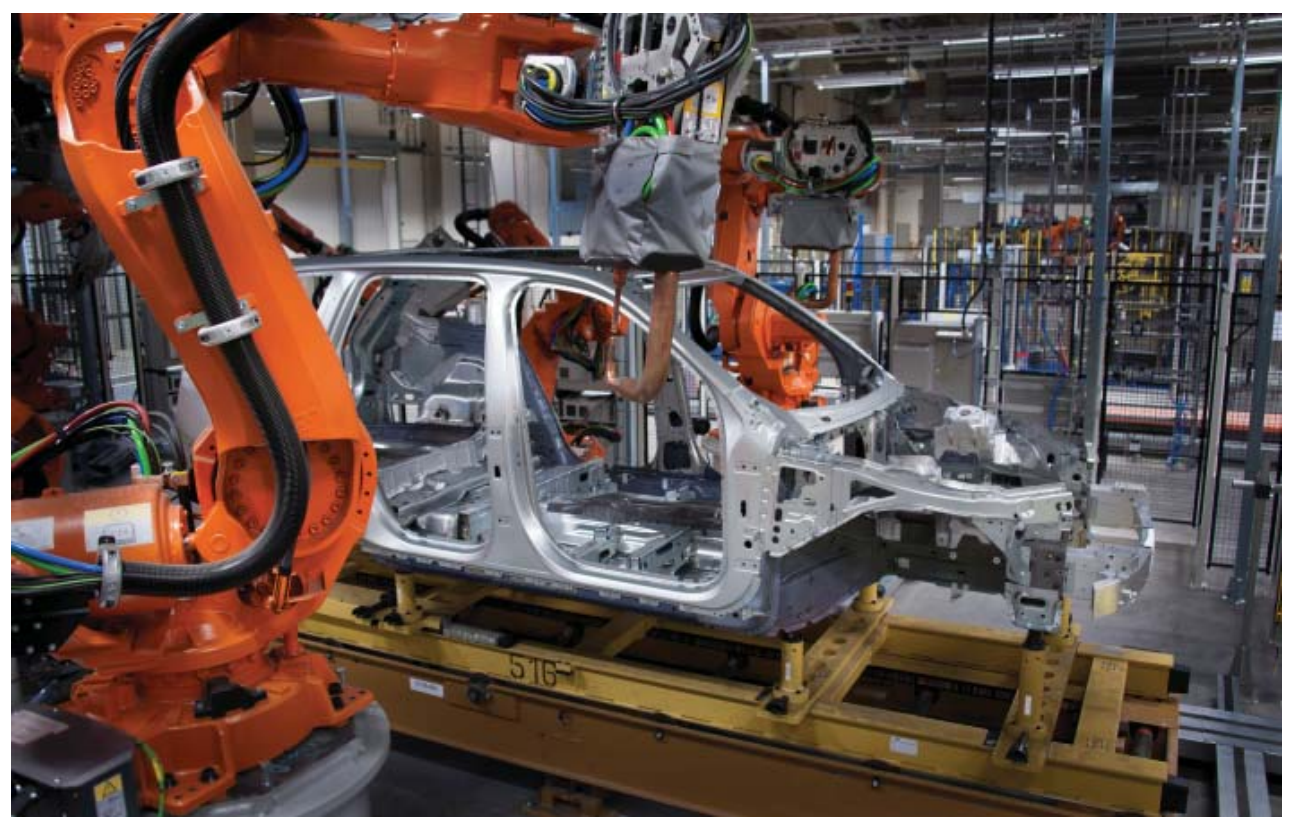

Figure 4. Production of the second generation XC90 at Volvo Cars Torslanda [picture courtesy of Volvo Cars $A B]$. 


\subsection{AIMS AND OBJECTIVES}

The overall aim of this thesis is to enhance the product realization process by increasing knowledge of the relationship between product and production development in a certain context: the introduction of new materials into existing production systems within the automotive industry.

The objective of this thesis is to increase the knowledge of how product development decisions affect the production development design space, and vice versa, when developing in new materials (or materials where the organization has very limited prior knowledge) for existing production systems in the automotive industry.

The value gained for a company from a specific product $(\mathrm{P})$ can be described as [24]

$$
\prod P=\int_{0}^{\infty} e^{-r t}(Q(t)(p(t)-c(t))-F(t)-S(t)-D(t)) d t,
$$

where $Q(t)$ is the rate of unit sales; $p(t)$ is the unit revenue; $c(t)$ is the variable unit cost; $\mathrm{F}(\mathrm{t})$ is the design-specific fixed cost; $\mathrm{S}(\mathrm{t})$ is the system cost (including, among other things, overhead), support functions, and so on; and $\mathrm{D}(\mathrm{t})$ is the cost from product and process development [24]. The effect of the research presented in this thesis could be a reduction in $\mathrm{D}(\mathrm{t})$ in order to reduce risks of introducing new materials in existing production systems. 


\subsection{RESEARCH QUESTIONS}

In order to aim the research process towards the research objective, three research questions were formulated. These three research questions correspond to the studies performed. The conclusions should fit the topic of introduction of new materials in the automotive industry, and highlight different aspects of this complex challenge.

\section{RESEARCH QUESTION 1}

How does the production system affect the introduction of new materials in products?

\section{RESEARCH QUESTION 2}

How well suited are current product development processes to manage the introduction of new materials?

\section{RESEARCH QUESTION 3}

How could product and production development processes be altered to ease the introduction of new materials?

\section{Structure of the thesis}

The thesis has been divided into four distinct sections, as seen in figure 5: Introducing the work, Frame of reference, Technological mapping and Contribution. In Introducing the work, the background for the thesis is presented along with aims, objectives and research questions. Frame of reference explains the theoretical framework and research methodology that the research in this thesis is based on. In the section Technological mapping, the author highlights material characteristics needed to explain the technological challenge of introducing new materials in existing production 
systems, explores the state of the industry and presents a generalized model of car production. In the final section, Contribution, a state-of-the-industry review is presented along with a theoretical analysis and descriptions of four case studies performed. These six data sets are then analyzed to formulate conclusions to the research questions presented in the first section.

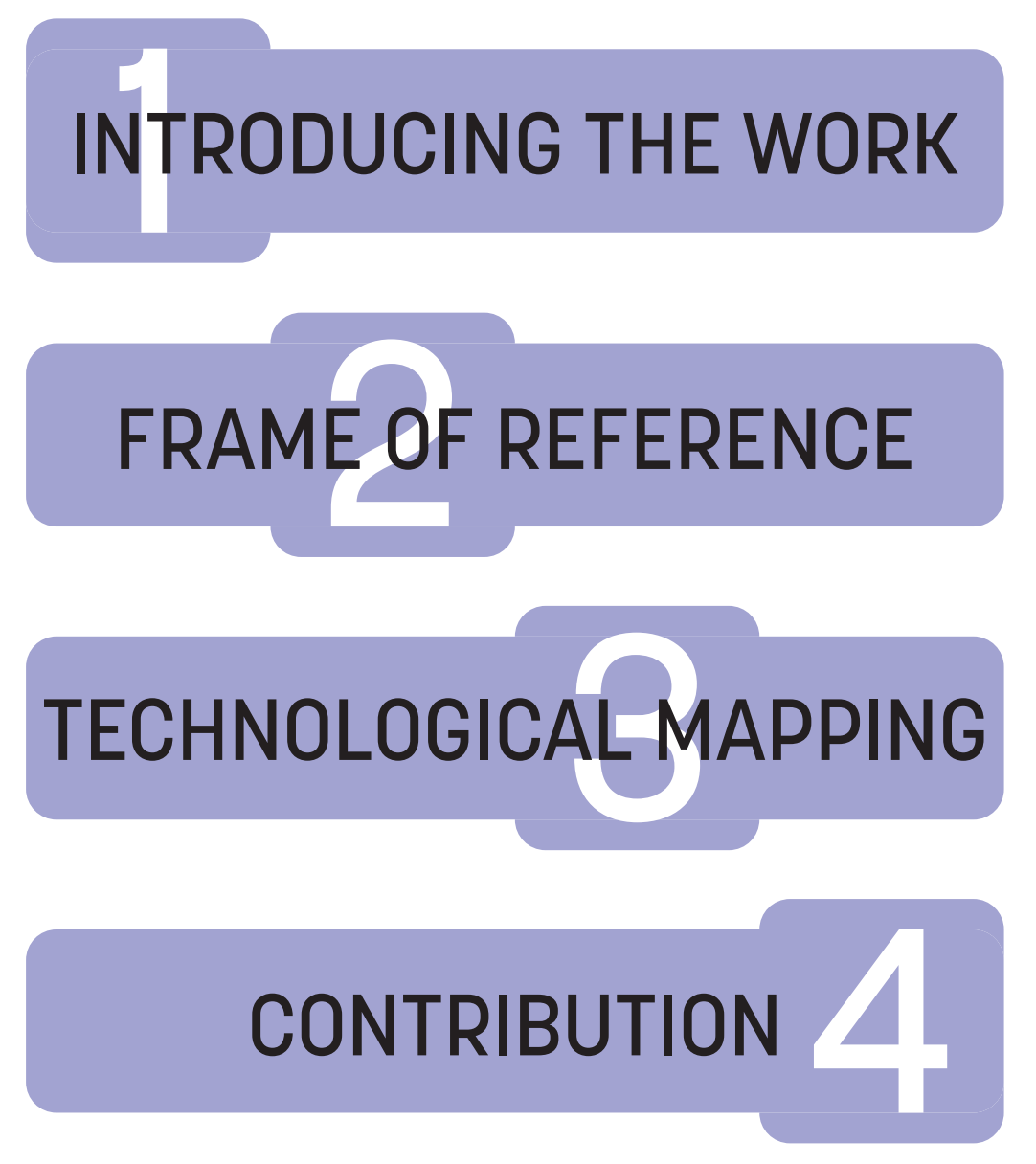

Figure 5. The main structure of the thesis. 



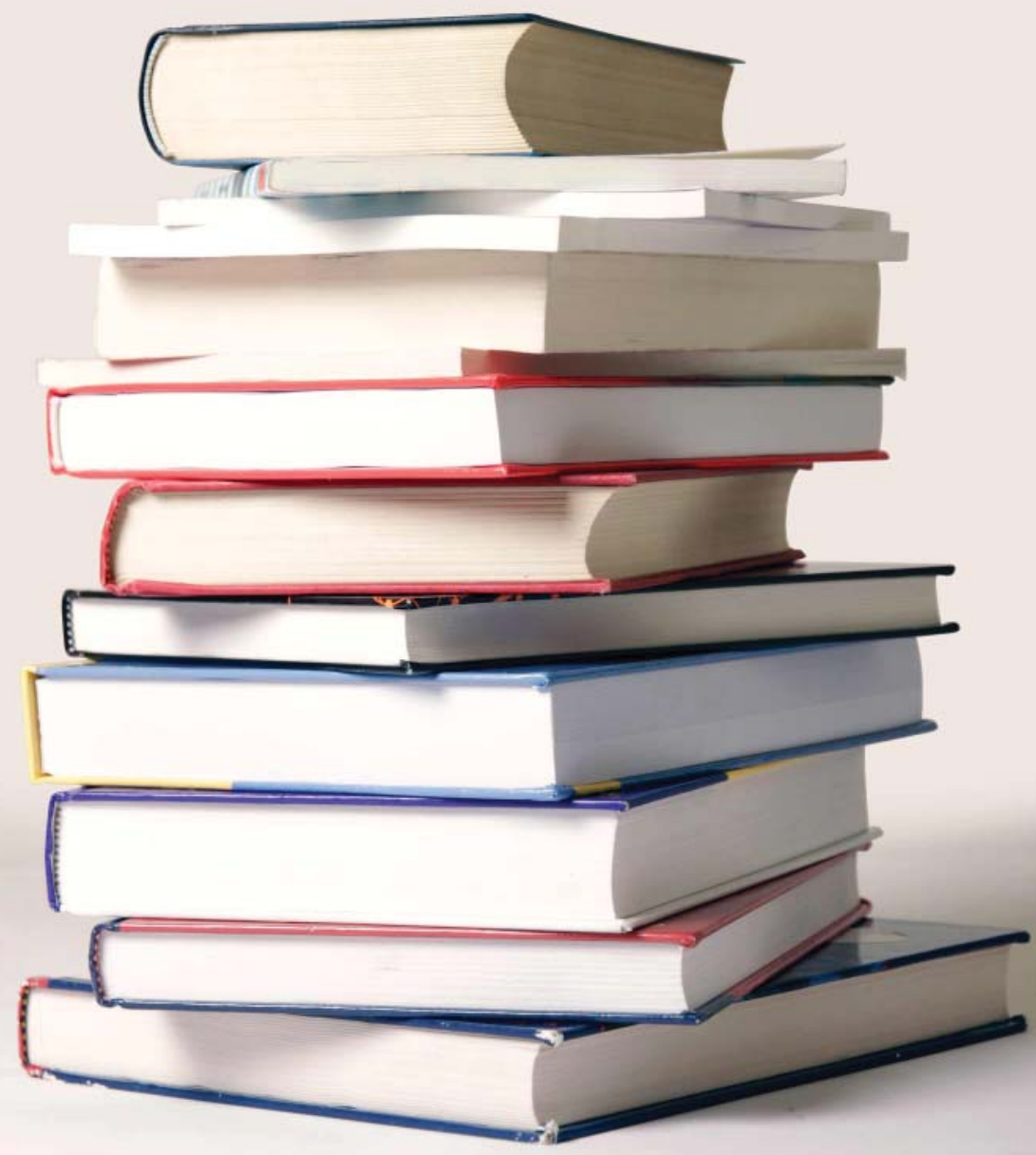

PART 2 - FRAME OF REFERENCE 


\section{PART 2 - FRAME OF REFERENCE}

In the frame of reference, the theoretical framework is presented along with the methodology used in this thesis. This part should be read as a benchmarking of existing work in the academic arena, especially regarding the research fields of product development and production systems.

Picture on previous page courtesy of Philip Ekströmer. 


\subsection{THEORETICAL OVERVIEW}

The theoretical overview will cover two domains: product development and production systems. Some effort will also be put into exploring the overlap between the domains that can be seen in figure 6 .

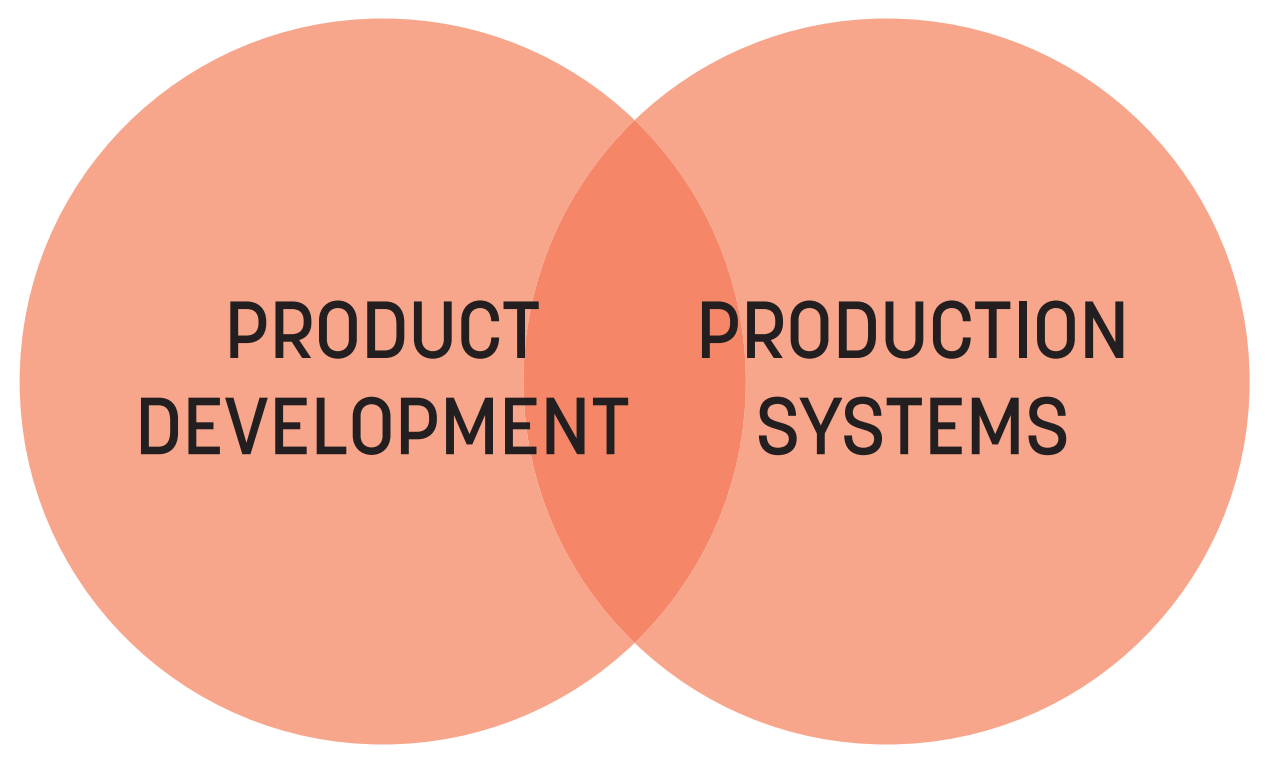

Figure 6. A visualization of the theoretical overview. 


\section{Product development}

Product development is, as defined by Krishnan and Ulrich, "the transformation of a market opportunity and a set of assumptions about product technology into a product ready for sale" [16]. Product development processes are therefore the sequencing of methods that companies use to bring new products to a demanding market [17], with the goal to "create a 'recipe' for producing a product" [18] that can increase the company's revenue. The impact of the product development process on the resulting product is debated: some authors have proposed a clear connection between systematic product development processes and commercial gain [25, 26], while others suggest that it is not the methods but rather the interactions between actors in the organization that undertake the development project that creates profitable products, and that what has been contributed to the methodology by other authors has been confused with the result of the process [27]. This has analogies in work on software design, suggesting that the rational design process is at best a work of fiction, but that there might be reasons to fake a rational design process by creating documentation suggesting such [28]. Others have reported on a connection between the usage of formal methods and development time (shortened) and project failure rate (reduced) [29].

With a cross-disciplinary topic like product development, different perspectives become apparent in academic publications. At least four common - and different perspectives on product development exist: marketing, organizational, engineering design and operations management [16]. These perspectives also affect which type of knowledge regarding the product development process is presented in the research. Looking specifically at the interface between design and manufacturing, Dekkers et al. [30] present six reoccurring themes on the interface stemming from these perspectives on product development: a) integral productivity, b) order entry points and modularity, c) product life cycle management, d) sourcing decisions 
and supplier involvement, e) integrated processes and coordination, f) enabling through ICT" [30].

\section{Product development processes}

Product development processes can be divided into two types of process models: linear or quasi-linear process models and non-linear process models. In linear or quasi-linear process models there is a clear sequencing of tasks, and while iterations might be mentioned in the description of the process, they are not emphasized nor described in the visualizations of the process models. The iteration and lack of sequencing is more articulated in the non-linear process models, some of which explicitly describe a working process with no self-evident order of tasks and many iterations before a product is finished.

\section{Linear or quasi-linear process models}

Linear or quasi-linear process models emphasize a sequential dependence between different activities within a product development project. Established variants of the linear or quasi-linear process have been introduced by Ulrich and Eppinger [31], Ullman [32], Cooper (with the stage-gate model) [25, 33, 34, 35] and the Systematic Engineering Design community led by Pahl, Beitz, Hubka and Eder [26, 36]. Linear product development process models are restricted by their lead times and the builtin sequential approach to development tasks [17].

Ulrich and Eppinger [31] describe a simplified, linear model of the development of new products (as seen in figure 7), with focus on the types of thinking involved (divergent or convergent). Focus is on the three functions in a company central to the development of new products: marketing, design and manufacturing [31]. Ulrich and Eppinger suggest six important and distinct phases in the development of new products [31], something that is reinforced by Ullman [32]. Cooper suggests five stages instead of six [25]. The Systematic Engineering Design community 
is split on how many phases a product development project should be divided into; Hubka and Eder suggest six phases [36], while Pahl and Beitz propose five [26]. Apparent in all descriptions is that the product development process can be divided into distinct and identifiable phases with different activities, tools and objectives. Instead of referring to different phases, one can talk about development activities and what happens within these activities.

An interesting anomaly is that the stage-gate model does not start with a user problem of some sort, but instead begins with a product idea. This means that the following feasibility analysis and customer/user research stage is colored by the initial product idea. Other linear product development process models start with a user problem.

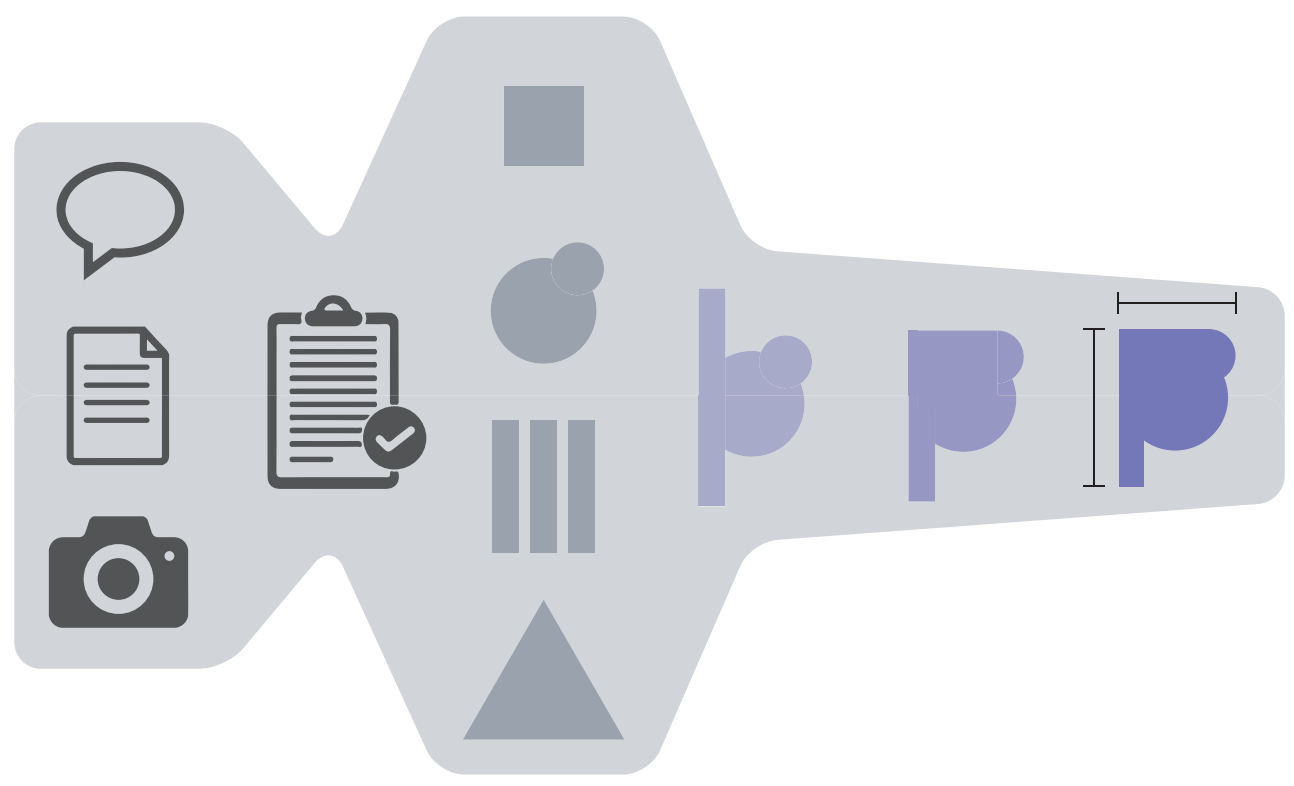

Figure 7. The product development process as described by Ulrich and Eppinger [31]. 
Common for all of the linear product development process models is that they do not propose a plan of action for ambiguous input, especially if the input is some sort of analysis based on output from the process itself. . The processes are designed to progress, with the next phase or activity building on a clearly defined input which comes from the output from an earlier phase or activity. This implies that work might halt in a linear process if the result of an activity is "maybe" instead of a clear "yes" or "no".

\section{Non-linear process models}

Non-linear process models do not have a common view on the progression of the product development process, but all stray away from the linear and sequential progression model described by, for example, Ulrich and Eppinger [31]. Concurrent engineering, as coined by Prasad [37], is described as two sets of technological and organizational factors that require integration and development: integrated product and process organization and integrated product development. Concurrent engineering principles have been used to integrate product and production systems development in some cases [38], then often coupled with systems engineering principles and their focus on holistic development [39], as seen in Figure 8. Concurrent engineering could be used to develop products and production systems in collaboration if both are modeled as a combined system. Systems engineering could be used to describe such a complex system, although this requires access to detailed data on a large number of parameters.

Another way of approaching non-linear development is to adapt Agile development strategies. The Agile development methodology originates in software development [40], and works around an iterative and incremental process where changes in requirements are encouraged in order to maximize the relevancy of the finished product [41]. One of the main goals is to have a functioning product at the end of each iteration [41]. 


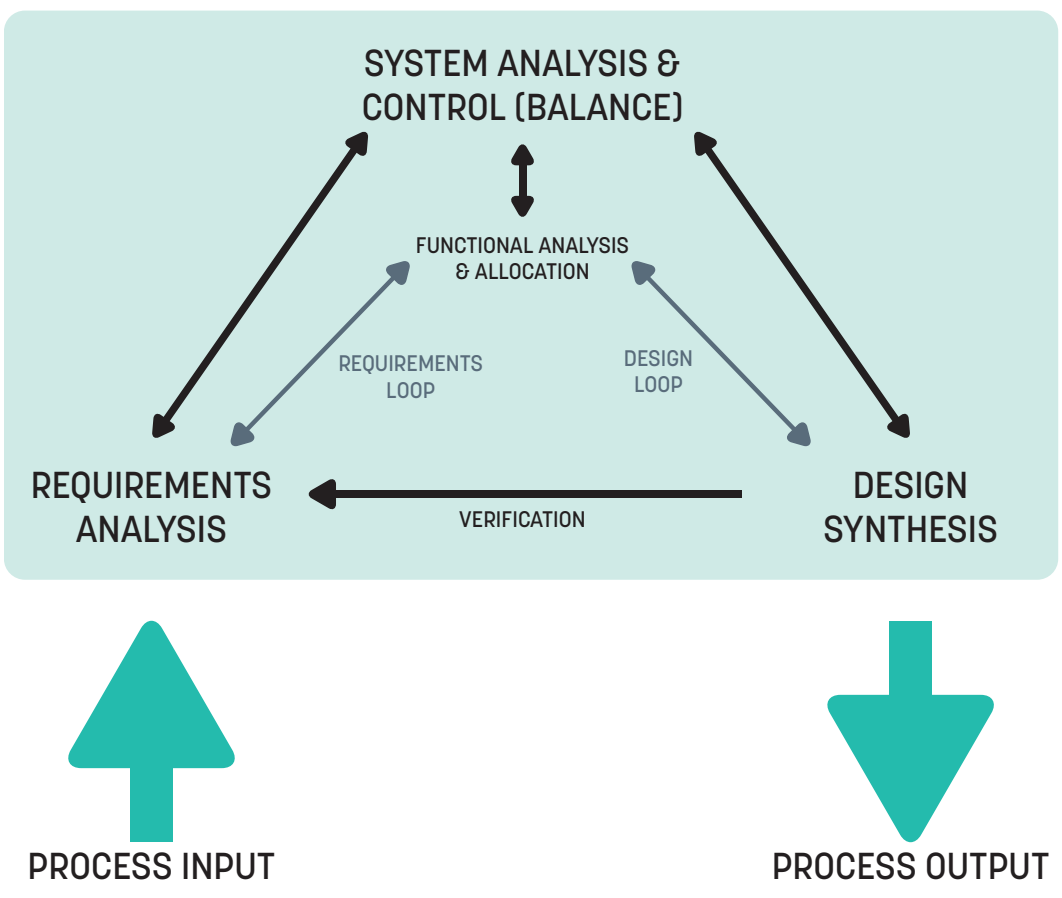

Figure 8. Systems Engineering as described by Prasad [37].

\section{Analysis of product development process models}

While all the evaluated product development process (PDP) methodologies address production, there is no real consensus on how the production system should be developed at the same time as new products are developed. The methodologies mentioned in this thesis still view the production system as a fixed system with a set of restrictions that could be adhered to or discarded, but not reworked or abstracted as, for example, customer demands.

The PDP methodologies described as linear (Ulrich \& Eppinger, stage-gate models) seem to be more challenging to combine with an integrated model of product and production development. This could be due to the iterative nature of an integrated product and production development process, but cannot be solely 
contributed to this factor. While visual representations of the process are important, they do not give the full representation of the authors' line of thought on the product development process.

Neither the linear nor non-linear models are perfectly suited for integrating product and production system development, since the linear models have issues with ambiguity in outputs from activities, while the non-linear models require either large quantities of reliable data reducing the opportunity for innovation or require an extremely modular output from the process, more akin to software than integrated systems of software and hardware.

\section{Product modularity, platforms and architecture}

In order to rationalize the development and manufacturing of multiple products and variants in the same manufacturing facility resulting in a higher number of possible product variants for the same cost and a reduced time to market [42], product-producing companies have developed modularity strategies for products and product families. Product modularity means that the product is divided into several sub-groups or sub-systems [43], with interfaces between modules. Typical interfaces are attachment interfaces, spatial interfaces, transfer interfaces, control/communication interfaces, user interfaces and environmental interfaces [44]. These modules can then be integrated into products in different manners; within a company, the manner of integrating modules and components is called an architecture [45]. Architectures can be both highly modular (with a high level of interchangeability between modules) and highly integrated (with a low level of interchangeability between modules) [46]. According to Shibata et al. [47], as technology matures, product and technology-related knowledge increases and market demands change, most product segments evolve from an integrated architecture with complex interfaces towards a more open modularity with less complexity in interfaces 
and in the connection between structures and functions.

Since components can be divided into standard segment components, brand-identifying components and specific model components [43], product-producing components use this to group components of the same class into modules in order to account for future design updates [48].

Product platforms are combinations of an architecture and standard segment or brand-identifying components and modules that are shared across a range or family of products [49]. Platforms are used to reduce development time for new products while adding capabilities to upgrade or introduce new products [50] and lower variable cost for subsystems [49], but can generate a level of overdesign for low-end products and are not suitable to implement if the market diversity is too low or too high [49]. Some researchers have suggested an expansion of the product platform topic to further include production processes [51].

\section{Design for manufacturing and assembly}

Design for manufacturing and assembly, or DFMA, is a structured approach to product development in order to minimize waste (in time, cost and material) in production and to create efficient products. Ulrich et al. [24] describe the goal of DFM, a part of DFMA, as to make a product easy to manufacture during the design phase of the product development process. Two important objectives in DFMA are reducing the number of components and thus reducing processing and assembly, and designing the remaining components in order to simplify processing and assembly [52]. Value engineering, the practice of questioning material and process selections in order to find solutions with lower costs while still providing a comparable functionality, is also an important part of DFMA [53]. One of the main changes of the design process is to spend more time in the conceptual design phases in order to reduce time needed to change design due to manufacturing restrictions [54]. 
DFMA is one way of mitigating the risks of over-the-wall design approaches, , where the design engineer finishes the design on their own and delivers it to the manufacturing engineer to figure out how to produce [54]. The over-the-wall design approach was the traditional way of developing new products when the complexity of products had exceeded what one person could manage, but before structured ways of performing tasks within the development process simultaneously or in parallel had been developed [32].

\section{Production Systems}

All cars, and other products, have at some point in time been made into a product. The terms manufacturing and production are sometimes used interchangeably for the activity of converting raw materials into products. Kalpakjian and Schmid [55] describe this as manufacturing, and define the activity as "the process of converting raw materials into product." Merriam-Webster defines production as "the creation of utility; especially: the making of goods available for use" [56], and manufacturing as "the process of making wares by hand or by machinery especially when carried on systematically with division of labor" [57], so these two words have very similar meaning in the English language. Therefore, the author has chosen to define production and manufacturing within the work of this thesis.

Production is, in this thesis, defined as the umbrella term for all activities involved in transforming the product from a digital or physical description of the product, its components and how they are interfacing each other, into a physical entity ready to be sold and used. In this thesis, production consists of manufacturing and assembly (as seen in Figure 9), and manufacturing in itself consists of activities such as forming, cutting, joining, casting and surface treatment, as illustrated in Figure 9. These descriptions of manufacturing and assembly are very similar to what Boothroyd et. al use in their base for DFMA [54]. 
While joining is present both as a manufacturing and assembly process, permanent joining would generally be considered a manufacturing process and non-permanent joining an assembly process, but there are exceptions to this classification.

This aforementioned definition of production does not take software changes into account. This is based on the view that a software installation or change is a rationalization of a production process (different hardware with implemented software for each variant) into the reconfiguration of the software. As an example, the engine control unit in a line of cars could either be dedicated and have different hardware specifications for each power output, or have generalized hardware and use software reconfiguration in order to differentiate the product. In this thesis, the first scenario is assumed to be the case within the production process.

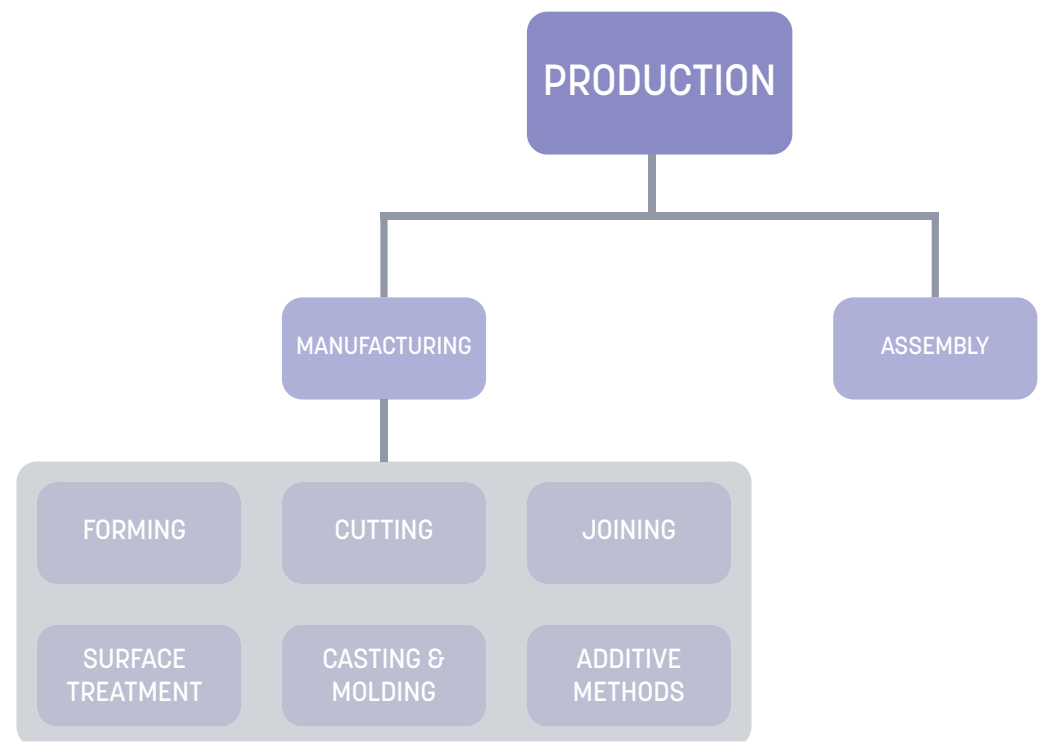

Figure 9. The terminology of production used in this thesis.

All product-producing companies have some sort of production system, in-house. The production system can be defined as "the people, equipment, and procedures that are organized for the combination of materials and processes 
that comprise a company's manufacturing operations" [15], and production development should be seen as the development of the system.

\section{Manufacturing}

In this thesis, manufacturing is used to describe the physical realization of components from raw material to finished component for assembly. In metal manufacturing, the manufacturing has been classified into different activities such as casting, powder metallurgy, plastic forming, cutting, machining, unorthodox machining or cutting, joining and surface treatment [58]. This would be similar for other materials, with smaller changes (casting in polymers is referred to as molding, as an example). For composite materials, casting is replaced with molding, and plastic forming is unusual with the exception of sheet molding compound, SMC [59], that is introduced in the manufacturing process as a sheet and then formed to manufacture components.

The three most defining parameters of manufacturing processes are function, quality and cost. These three parameters are in conflict with each other, as the lowest cost cannot be combined with the highest quality and highest functionality [60].

\section{Assembly}

Assembly is the activity consisting of joining components together into systems or products [61]. This is usually the final part of the production process, and therefore dependent on upstream activities in the production process [61].

The assembly process can be organized in several different ways, with job shop assembly [62], single-model continuous assembly lines [62], batch assembly lines [62] and mixed-model assembly lines [63] being some of the different assembly process organizations. The organization of the assembly process affects the level of product variance in each work station and the sequencing of components assembled to the product. 


\section{Production development}

While products and production equipment are developed simultaneously in industry today, the development processes are not integrated but very much independent, bar some specific milestones where the projects are synchronized [64]. Development of the production system can be divided into two categories, technology development and production development, where technology development is development of the production system applied to existing products and production development is development of the production system applied to new products (as described in figure 10) $[65]$.

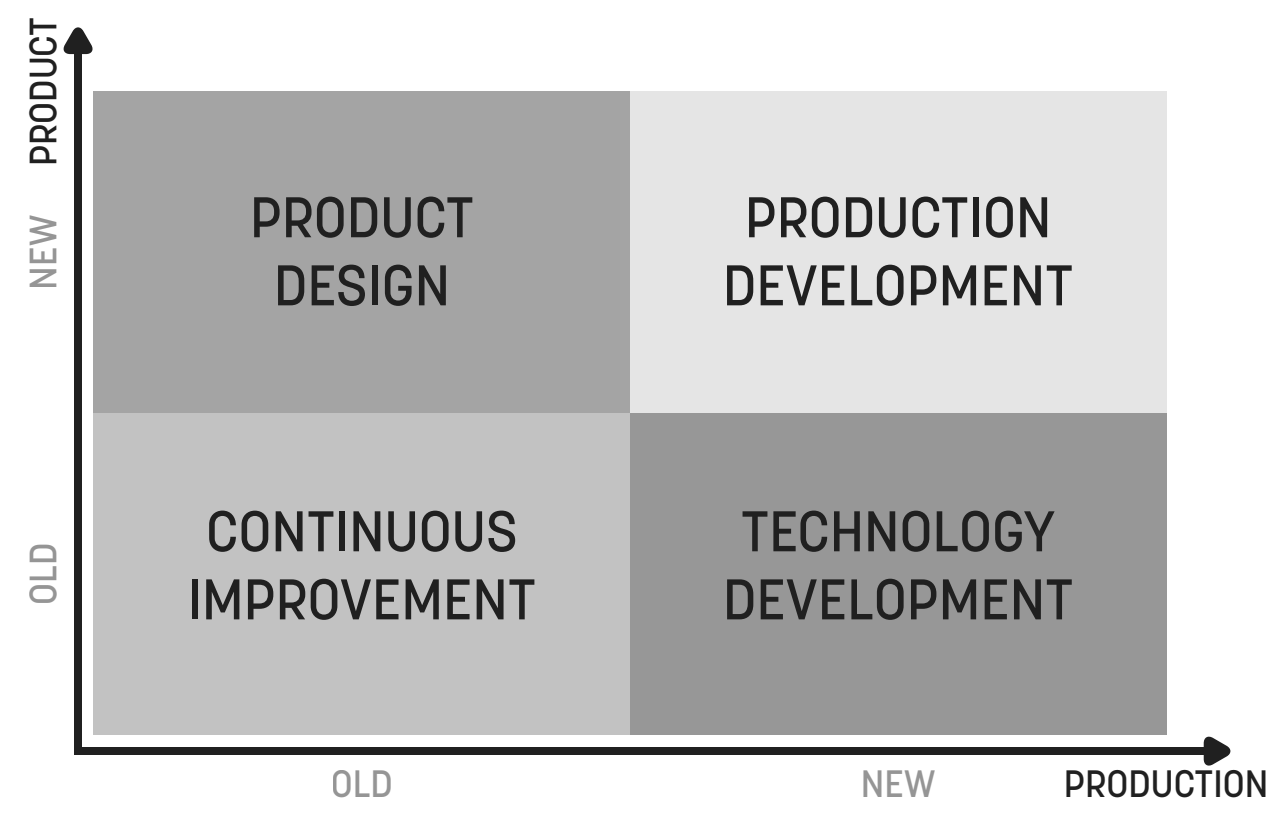

Figure 10. The Product-Production mix as described by Schätz [65].

Bellgran [61] describes a development process for the assembly system (a subset of the production system) that includes two main elements: preparatory design and design specification. The preparatory design consists of the early design activities with low investment density, while the design specification element is focused 
on complexity management, strategy and design criteria [61]. Schätz [65] describes production development, both at the cell and system level, as a part of the product development process. Traditionally, production development has been performed after the product design is finished in a sequential, over-the-wall manner, but newer concurrent approaches have been applied to production development as well as product development in general $[37,65]$, while others discuss the co-evolution of products and production systems [66].

\section{Flexibility in production}

Production flexibility is a measurement of how adaptive the production system is to change [67], and is derived from the definition of flexibility as the ability to manage changing circumstances and uncertainty [68]. These changes can be due to internal (such as small batch volumes) or external (such as fluctuations in market demand) factors [67,69], but only within a predefined range of values [15]. A production system can be flexible in different ways, called dimensions [70]. D'Souza and Williams [70] define the four flexibility dimensions of volume, variety, process and materials handling. These dimensions consists of several measures [70] including volume flexibility $[67,69,70]$, mix flexibility $[67,69,70]$ and changeover flexibility $[67,69,70]$. Slack [71] instead proposes the dimensions of product, mix, volume and delivery flexibility.

All flexibility dimensions should not be fully utilized at the same time in the same production system [15, 72, 73], and according to Slack [71], managers in industry often seek to limit the need for flexibility since flexibility can be viewed as a cost (i.e., underutilized equipment and facilities and waste). This requires a review of the tasks at hand and a ranking of prioritized dimensions of flexibility [69]. A review of the level of uncertainty affecting the decision should also be performed in order to assess the actual need of flexibility [68]. 


\subsection{RESEARCH METHODOLOGY}

In this chapter, the research methodology of this thesis is presented. First, the general process is described to give context to the structure and reasoning behind the approach taken. Second, the two main themes of the research (case studies and action research/participation action research) are further described.

\section{General process}

The general research process for the work presented in this thesis consists of literature studies, observations and interviews, along with four case studies. The four case projects were performed sequentially with no overlap between the projects themselves, as shown in figure 11. The first two case projects were performed on student projects (shown in orange in figure 11), the third had the researcher as the design engineer (shown in purple in figure 11) and the fourth had the researcher (again in purple) being the project coordinator within an industry project (engineers in industry shown in grey in figure 11).

Outcomes from the literature study formed the basis for the case projects, along with observations and interviews in industry. Each case was first briefly analyzed before setting up the next case study.

Documentation from each case has been compiled and used to conduct a combined analysis along with the current state of the industry, as well as a theoretical review to understand and describe how integrated product and production development is performed, as seen in figure 12.

The multiple-case study, in combination with industrial observations and literature reviews, is a deviation from the main research methods on integrated product and production development, that are survey studies and single-case studies [30]. While case studies are explicitly more descriptive and suitable for explaining a set of decisions $[74]$ as well as the social interactions that are the core aspects 


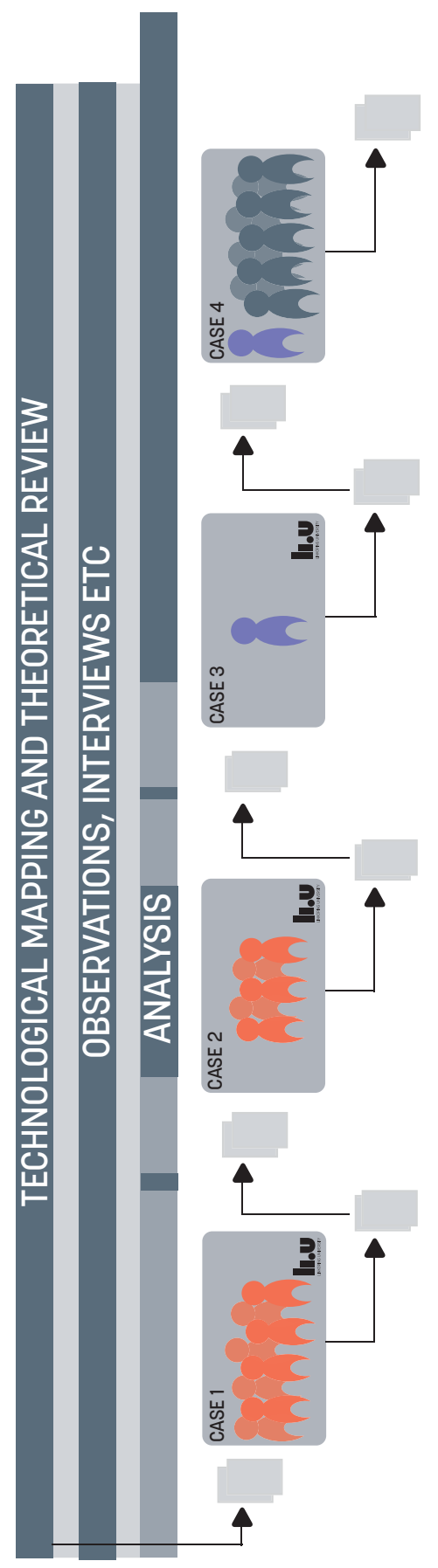

Figure 11. Temporal disposition of the work presented in this thesis. 
of engineering [75], as Dekkers et al. [30] interpret Timpf [76], there is a risk in making valid generalizations from a single-case study. Since many interactions or occasions are unique within a single case, the basis for generalization is limited. This could be mitigated by aggregating several cases into a multiple-case study. A series of case studies based on industrial challenges with analysis and further development of the next case in collaboration with industry is similar to the "industry as a laboratory" research approach, initially presented by Potts [77] and further expanded by Björnsson $[7,78]$. Cases have been designed as student team case projects, researcher case projects and industrial participation action research projects, further differentiating the data input in order to generate generalizable knowledge.
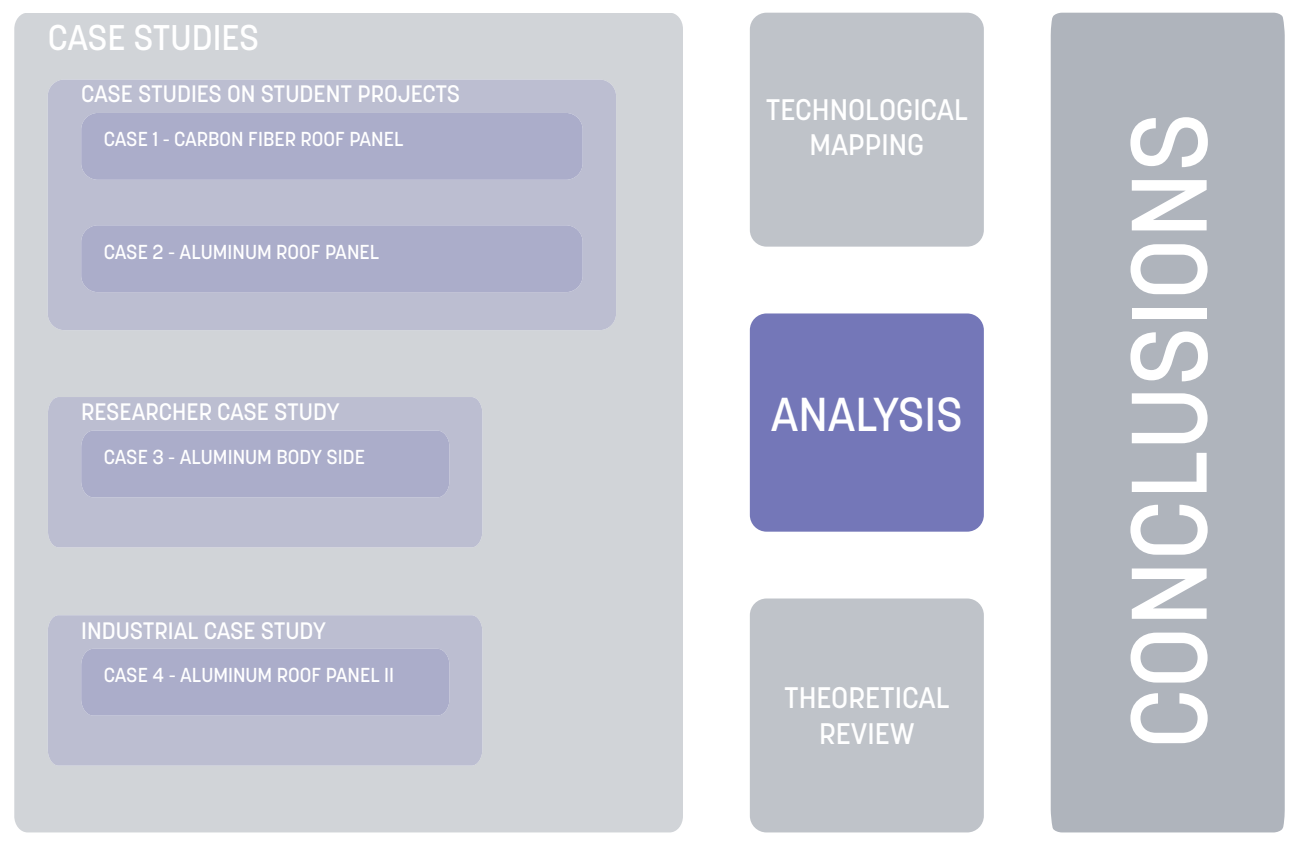

Figure 12. Structural disposition of the work presented in this thesis.

Ottosson \& Björk [79] have proposed an inverse relationship between the distance between researcher and the object of research, and reliability of research 
(as depicted in figure 13). This implies that the researcher should have an active role in the cases performed, rather than a passive and distant one. In an opposite take, the research efforts identified by Ottoson \& Björk [79] as having the largest distance between the researcher and the object or occasion researched are the research efforts most replicable. In order to ensure a high level of research quality, by ensuring replicability (and thus enabling falsification) as well as reliability, a combined approach using research activities with both high reliability (short distance between researcher and the object of research) and high replicability (long distance between researcher and the object of research) is a suitable way of creating a general research methodology in order to generate generalizable and useful knowledge.

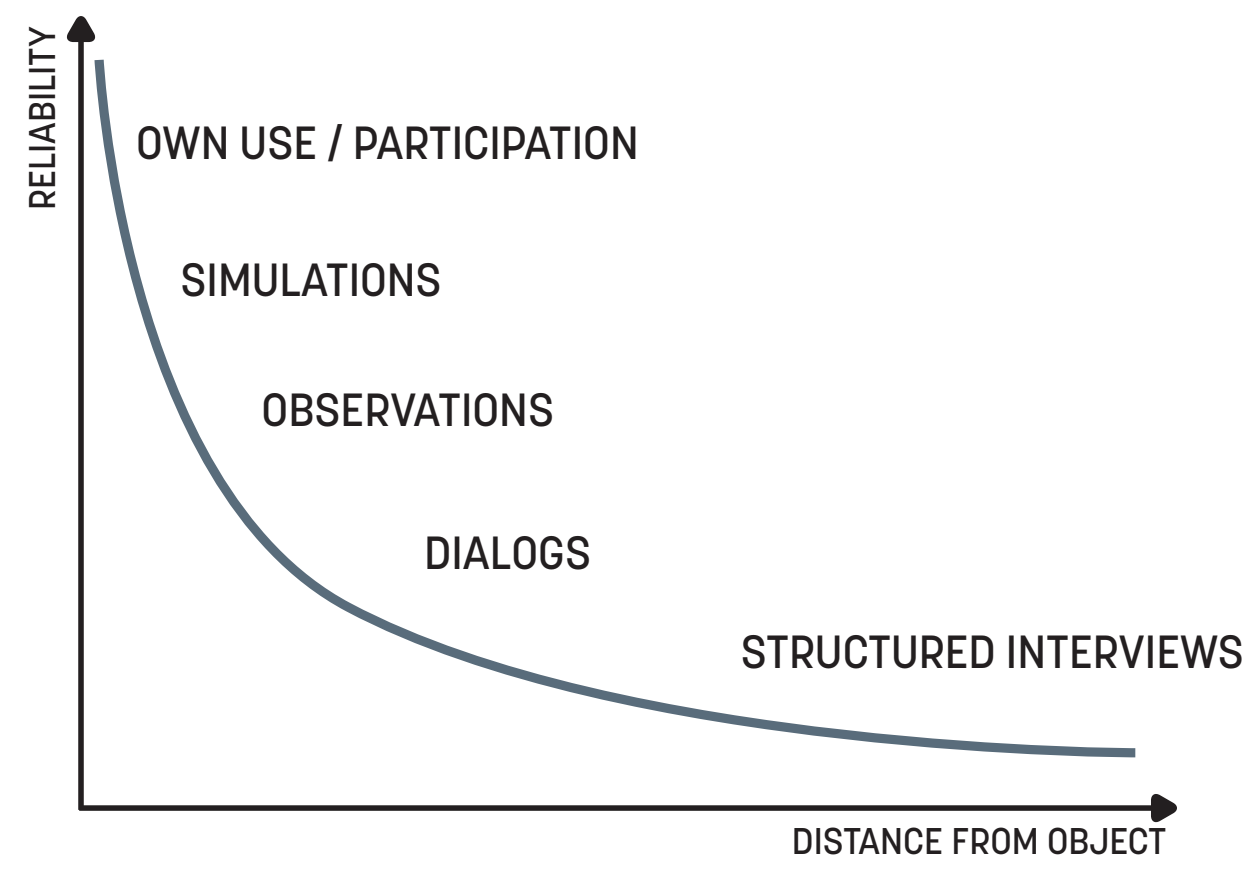

Figure 13. A figure of how the distance to the object or occasion researched negatively affects reliability, adapted from [79]. 


\section{Case study research}

A case study is a form of descriptive, qualitative research, more aiming to answer questions relating to "how?" and "why?" than for example "what?" or "how much?" [74]. Case studies have been shown to be useful when the object or environment under study is hard to define or "messy" [80]. Combined with the suitability of case studies to investigate complex events [81], case studies have been popular in both product and production development research. Examples are implementations of new development approaches [82], validations of design tools [83], investigations of material efficiency [84], generating possible concepts for novel human-robot collaboration systems [85], data gathering regarding assembly flexibility [81], the effect of responsiveness and flexibility to customers on manufacturing [86] and comparing strategies for competitiveness in manufacturing companies between countries [87].

A project in engineering design in general, and student projects in particular, can be described as a way of going from a scope, via using data, tools and knowledge in a process, into creating a result (as described in figure 14). In figure 14, there is an interaction between scope, knowledge, tools, data and process in order to create the best possible result with available resources. In the case of an engineering design project, the process is the sequencing of activities to progress from scope to result.

If the process is to be studied, the process itself cannot be validated with industrial examples. What could be done instead is to create the project scope so that it is industry-like and has industrial relevance, and so that the data the case group gets is relevant and industry-like. It is also important to identify differences in knowledge between students and engineers in industry, provide tools similar to those in industry and evaluate whether the result is reasonable from an industrial point of view. 

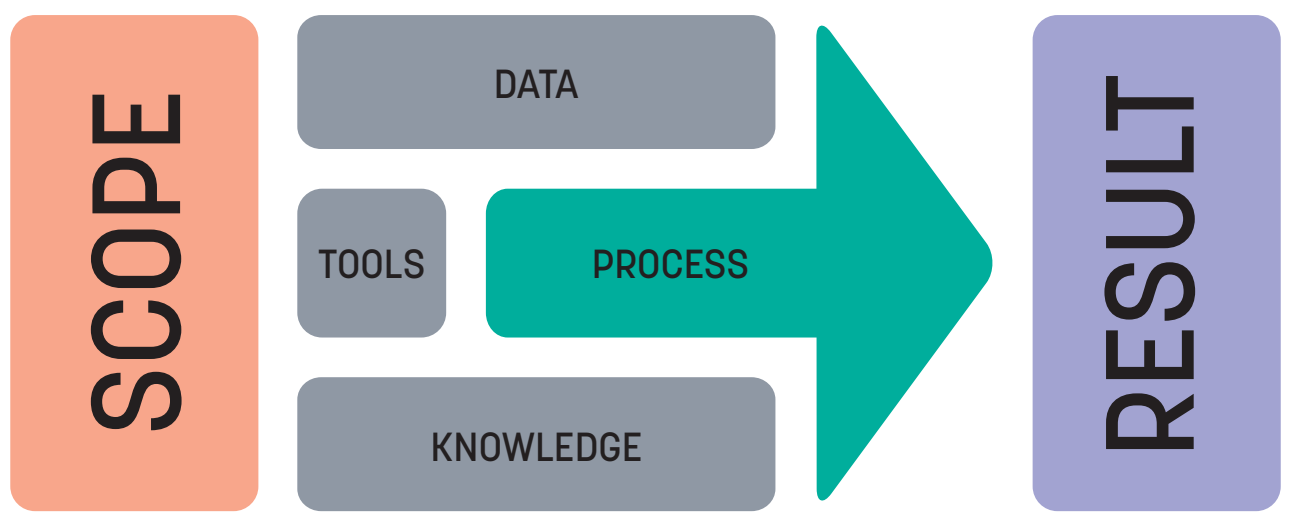

Figure 14. A generic description of an engineering design project.

Since the aim of the research presented in this thesis is not to exactly identify the process that is used in industry, but instead to generate in-depth knowledge about the types of challenges that can occur in these types of projects, a process aligning reasonably with what is done in industry is needed in order to consider the data interesting and significant.

If the scope in figure 14 is developed in collaboration with industry, and the result is evaluated by experts from industry, the input and output of the project can be regulated and deemed as similar enough to industry projects. If an industrial contact can also provide real or realistic data, the probability of a realistic result increases and the process is furthermore boxed in. While there are differences in how students and industry professionals approach certain challenges, knowledge from a case project on students can be transferred to be useful in industry if the project has an appropriate scope, is set up properly (with regard to data, tools and knowledge) and the result from the project can be deemed reasonable. If these three properties exist, the process studied in the case study is similar enough to an industrial process to generate valuable knowledge, even if the case participants are students. 
Multiple data collection methods should be used, preferably with mandatory course assignments and other teaching activities as a part of the data collection to reduce the risk of participants focusing more on delivering data than performing the project in the case. Since there are differences in knowledge between engineering students and engineers in industry, a multiple-case study combining cases is recommended in order to maximize data to analyze.

Specific qualities in the case that affect data collection regarding the work process are the project scope (how well this resonates with industry-based projects), knowledge (of the participants in the project), data given as input to the project, tools used in the project and the result of the project. The least robust qualities are the input data and the project result.

\section{Action research and participation action research}

Action research, originating from the field of educational research [89], is a methodology where the researcher is participating in the subject that is being observed [90]. Simplified, action research can be described as a series of look-think-act [88] (as seen in figure 15) or action-reflection loops ( [91] via [89, 90]), as seen in figure 16.

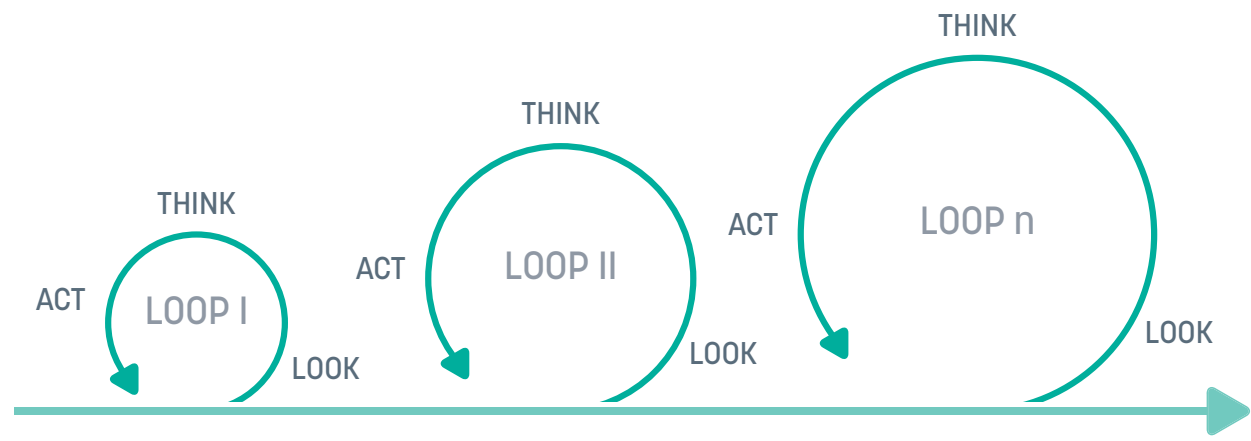

Figure 15. The look-think-act loop of action research, adapted from [88] .. 
Like case study research, action research is also considered a form of qualitative research [88] but with the researcher more immersed in the object of study. The research work focuses on process rather than results, and views the researcher as a catalyst for the work process [92].

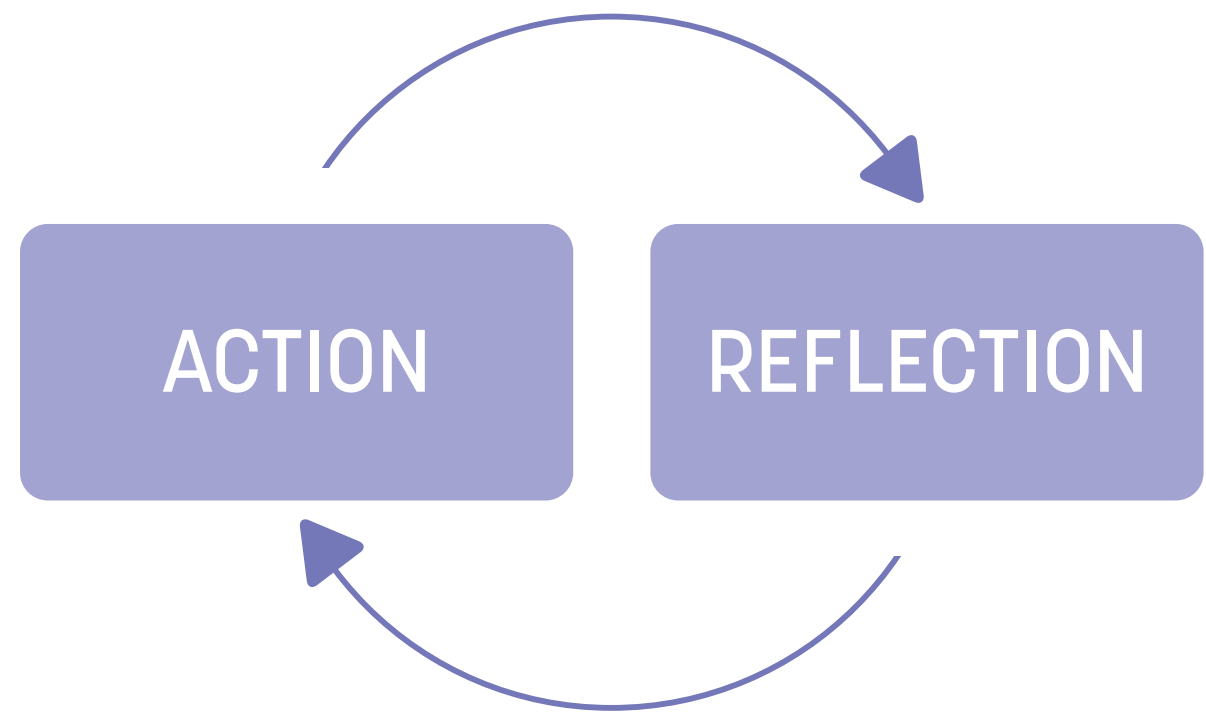

Figure 16. The action-reflection loop as described by [91] and adapted from [89].

Participation action research (PAR) is an expansion of the action research methodology specifically intended to generate knowledge regarding development processes [93]. In PAR, the researcher works actively as a manager managing a development project of the kind that is to be researched; this is done to immerse the researcher in the complexity of a development process and gather implicit knowledge as well as unspoken information used by developers in the process [93]. Ottosson [93] proposes a participation action research approach, but highlights the risk of the researcher becoming too immersed in the development environment and losing the scientific approach to the development process.

A solution to this could be to have a scientific environment present during the project where the researcher can retract and reflect as the project progresses, 
as presented in figure 17. In this thesis, a combination of case studies using participation action research, literature and industry reviews and industrial observations has been used to gather data. The case studies have employed different levels of active participation, with Case 3 having the highest level of participation (the author performing the work), Case 4 the second-highest (the author acting as a coordinator), and Cases 1 and 2 the lowest (the author acting as a supervisor).

\section{"TRADITIONAL OBSERVATIONAL RESEARCH"}

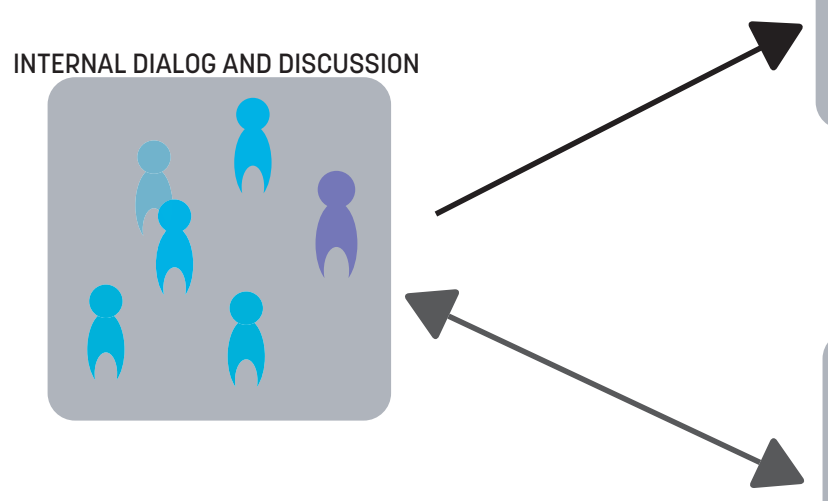

PARTICIPATION ACTION RESEARCH
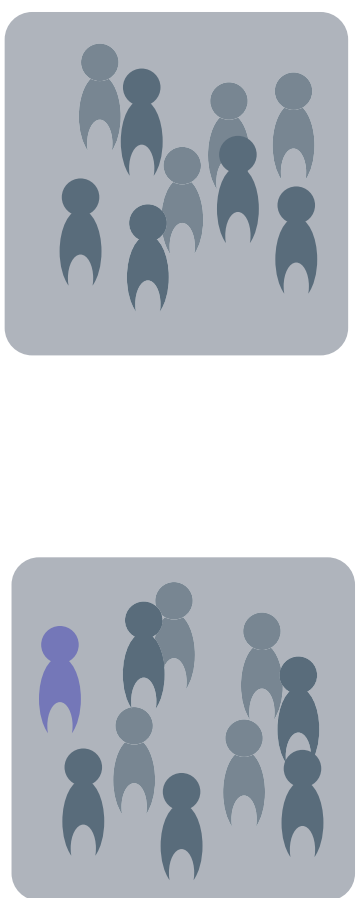

Figure 17. The difference between participation action research (the lower ellipse on the right) and traditional observational research (the upper ellipse on the right], adapted from [93]. 


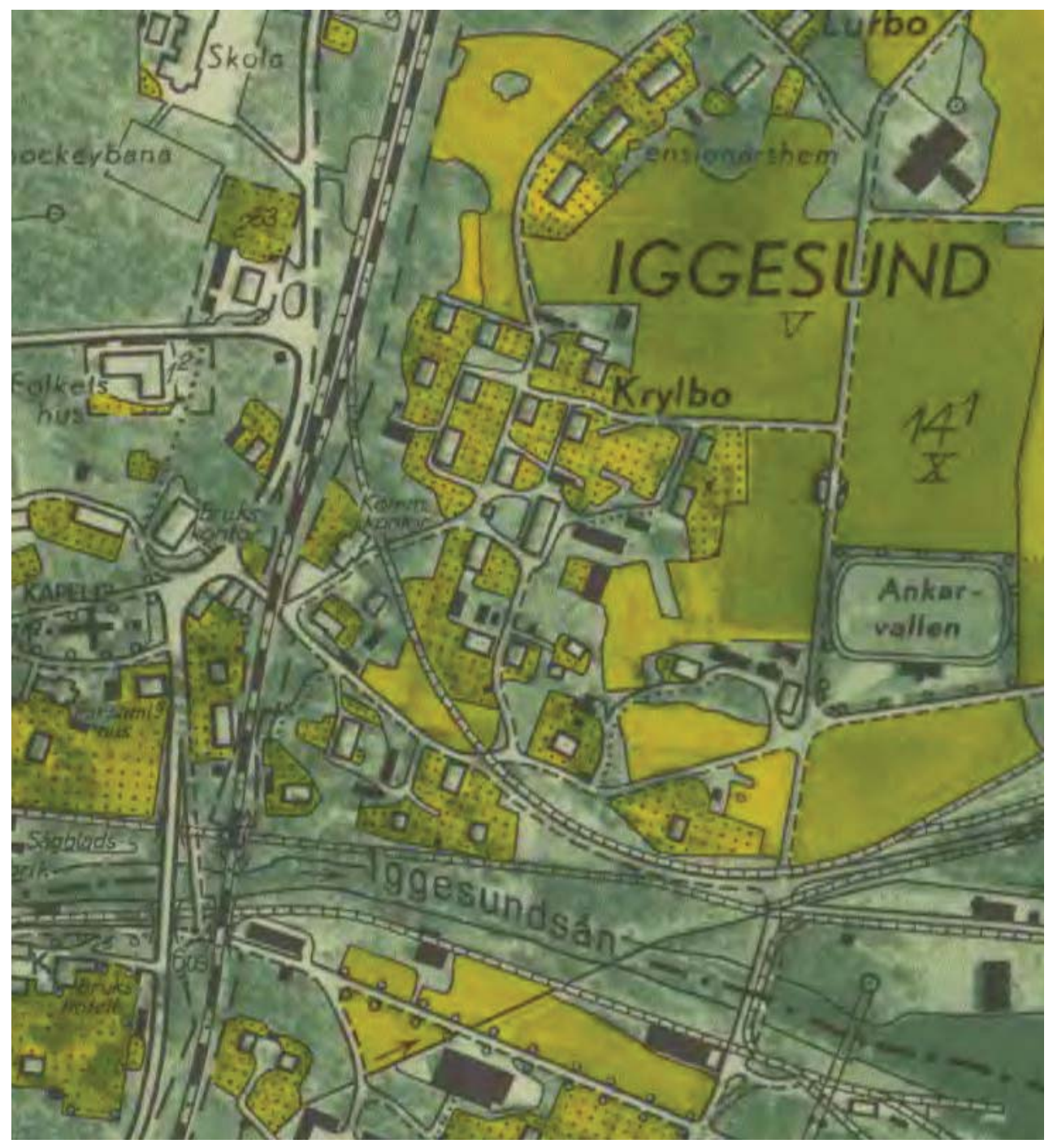

\section{PART 3 - TECHNOLOGI- CAL MAPPING}




\section{PART 3 - TECHNOLOGICAL MAPPING}

In the technological mapping, material properties and industrial implementation of multi-material design are presented, followed by a general description of vehicle production. This part of the thesis should be read as a presentation of possible materials to combine and introduce, with a brief explanation of differences in properties, as well as an industry-review of multi-material products in order to understand the state of the industry. Parts of the material presented in this section is also presented in Paper A.

Picture on previous page courtesy of Lantmäteriet (Ekonomiska kartan 1956, kartblad Iggesund J13315H7d59) 


\subsection{MATERIAL PROPERTIES}

Material properties are descriptions of how materials behave under certain specific conditions. These behaviors are fundamental in the selection of materials in mechanical engineering, since this determines whether the product will fulfill the requirements set up for it. Common materials for automotive components are metals (either in steel alloys or aluminum or other lightweight alloys) and polymers (sometimes in the form of polymer composites).

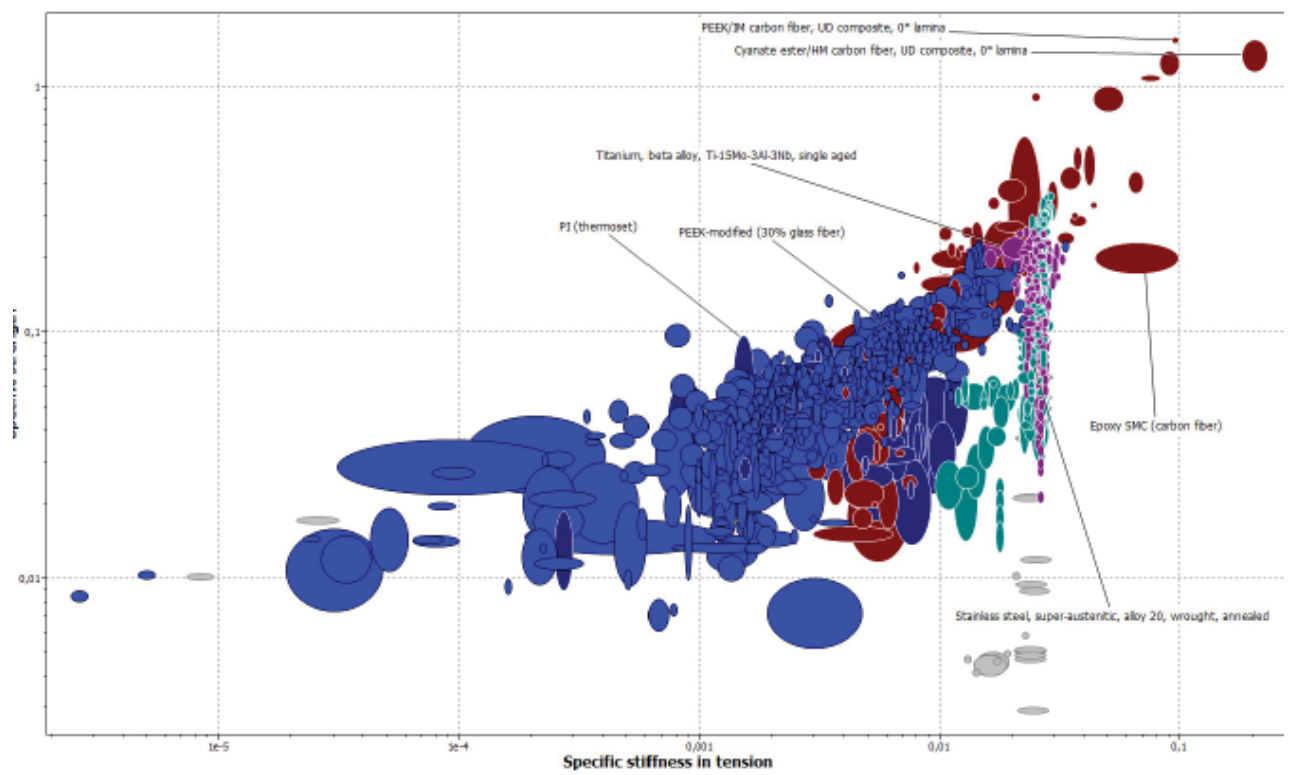

Figure 18. Specific strength vs. specific stiffness for polymers, composites and metals [data courtesy of Granta Design Ltd]. 
Two interesting material properties are specific strength and specific stiffness. In combination, these two describe how a material can be manipulated without rupturing, something that is of great interest when evaluating materials for panel forming and later use and risk of blunt force impact during use (impact from opening doors at a parking lot, tools, etc.). Materials with both high specific strength and specific stiffness are more durable to smaller "dings" or bumps, since they will not deform as much as weaker materials. In figure 18, polymers (the blue grouping) is shown to have both lower specific strength and specific stiffness than metals (red, green and magenta groupings). This implies that the polymers are less likely to withstand small bumps without leaving marks.

Two other parameters related to mechanical manipulation of the material are yield strength and tensile strength. Yield strength is the stress the material can manage without plastic deformation [94], and tensile strength is the stress the material can manage before necking and following catastrophic failure [95].

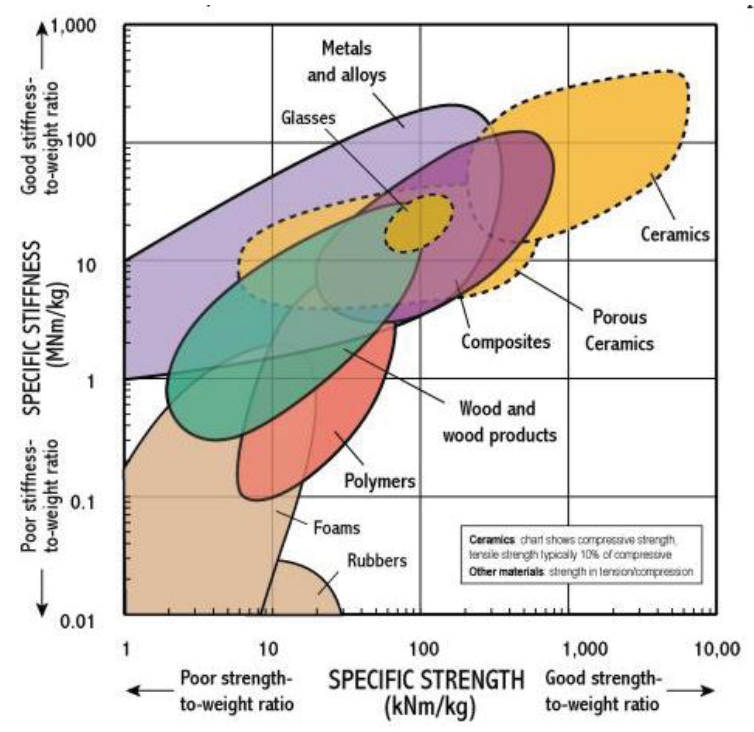

Figure 19. Specific stiffness over specific strength for material classes. A higher specific strength but similar specific stiffness can be seen for composites [compared to metals and alloys]. [96] 
Materials with a tensile strength very close to yield strength are called brittle, since they do not deform before failure [94]. In figure 20, the blue grouping showing polymers has both lower yield and tensile strength, and has a slightly higher $\mathrm{Y} / \mathrm{X}$ coordinate ratio indicating a more brittle behavior. Metals, the red, green and magenta groupings in Figure 20, have higher yield and tensile strengths.

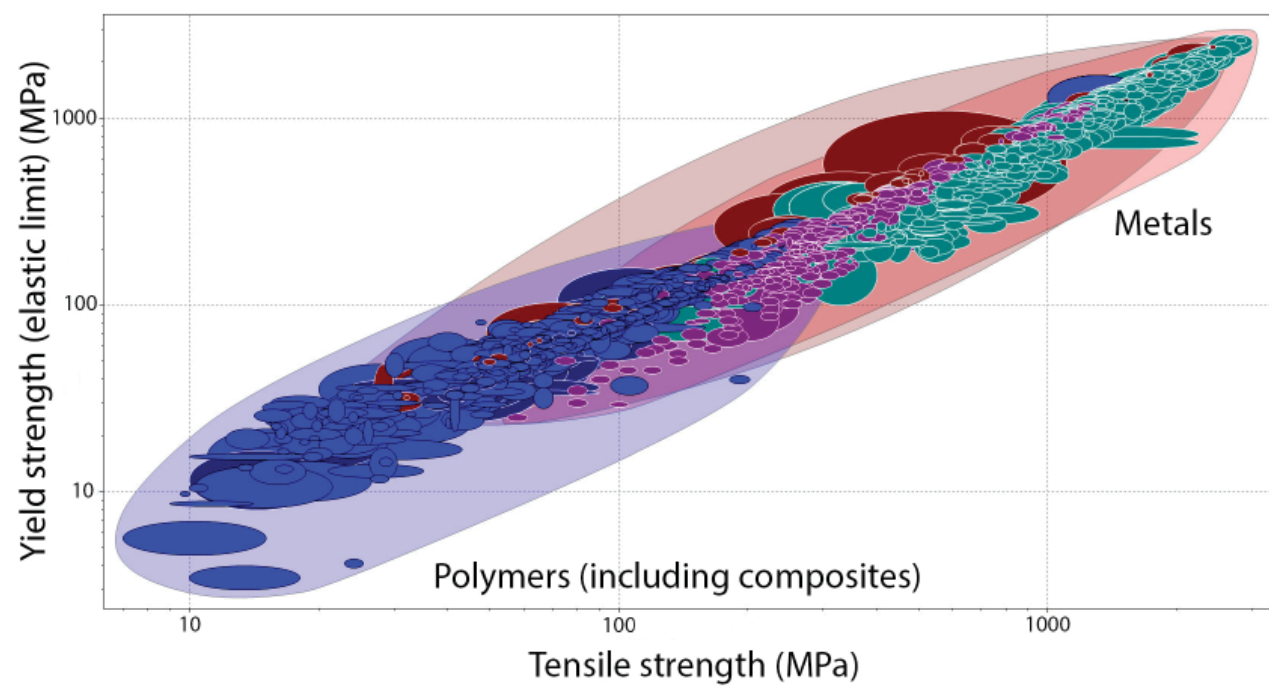

Figure 20. Yield strength vs. tensile strength for different materials [data courtesy of Granta Design Ltd].

Two temperature-related parameters are the thermal expansion coefficient and the maximum service temperature. The thermal expansion coefficient describes how much a material expands when being exposed to heat, and the maximum service temperature is the highest temperature where the material keeps a majority of its strength [97] and can be reasonably used for a prolonged period of time. In Figure 12 , it becomes evident that metals are consistent in terms of thermal expansion, but that the maximum service temperature differs greatly (this is shown by the flat, wide grouping of metals near the $\mathrm{X}$-axis in figure 21). Polymers and polymer composites, on the other hand, show no significant conformity in either thermal expansion rate or maximum service temperature (this is shown by the much larger, quadrangle shape 
of the polymer grouping in Figure 21), even though the thermal expansion cofefficient is in general lower for metals, and the maximum service temperature is in general higher for metals.

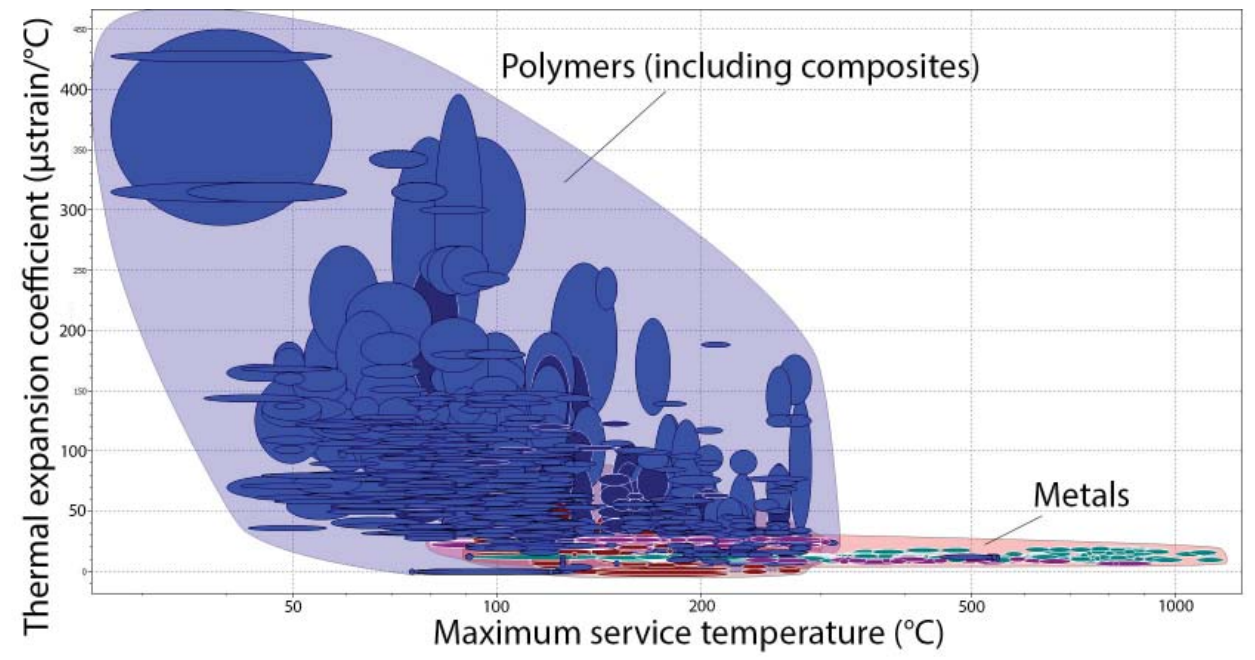

Figure 21. Thermal expansion coefficient vs. maximum service temperature for different materials [data courtesy of Granta Design Ltd].

A combination of strength and maximum service temperature is sometimes needed to manage combined requirements. These requirements can occur when components are stressed during increased temperatures.

Figure 22 shows the generalized material properties for all material classes, and it can be seen that material properties can differ greatly between materials and material classes. 


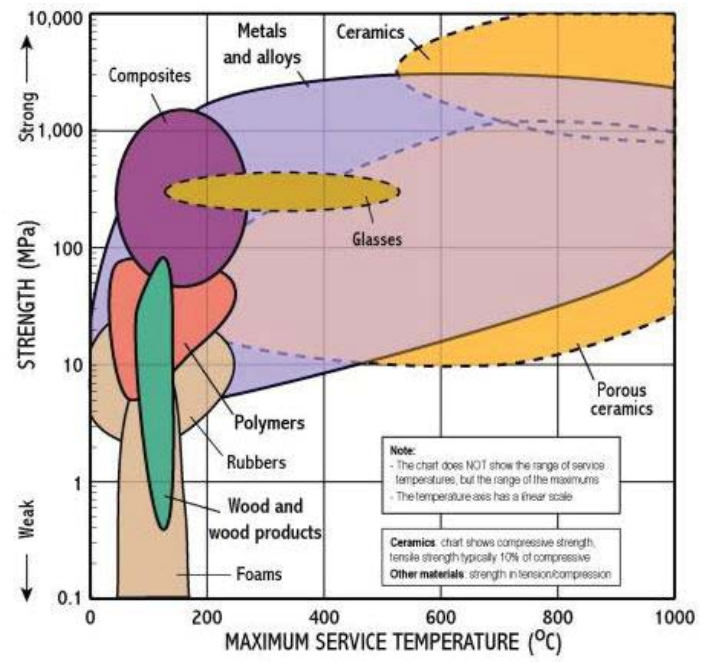

Figure 22. Strength over maximum service temperature. Both composites and polymers are shown to have lower possible maximum service temperature than metals and alloys. [96]

Diving deeper into material properties, looking at materials and alloys in particular (figure 23) there are vast differences even within this material class. Lead has a significantly lower maximum service temperature than nickel, with steel (both mild and stainless) somewhere in between.

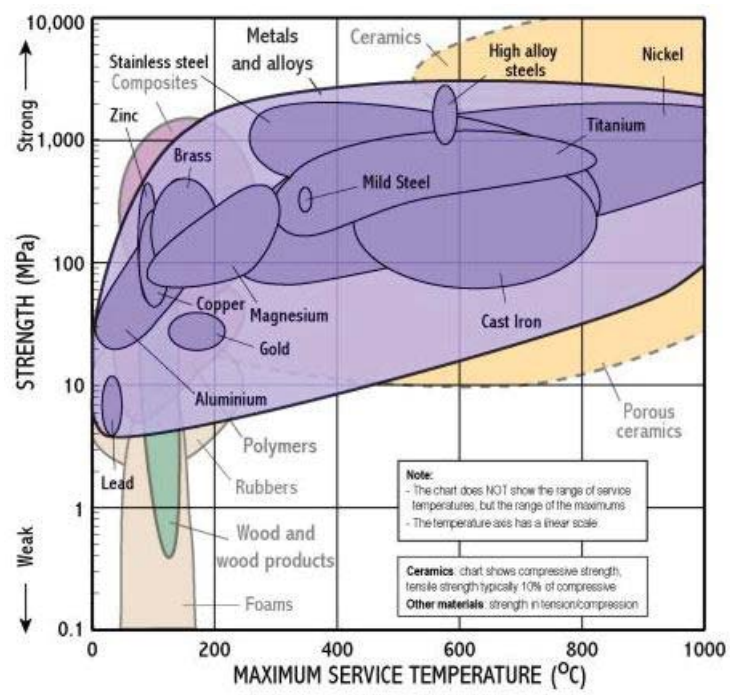

Figure 23. Strength over maximum service temperature for metals and alloys. The difference between different metals and alloys becomes evident. [96] 
In the same figure 23 , the difference in strength between different metals is also shown. As in the case of maximum service temperature, lead is at the lower end of the scale and nickel is at the higher end. Aluminum and steel alloys have properties in the mid to high range, with high-alloy steels being some of the absolutely strongest metals.

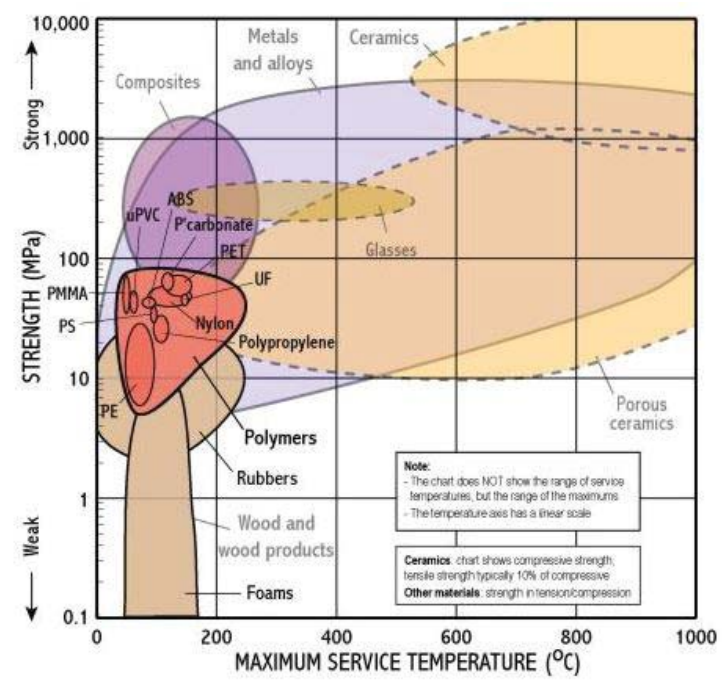

Figure 24. Strength over maximum service temperature for polymers. [96]

Polymers have a much tighter span of maximum service temperature, and if foams and rubbers are excluded, this is applicable for strength as well (see figure 24). The maximum values are lower than for metals and alloys, but the differences within the material class are much smaller. The differences in properties are as small among polymer composites, but the composite materials are typically much stronger. The maximum service temperature range, on the other hand, is very similar to the pure polymers, as can be seen in figure 25 . 


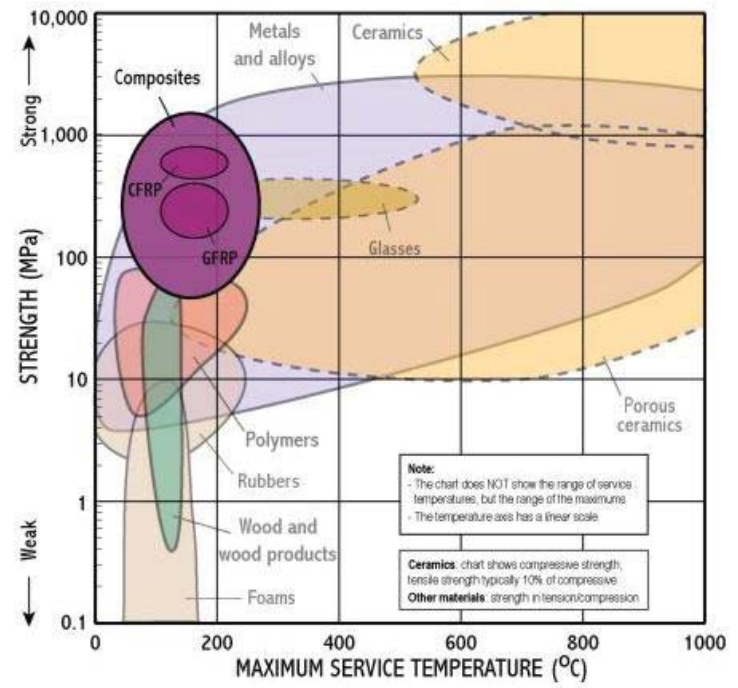

Figure 25. Strength over maximum service temperature for polymer composites. CFRP and GFRP are shown to have similar maximum service temperature, but a difference in strength. [96] 


\subsection{STATE OF THE INDUSTRY}

When discussing the introduction of new materials into the automotive industry, some overview of industry trends is needed. While the automotive industry has used lightweight materials as niche or low-volume solutions for a long time, some stakeholders in the industry foresee an increased use of hybrid or multi-material designs [98] in the near future. As an example, different polymer-based materials have been used for hang-on parts such as hatches, hoods and fenders for a long time [99], but in the form of fiber-reinforced polymer composites they have also recently been used in roofs [100] and in more intricate multi-material designs of hang-on parts [101], as can be seen in figure 26 .

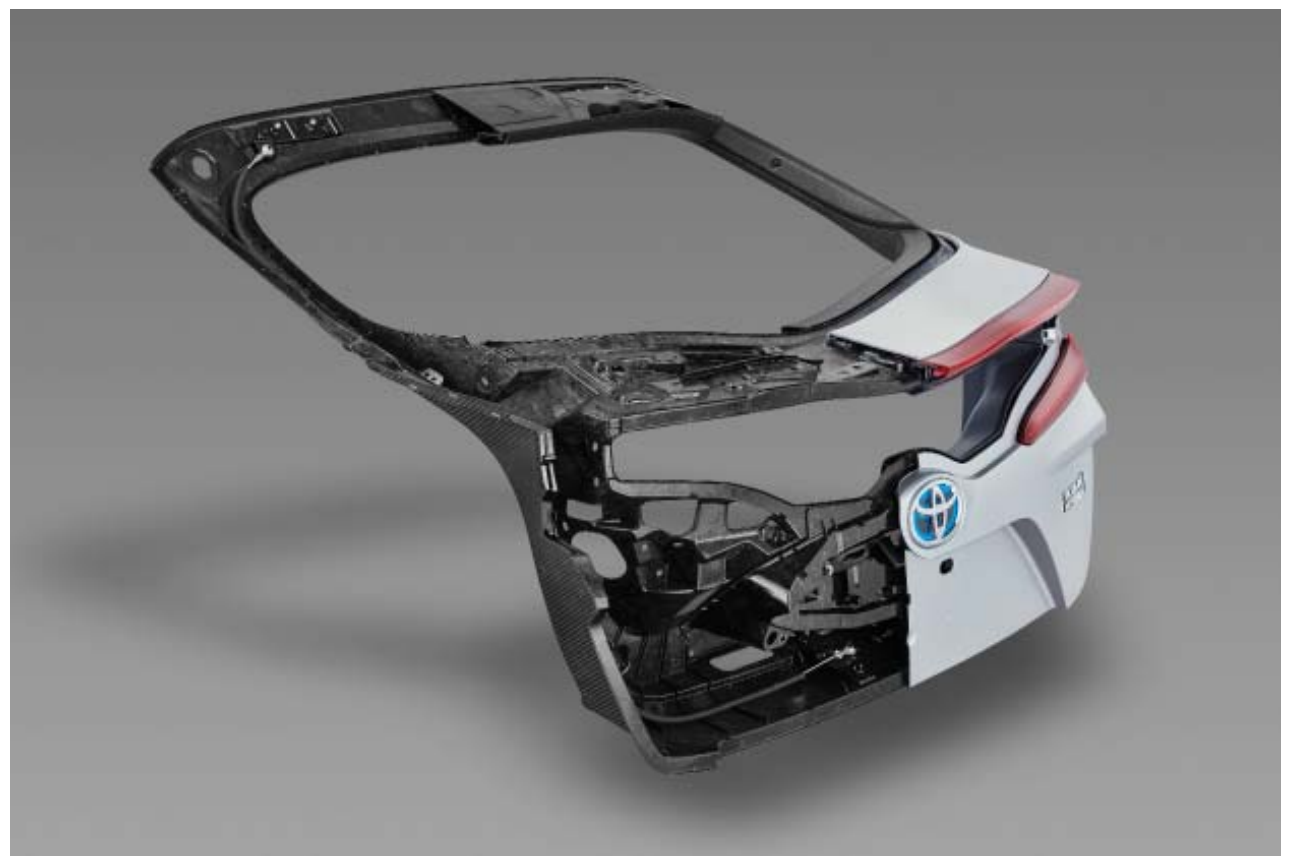

Figure 26. The tailgate of the 2017 Toyota Prius, exhibiting an integrated design with CFRP and aluminum [picture courtesy of Toyota]. 
The first documented use of FRP body panels in a car dates back to 1941, when Ford presented the "Soybean Car" [102]. Looking at mass-produced vehicles, two pioneering cars were the Chevrolet Corvette, launched in 1953, and the Lotus Elite (Type 14), launched in 1957 (as seen in figure 27). The Corvette used an FRP body on a traditional steel frame [103], while the Elite utilized an FRP monocoque design [104]. Approximately 35 years ago, in 1981, the first car with a CFRP main load-bearing structure was introduced with the McLaren MP4/1 Formula 1 car [105], and since then the material has been used for load-bearing structures in different types of sports cars in parallel with the introduction of fiber composites in hang-on parts in mass production vehicles.

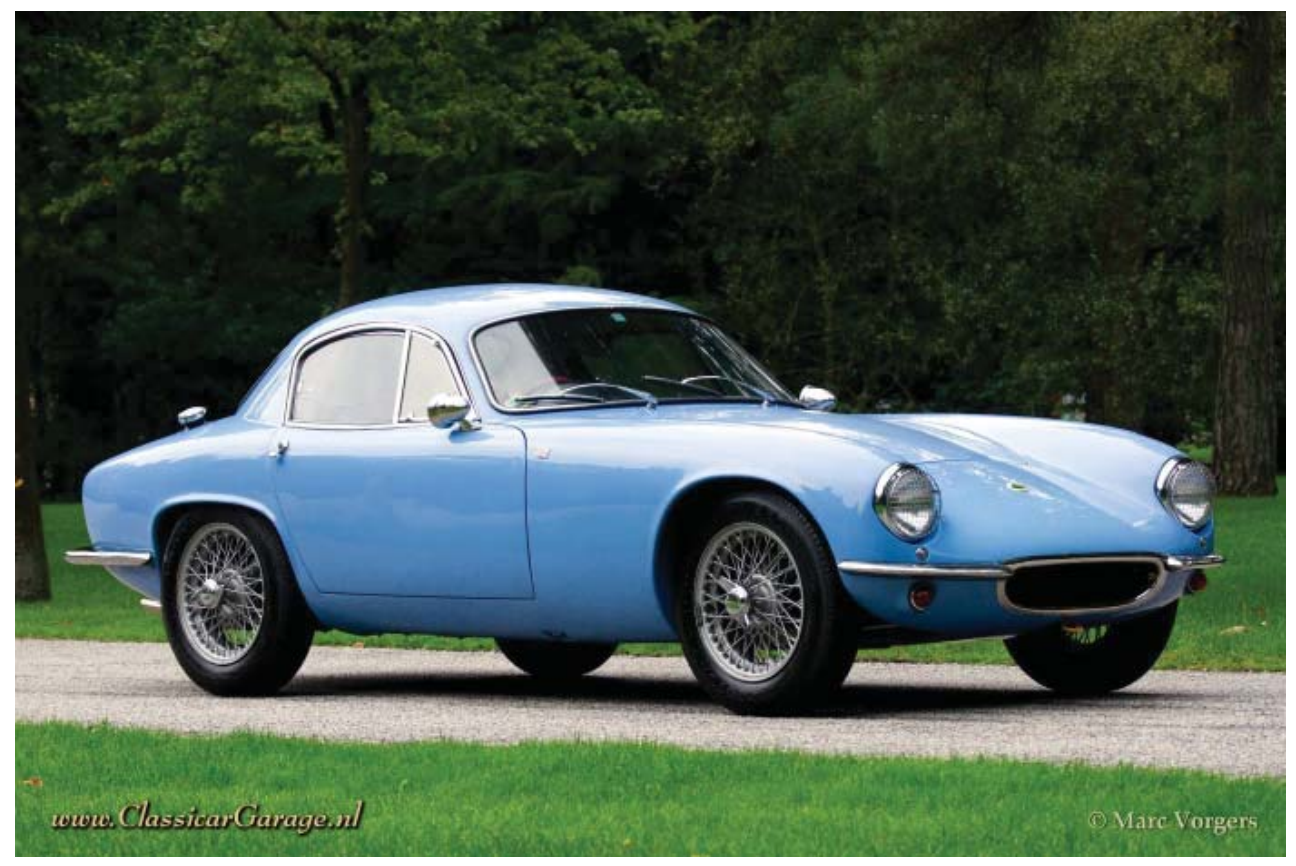

Figure 27. Lotus Elite (Type 14] [picture courtesy of ClassicarGarage / Marc Vorgers]. 
Currently, a number of different vehicles are being released with different types of multi-material solutions even further integrated into the bodies. The trend seems to be to introduce lightweight materials in more integrated designs, in low-cost products and in transitioning from low production volumes to mass production (production numbers of at least 10,000 units yearly). A few examples of such cars are presented on the following pages, based on company-provided data and industry literature.

\section{Audi TT Coupe}

The 2014 model year and up Audi TT (see figure 28) has a body using stamped aluminum sheets for all outer body panels, while the floor and firewall are made out of regular steel panels. Cast aluminum and aluminum profiles are utilized in safety-critical areas such as A-pillars, door sills and crash beams.

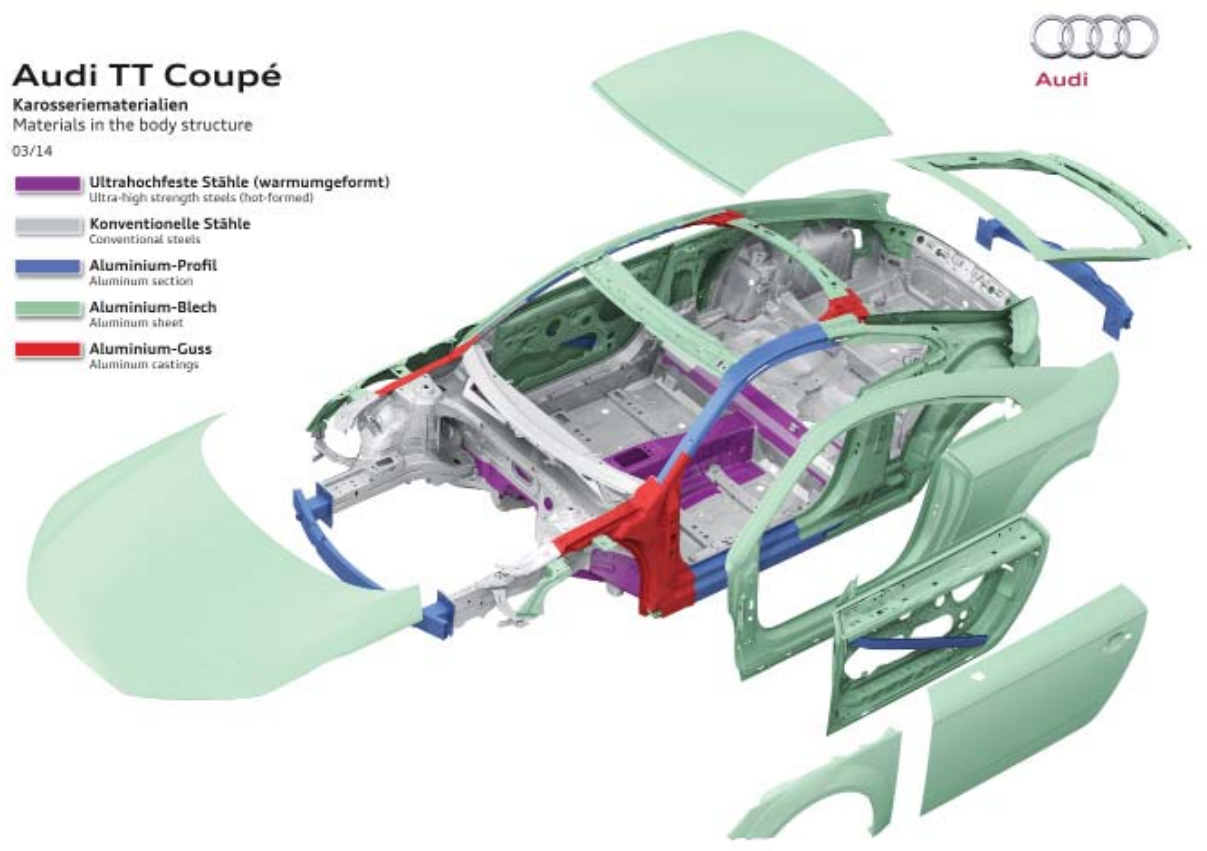

Figure 28. The Audi TT body, using aluminum and regular steel for a majority of the body structure [Picture courtesy of Audi AG]. 


\section{Audi Q7}

The 2015 model year and up Audi Q7 has an aluminum-intensive body, with both cast and stamped aluminum integrated with high-strength steel in, for example, B-pillars, as can be seen in figure 29 .

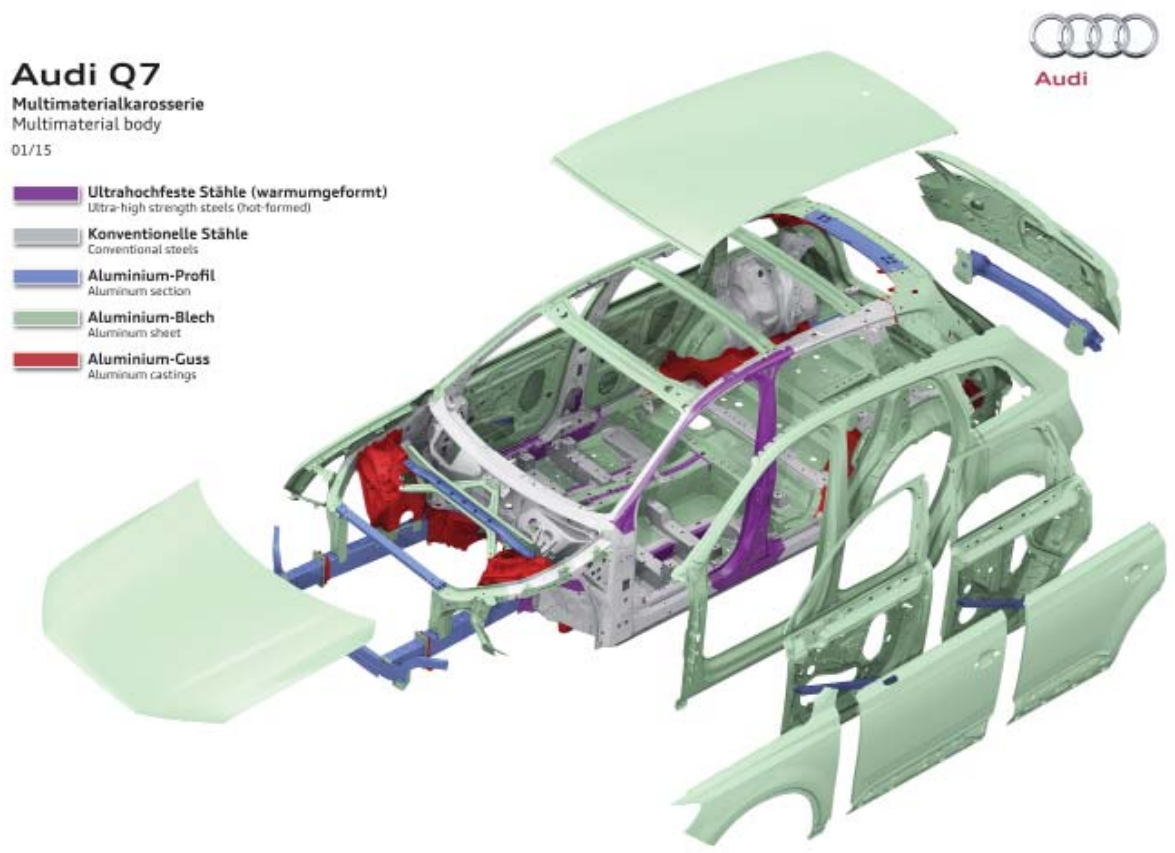

Figure 29. The Audi Q7 body, using stamped aluminum sheets for most of its structural strength, combined with high-strength steel in safety-critical areas [Picture courtesy of Audi AG].

\section{BMW 7 Series}

The body of the 2015 model year and up BMW 7 Series [106] uses a combination of steel, aluminum and carbon fiber-reinforced plastics to reduce the mass of the BIW; several components (for example door sills, B pillars and roof beams) have been reinforced or replaced with CFRP panels instead of the traditional steel panels. These CFRP panels can be seen as the darker segment on the body in figure $30 \& 31$. 


\section{BMW EFFICIENT DYNAMICS.}

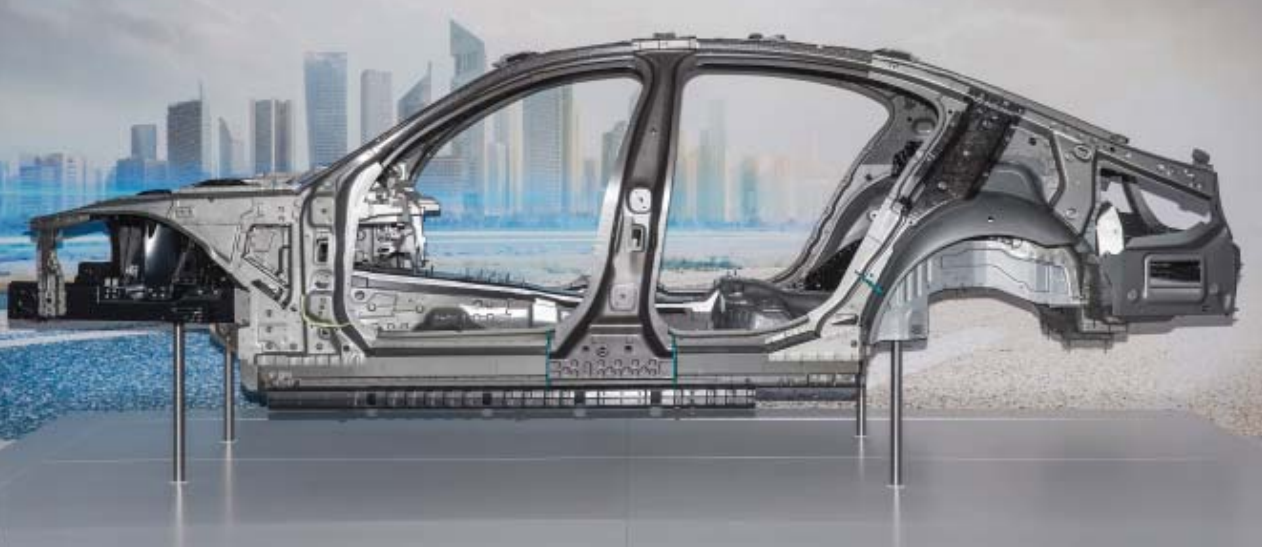

Figure 30. BMW 7 series carbon core structure [photo courtesy of BMW AG]. The CFRP B-pillar is prominent in the center of the picture, as well as the CFRP reinforcement panel behind the rear door opening.

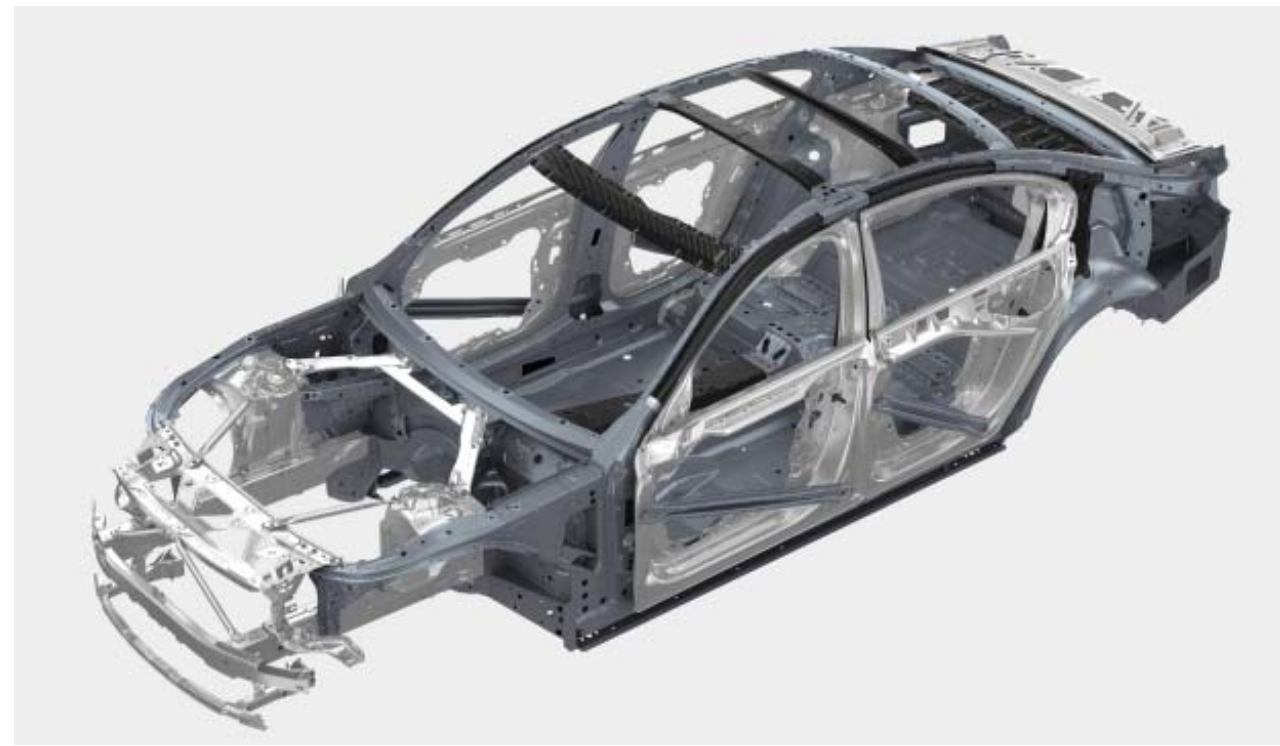

Figure 31. BMW 7 series carbon core structure, the CFRP panels can be seen in black and aluminum panels in light silver grey [photo courtesy of BMW AG]. 


\section{BMW i3}

The BMW i3 (first sold as a 2014 model year) is a small electric vehicle built up in two major modules, the drive module (where the powertrain and suspension are mounted) and the life module (where passengers are protected). The drive module is made as an aluminum skateboard, while the life module is a CFRP monocoque as seen in figure 32.

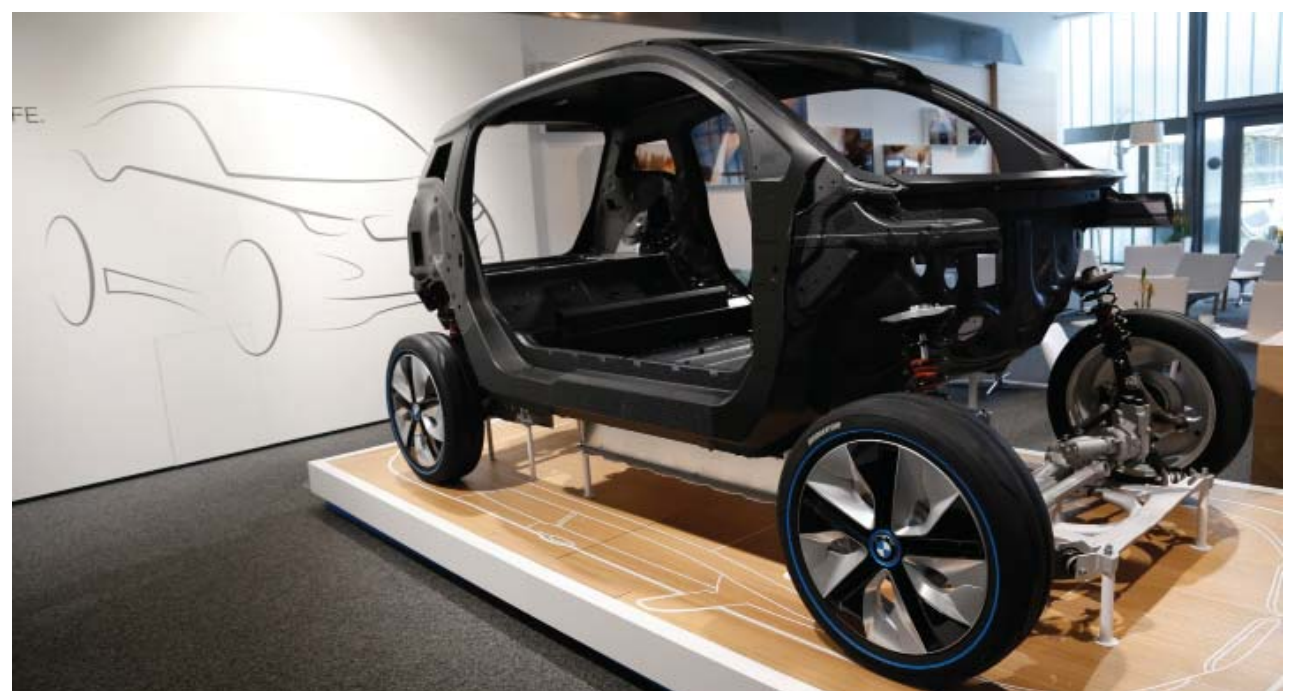

Figure 32. The BMW i3 showing both the drive module and the life module [picture courtesy of BMW AG].

\section{Cadillac CT6}

The Cadillac CT6 (2016 model year and up) is built on what General Motors calls the "Fusion Frame", a platform concept where a steel center section (marked in orange in figure 33) is clad with aluminum panels for everything that can be seen to affect the aesthetics of the vehicle (marked in grey in Figure 33). Aluminum is also used for structural components such as door sills and impact bars. 


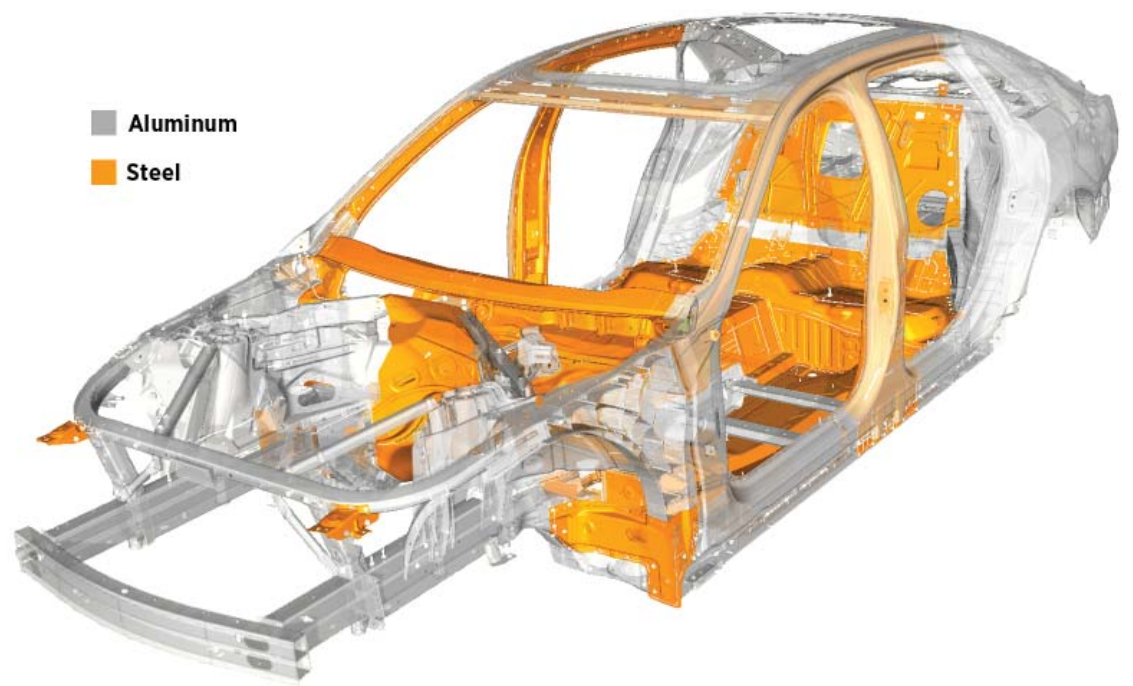

Figure 33. Cadillac CT6 "Fusion Frame" architecture [107]. The orange panels are of steel, while the grey panels and beams are made in aluminum [Picture courtesy of General Motors].

\section{Chevrolet Corvette}

Ever since its introduction in 1953 (see figure 34), the Chevrolet Corvette has utilized a fiber-reinforced composite body. Initially, the body was made in glass fiber-reinforced plastics, and the car was one of the first mass-produced cars to have a composite material body.

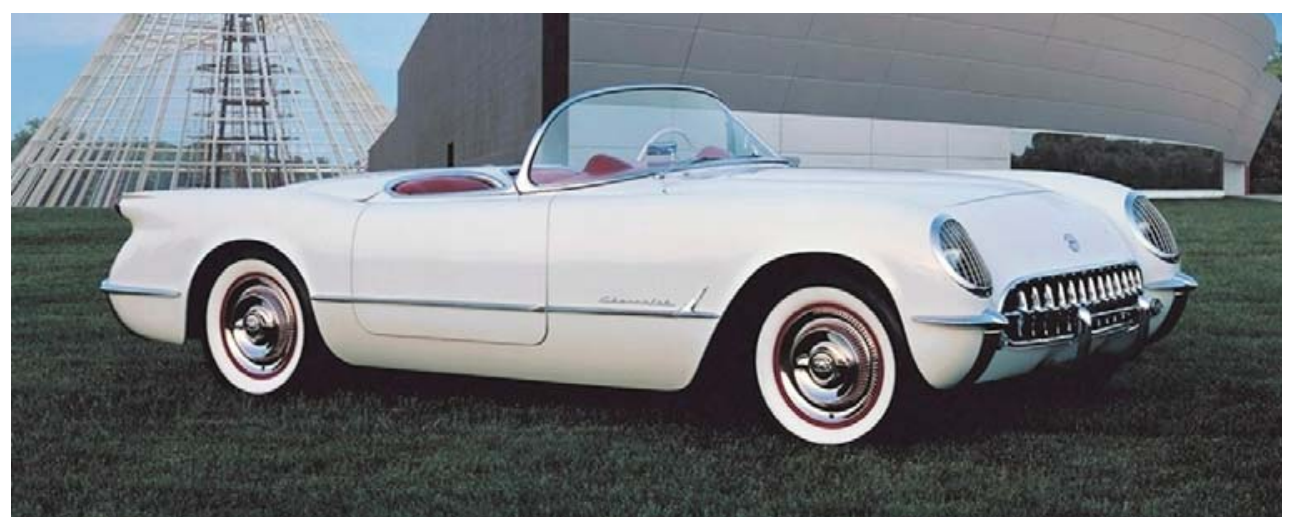

Figure 34. The 1953 Chevrolet Corvette, one of the first mass-produced cars to have a body made from composite materials [Picture courtesy of General Motors]. 
In the beginning, the body was placed on a steel frame, but later versions have transitioned into a unibody design. The lastest iteration, introduced as a 2014 model year, uses as an aluminum center section (shown in figure 35) clad with composite body panels.

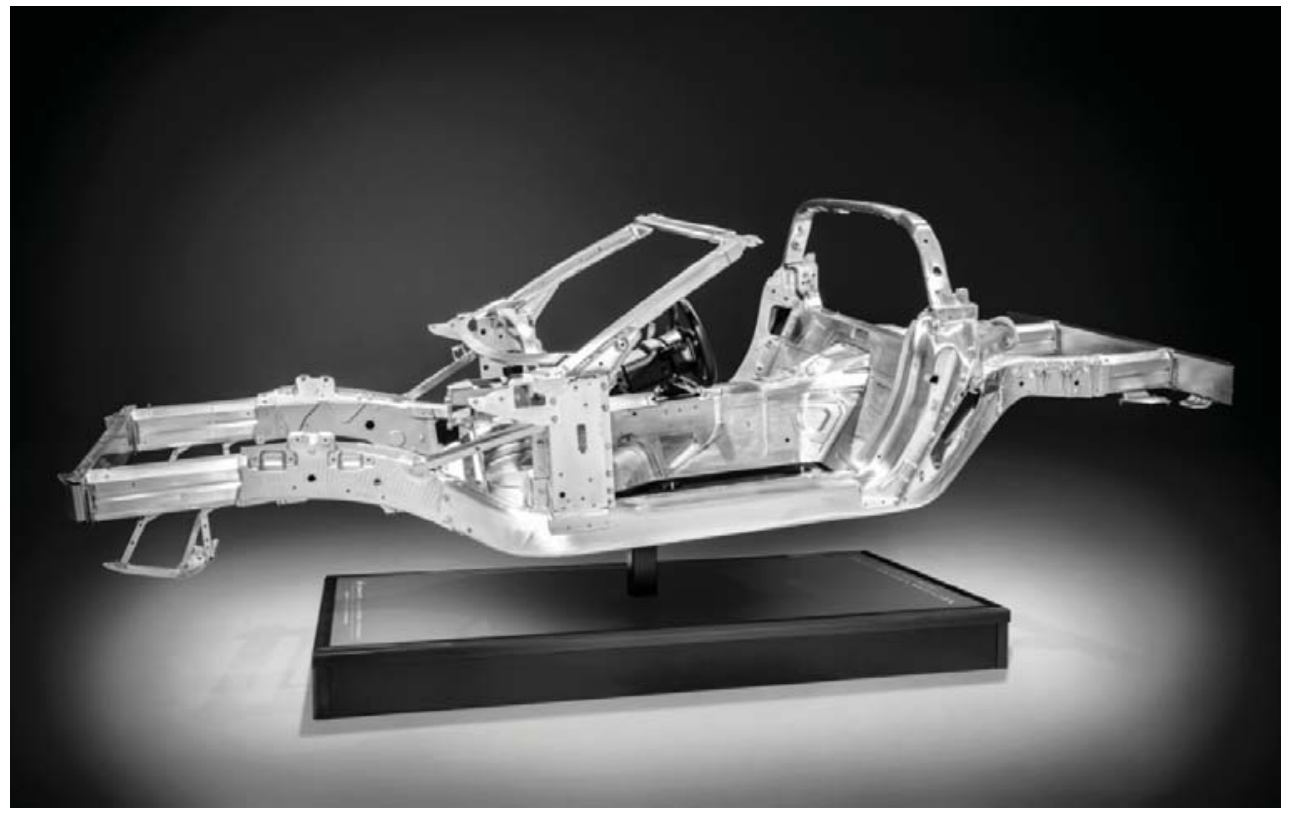

Figure 35. The 2014 Chevrolet Corvette Stingray aluminum center section [Picture courtesy of General Motors].

\section{Mercedes C-Class}

For the model year 2016 C-Class (figure 36 and 37), Mercedes developed a body with all hang-ons (doors, hood, fenders, trunk lid) in aluminum, along with an aluminum roof and cast aluminum suspension mountings (marked in green in Figure 37). The BIW also has a significant amount of high-strength steel (hot-formed as well as regular), where torsional stiffness is valuable. 


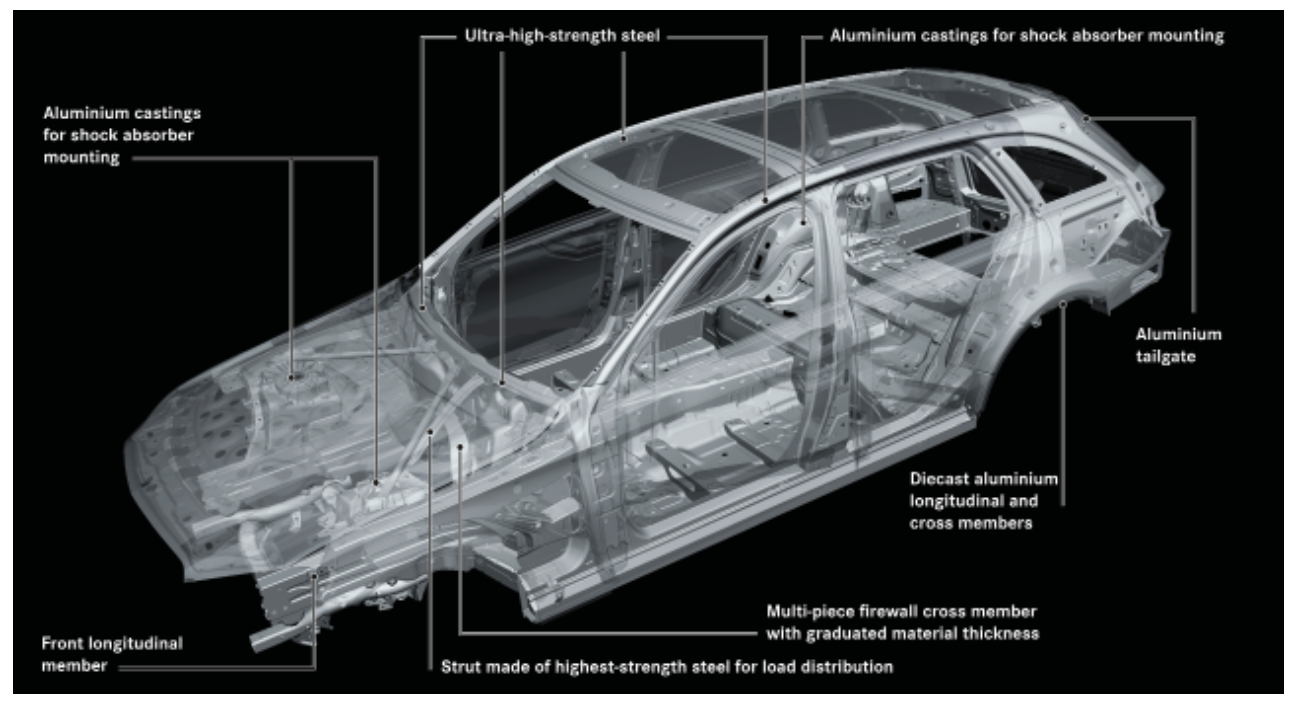

Figure 36. The new Mercedes C-Class has a significant amount of aluminum in its body panels, along with cast aluminum suspension mountings [picture courtesy of Daimler-Benz AG].

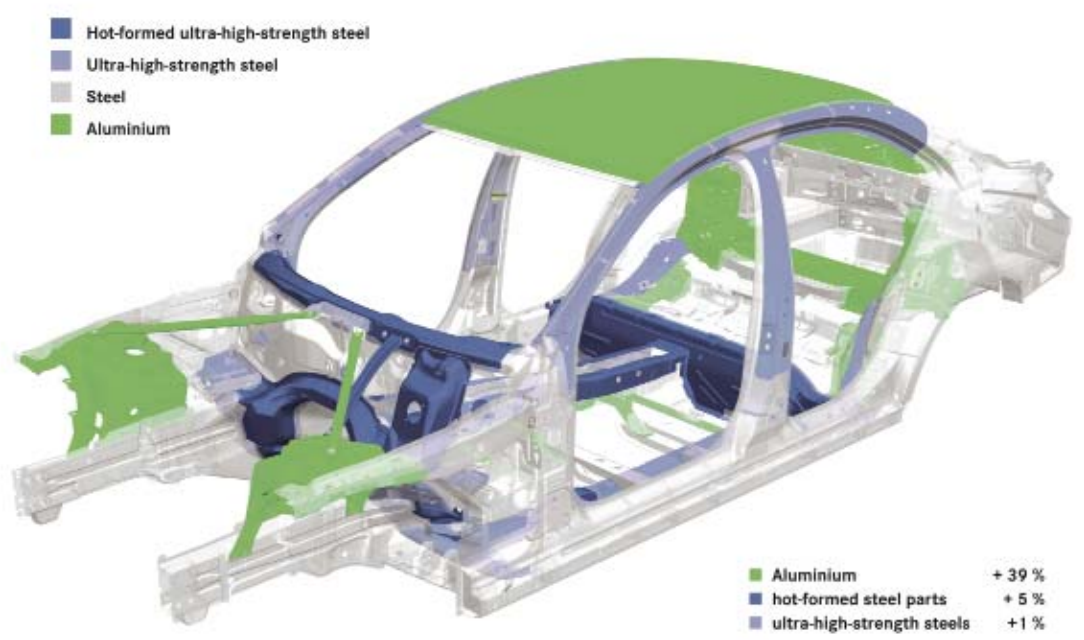

Figure 37. The new Mercedes C-Class has a significant amount of aluminum in its body panels, along with cast aluminum suspension mountings and high-strength steel grades [picture courtesy of Daimler-Benz $\mathrm{AG}$. 


\section{Mercedes GLC}

The Mercedes GLC (2016 model year and up) uses a combination of hot-formed steel, ultra-high-strength steel alloys and aluminum alloys in addition to the classical mild to high-strength steel alloys in the body, as can be seen in figure 38 . The aluminum alloys are used in panels up front or high in the vehicle, possibly to move the center of gravity backwards and downwards in the vehicle. Some additional aluminum parts are used in the front and rear suspension mountings.

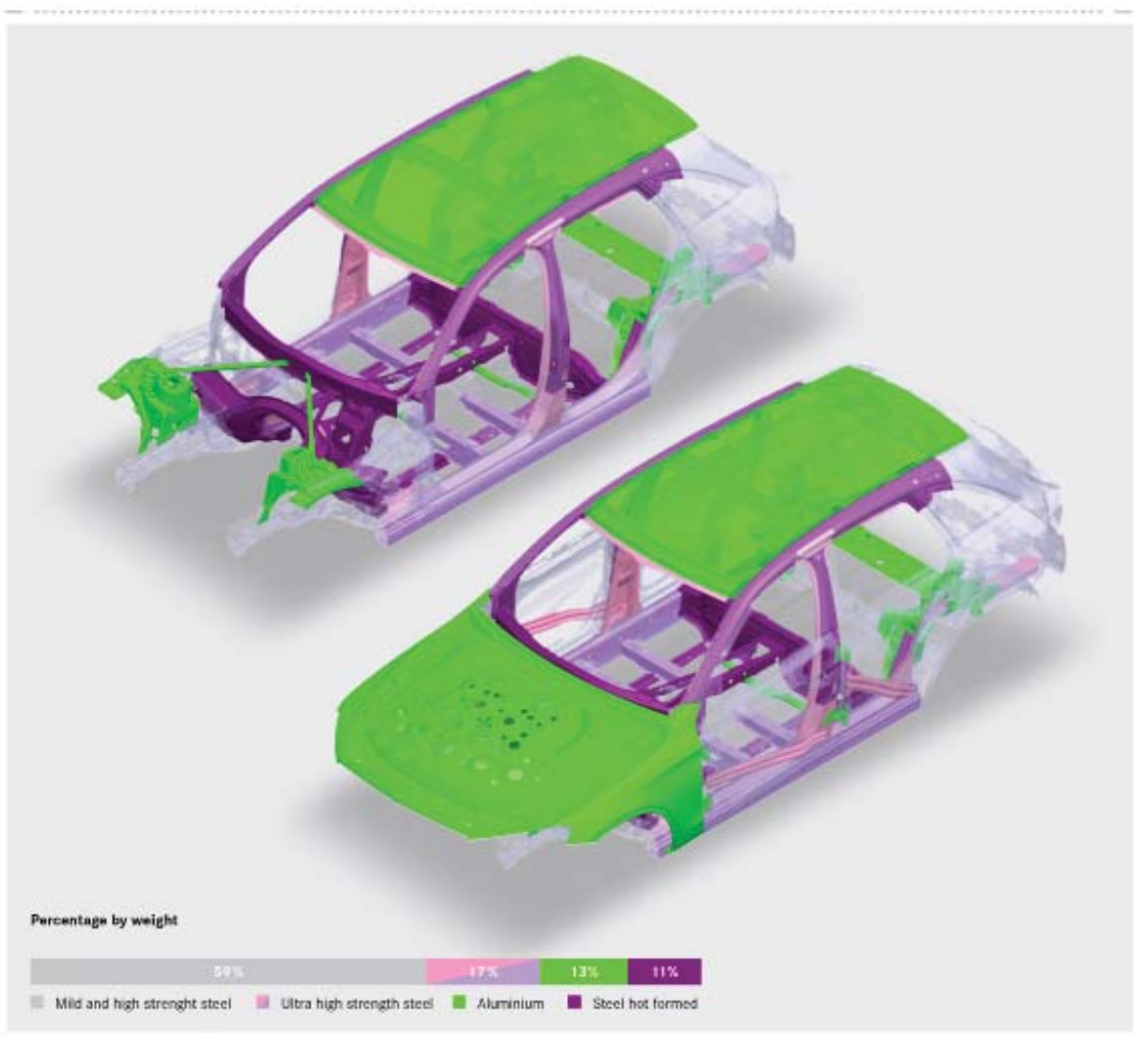

Figure 38. The Mercedes GLC showing the use of hot-formed steel, ultra-high-strength steel and aluminum in the body [pictures courtesy of Daimler-Benz AG]. 


\section{Volvo XC90}

Volvo's XC90 (2015 model year and up) utilizes high-strength steel and aluminum components (both cast and stamped components) in order to reduce mass. Throughout the BIW structure, multimaterial joints are present, as can be seen in figure 39 . Cast aluminum is used in the strut towers, while the hood and front quarters are made from stamped aluminum plate.

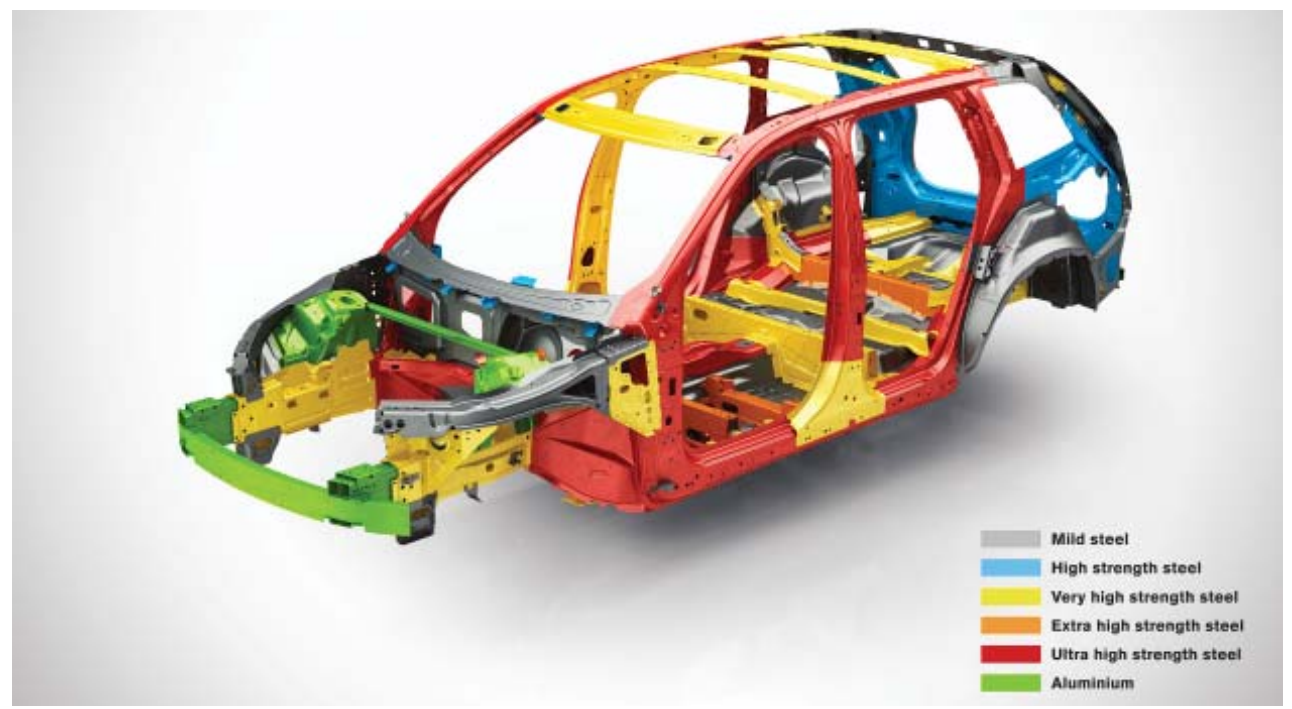

Figure 39. The Volvo XC90's various high-strength steel grade and aluminum hybrid structure [picture courtesy of Volvo Cars $A B]$.

\section{Summary of industry state}

From the presented industry examples, some trends can be seen:

-Almost all passenger vehicle conglomerates have a product line or platform with lightweight materials integrated

-Many companies try to incorporate lightweight materials in the upper parts of the body

-Multi-material designs are common

-Regular steel is exchanged for both high-strength steel and aluminum, depending on the application 


\subsection{A GENERAL MODEL FOR PASSENGER VEHICLE PRODUCTION}

In order to explain specific issues or challenges that occur when introducing new materials in an existing production system, a generalized model of passenger vehicle production is hereby presented (seen in figure 40). This generalized model is built upon on-site observations and unstructured interviews with employees at four factories producing vehicles for four different companies in three continents during 20142016, as well as video observations and literature findings from other passenger-vehicle producing companies.

The model explains the production flow from the stamping of body panels to the finished product ready for quality assurance testing before delivery. The flow follows the path of the main structure of the unibody structure, since this is commonly accepted as the identity carrier of the vehicle (as an example, the VIN tag is seen as the ID tag of the vehicle; this is usually joined to the unibody structure in some way).

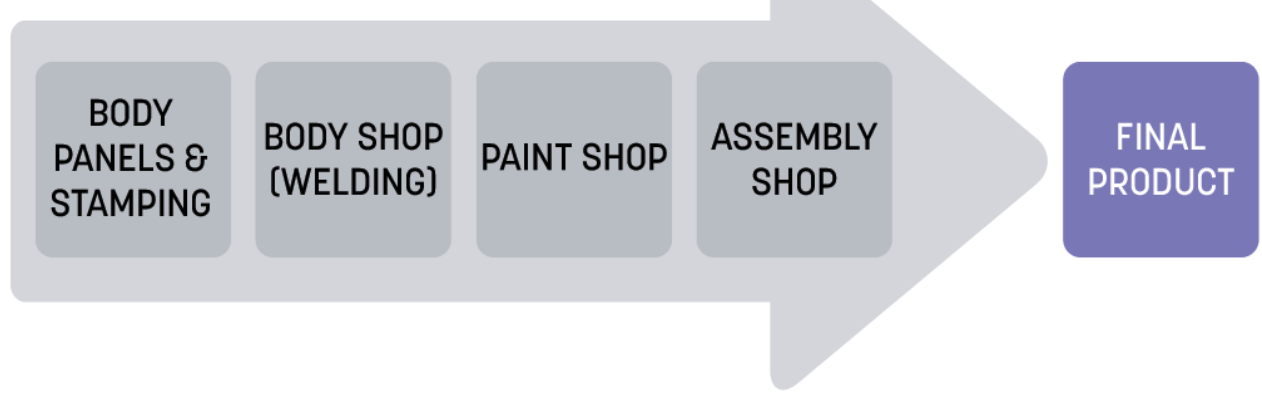

Figure 40. Generalized vehicle production model.

The process begins in the body stamping shop, where panels are formed and cut to size to be able to be used in later work stations (see figure 41). Some components are joined, such as the inner and outer panels of the hood and doors. The process is mainly parallelized and made in batches to reduce the downtime needed for switching tool sets. 


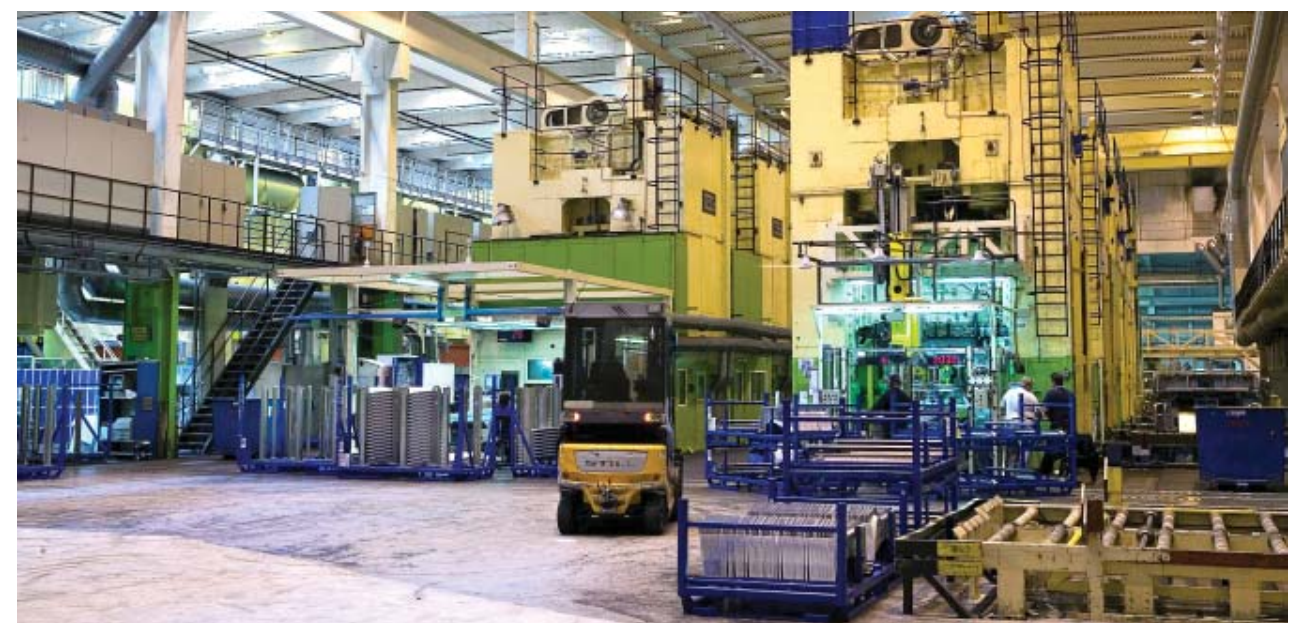

Figure 41. Picture of a body stamping shop [Picture courtesy of Volvo Cars AB].

The panels are transported to the body shop where they are distributed to specific work stations, and panels are welded together to start building the unibody (see figure 42). Enclosures (hood, trunk, doors) and their hinges are mounted, and some panels are screwed onto the unibody (usually front fenders). Here, the flow could be specialized, batched or mixed-model.

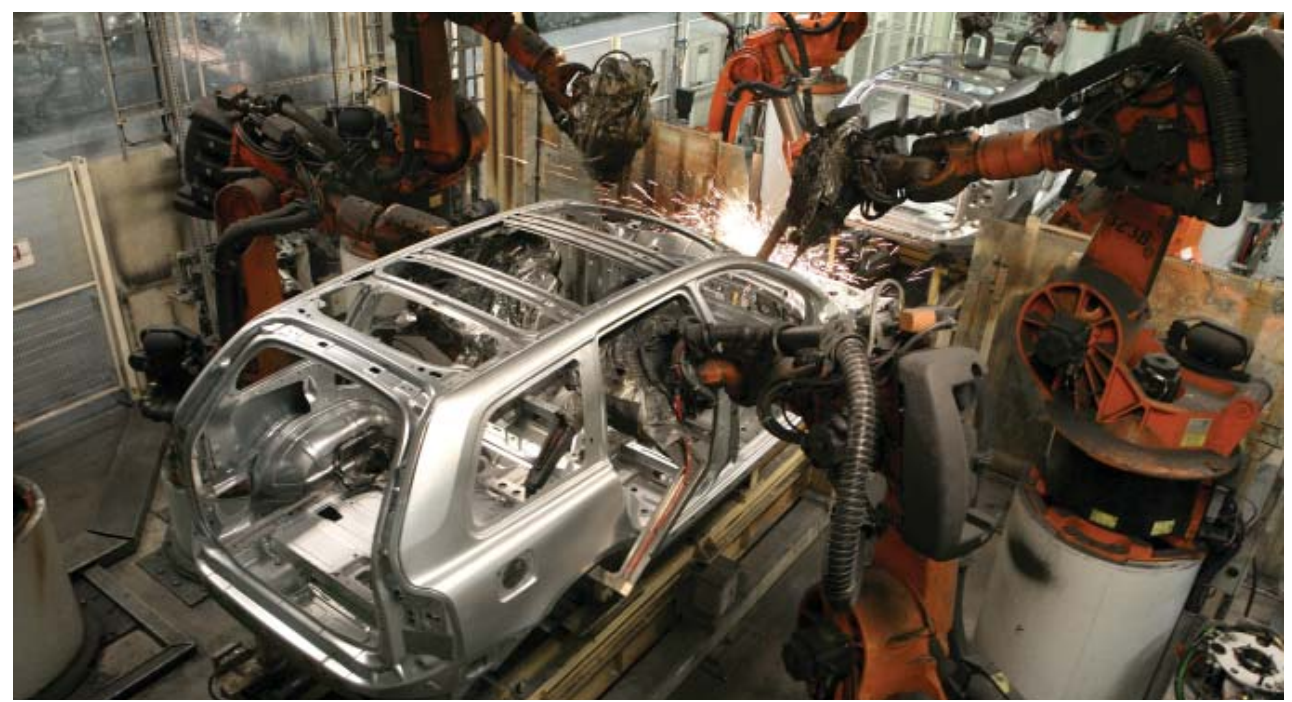

Figure 42. Automated unibody welding with welding robots in a body shop [picture courtesy of Volvo Cars $A B]$. 
The unibody is moved into the paint shop, where some panel seams are covered with filling material, before the body is coated with anti-corrosion protectives and painted with primer and topcoat (see figure 43). The unibody is then run through a curing oven, where the body is heated up to approximately 200 degrees Celsius for some time to cure the paint before it is polished and possible quality issues are rectified. Here, the flow could be specialized, batched or mixed-model.

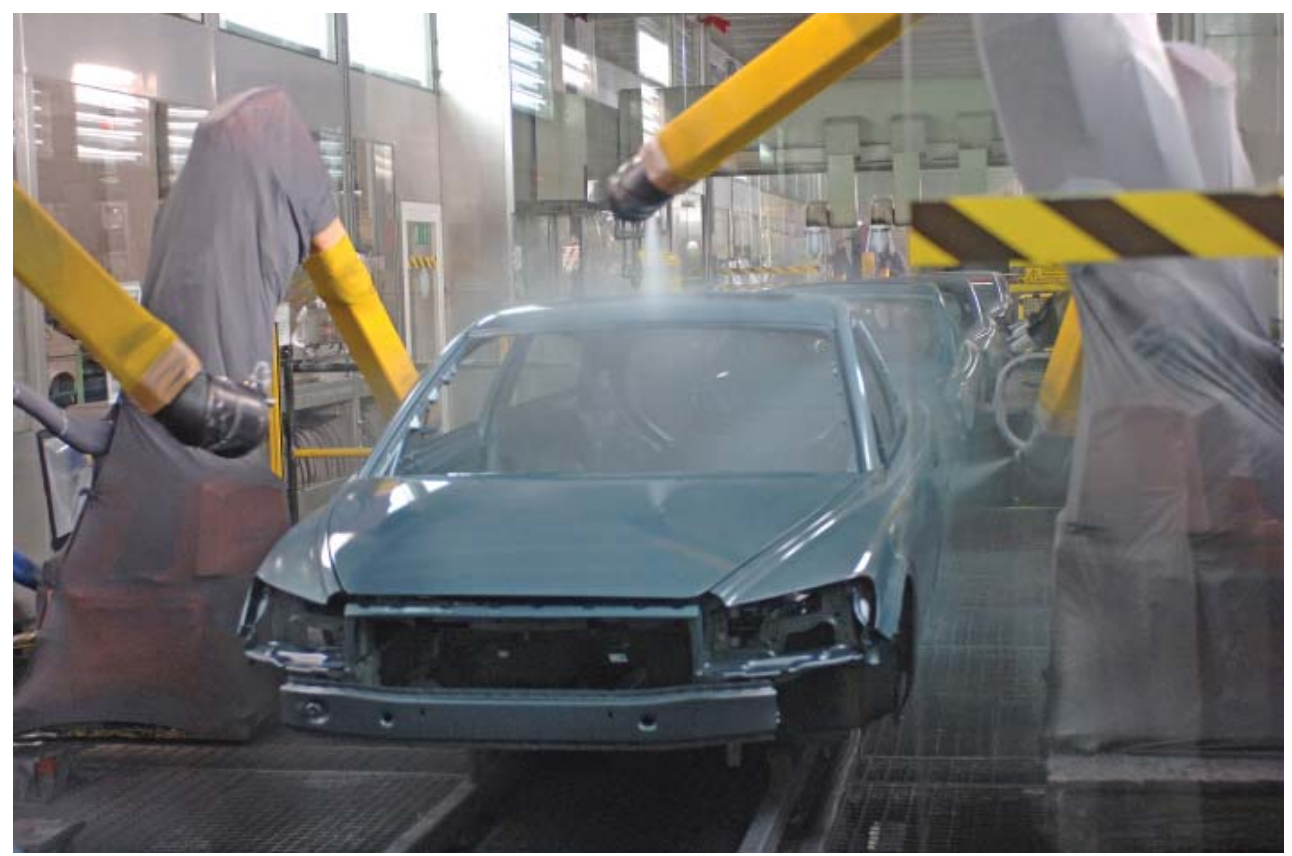

Figure 43. Automated topcoat painting in the paint shop [picture courtesy of Volvo Cars AB]. 
The painted unibody is moved into the assembly shop (see figure 44), where subsystems are assembled to the unibody to finish the car. The subsystems assembled can be classified into several categories: powertrain, chassis and suspension, electronics, interior and glasswork. Sometimes, multiple subsystems (such as powertrain and chassis and suspension) are assembled or fixed together to make a larger subsystem for a "marriage" with the unibody. Here, the flow could be specialized, batched and mixed-model.

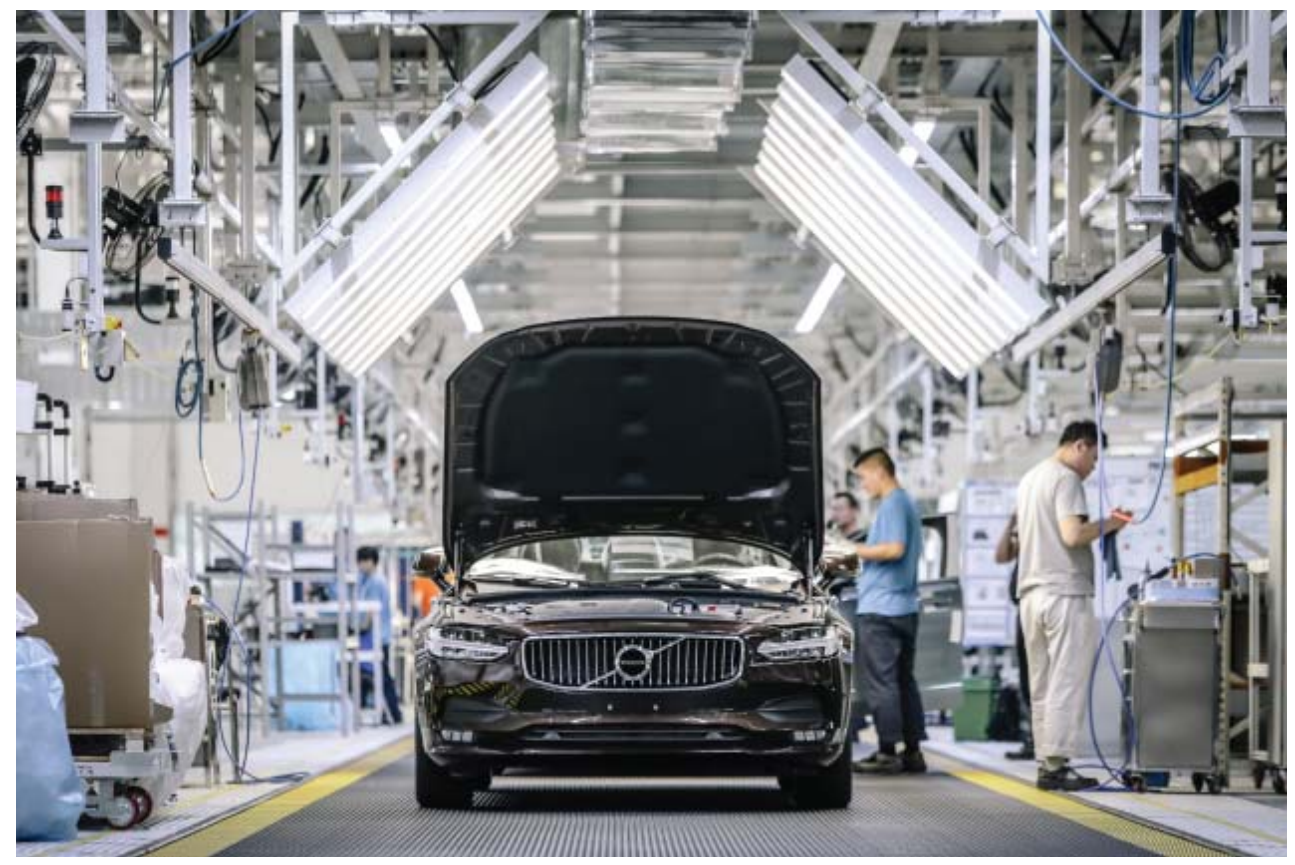

Figure 44. Final assembly of a modern passenger vehicle [picture courtesy of Volvo Cars AB]. 


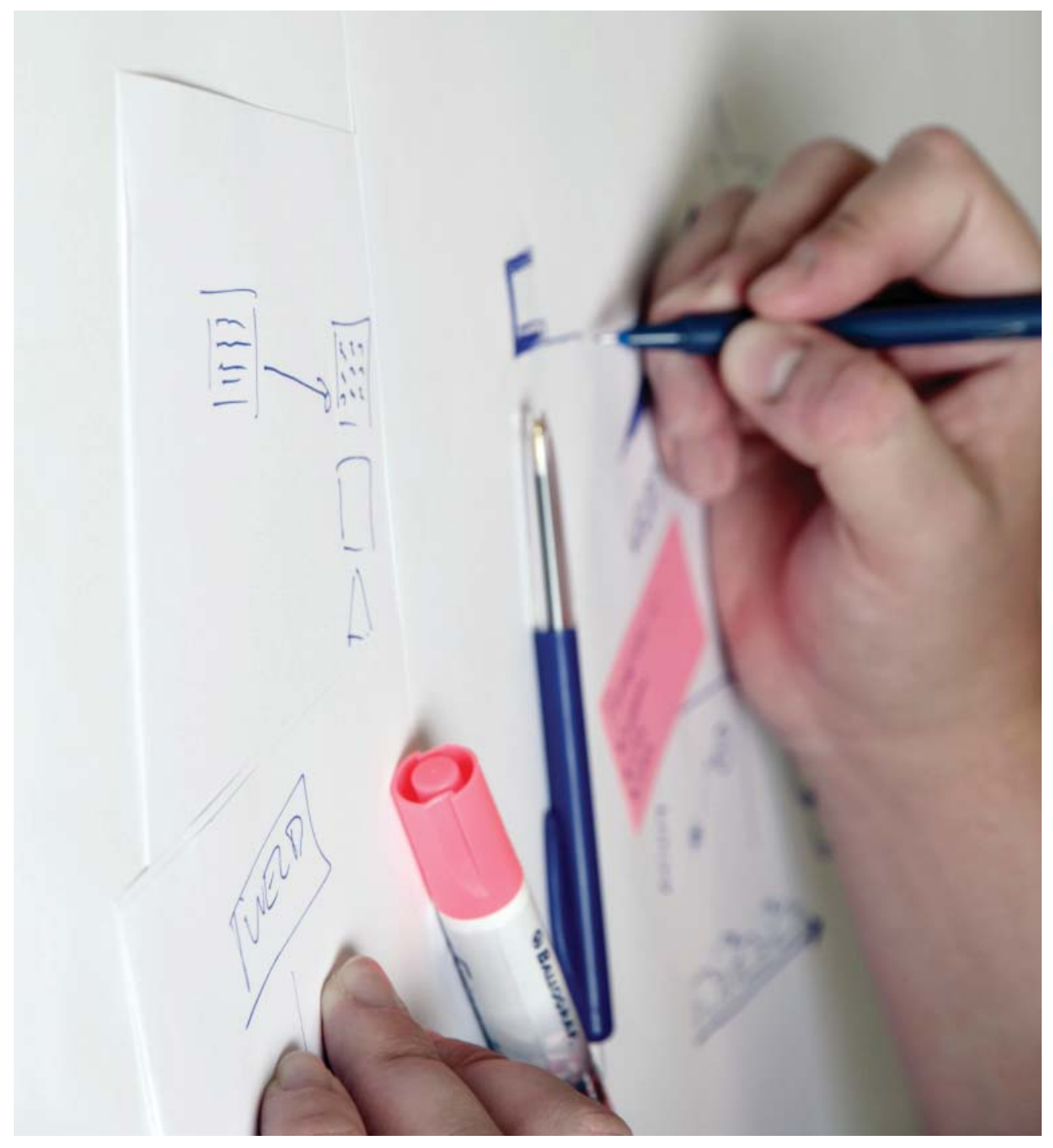

\section{PART 4 - CONTRIBUTION}




\section{PART 4 - CONTRIBUTION}

In the contribution, the work performed by the author is presented. First, a technical problem analysis is performed. After this, the four main cases are presented and an analysis of all the work performed is put forward in order to form the final conclusions. This part of the thesis should be read as the author's contribution to the academic knowledge base. Parts of the cases presented have been presented earlier in papers $\mathrm{B}$ and $\mathrm{C}$.

Picture on previous page courtesy of Philip Ekströmer 


\subsection{INDUSTRIAL PROBLEM ANALYSIS}

The research in this thesis aims to not only contribute to the academic knowledge base, but also contribute with knowledge that can be implemented in an effort to solve societal challenges. The review and definition of the industrial problem is done in two ways: one going backwards from the societal challenge of energy efficiency and making a technical problem analysis, and one analyzing the current situation in research on product development processes in an organizational problem analysis.

Technical problem analysis

If the challenge is to increase energy efficiency in road vehicle transportation, this challenge can be further investigated by defining energy consumption and energy efficiency in road vehicles.

Looking at a car driving along a road in a straight line (as in figure 45), the fuel consumption of this vehicle can be calculated using Equation 2. The energy consumption of a battery electric-powered vehicle would be calculated in a similar manner, using some smaller modifications. 


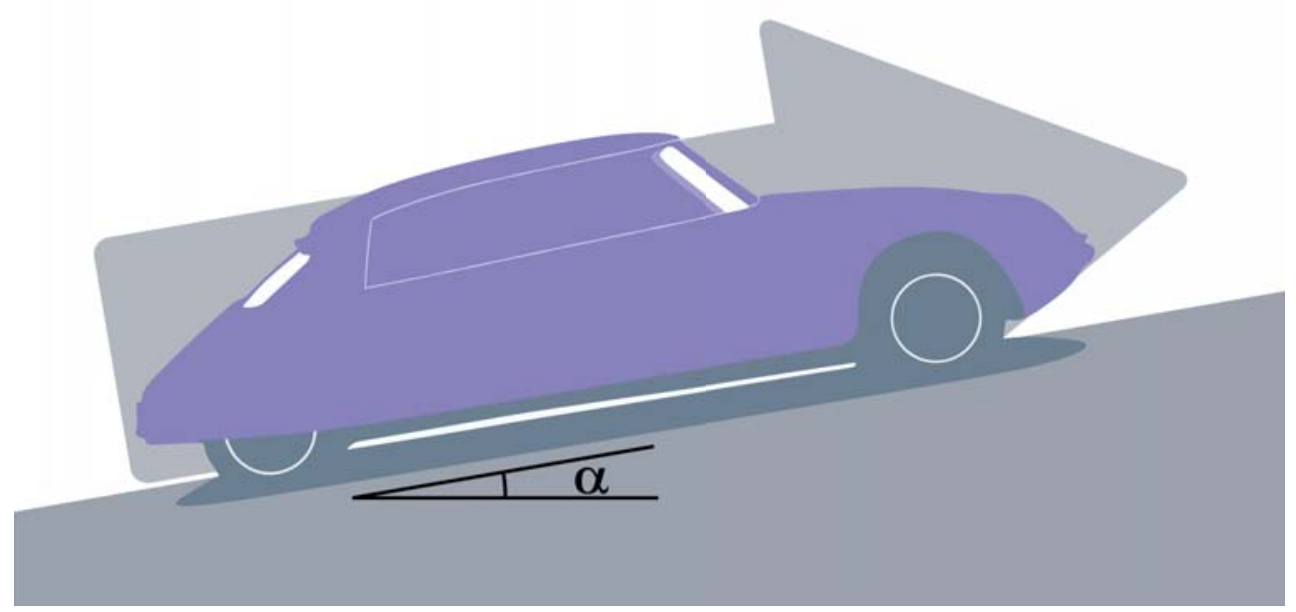

Figure 45. A passenger vehicle driving along a road.

$$
F C=\frac{\int b_{e} \cdot\left(\frac{F_{t} \cdot v}{\eta}\right) d t}{\int v d t}
$$

Looking further into Ft, the tractive force, an explanation can be seen below in Equation $3[109,110]$. Mass can be seen to contribute to the rolling resistance, acceleration resistance and climbing resistance $[109,110]$. Since few roads are perfectly horizontal, and much driving consists of acceleration or deceleration, all these resistances affect much of the driving in our society. So if vehicle mass can be reduced, each vehicle will either transport more payload for equal fuel consumption or have a lower fuel consumption per travelled distance. 


$$
\begin{aligned}
F_{t}=F_{R O L L}+ & F_{A C C}+F_{D R A G}+F_{C L I M B} \\
= & (f \cdot m g)+(m a)+\left(\frac{1}{2} C_{D} \cdot \rho_{A I R} \cdot v^{2} \cdot A\right)+m g \\
& \cdot \sin \alpha
\end{aligned}
$$

\section{Lightweighting}

Lightweighting is the activity of reducing mass in the end product. Lightweighting, or mass reduction, is recognized by Ulrich and Ellison [111] as one of the main drivers for developing bespoke solutions as opposed to using existing components and technology. The definition of material density is described as mass divided by volume, as seen in Equation 4:

$$
\rho=\frac{m}{V}
$$

However, in product development and engineering design work, density is seldom the resulting quality. This is especially true in land-based products, where buoyancy is not a defining quality of the product. Instead, requirements are usually based on the mass of the component. That suggests a restructure of Equation 5 to say:

$$
m=V \cdot \rho
$$

Mass reduction (from generation $\mathrm{n}$ to generation $\mathrm{n}+1$ of components or products) could be described as:

$$
\Delta m=m_{n+1}-m_{n}
$$


Equations 5 and 6 show that a reduced mass in a component can be achieved either by a reduction in volume $\left(\mathrm{v}_{\mathrm{n}+1}<\mathrm{v}_{\mathrm{n}}\right)$ or a reduction in density $\left(\rho_{\mathrm{n}+1}<\rho_{\mathrm{n}}\right)$, or a combination of both. In the extreme case, the entire mass reduction is achieved by switching to a material with lower density or by removing material from an existing design. This also means that mass reduction could be described as an optimization problem, where we are searching for

$$
\min _{V, \rho} f(V, \rho)
$$

for a set of boundary conditions affecting the possible values of $V$ and $\rho$. These boundary conditions are constructed by the customer requirements, product development processes, supply chains, production system restrictions, product cost and after-sales considerations. These boundary conditions are interdependent and non-static, which means that the at first the simple optimization problem from Equation 7 becomes a complex and complicated optimization problem, and thus it makes engineering sense to investigate non-mathematical ways of solving the problem. Some of these non-mathematical ways of solving the optimization problem could also increase knowledge about the boundary conditions for the mathematical solution.

\section{Organizational problem analysis}

Product development processes can be classified into two categories, linear and non-linear processes.

Linear product development processes have issues with ambiguous data input into the process, and ambiguous data can halt a product development project or kill off a project that might have been successful had it not been for decisions made on this ambiguous data. 
Non-linear product development processes need significant amounts of data and projects that can be segmented into small increments, either by having existing data (as in systems engineering, especially suited for the development of complex systems where precedents exist) or by being extremely modular (as in agile methodologies, especially suited for software development where each function or subscript can be tested individually).

\section{Concluding problem analysis}

A way of increasing energy efficiency in a passenger vehicle is to reduce the mass. This could be described as the optimization problem

$$
\min _{V, \rho} f(V, \rho)
$$

with boundary conditions on $\mathrm{V}$ and $\rho$ describing among other things the product development process, product requirements and production system restrictions. Due to the complexity of these boundary conditions, a non-mathematical approach to solving the problem should be investigated. This could be done by investigating the process in which the products are created.

Both existing classes of product development processes have challenges when working with the type of problem that the introduction of new materials is (ambiguous data input, lack of relevant data, complex systems of systems and lack of modularity). This means that there is not a clear-cut solution to what the product development process should look like. 


\subsection{CASE STUDIES}

Within the research work presented in this thesis, four case studies have been exectured. These four case studies will be presented on the following pages.

\section{Case 1 - Carbon fiber roof panel}

The first case, Case 1, was set up in collaboration with a product-producing company within the automotive industry investigating new material solutions to reduce the mass of the roof panel in the Body-In-White. The case was set up as a student project course case, the project team consisting of eight third-year students from the Master's program in Design \& Product Development. These students also wrote their bachelor thesis on specific topics within the project (see table 1). This case is also described in paper $\mathrm{C}$.

Table 1. Specializations within case 1.

\begin{tabular}{|r|l|l|}
\hline NO. OF STUDENTS & TOPIC & THESIS TITLE \\
\hline 2 & Product development & $\begin{array}{l}\text { Technical opportunities and limitations for light- } \\
\text { weight materials in the automotive } \\
\text { industry }\end{array}$ \\
\hline 2 & $\begin{array}{l}\text { Industrial design } \\
\text { engineering }\end{array}$ & $\begin{array}{l}\text { Design concepts for car roofs made of carbon fiber } \\
\text { composite }\end{array}$ \\
\hline 2 & Production & $\begin{array}{l}\text { Create a more efficient assembly process for car roof } \\
\text { structures when introducing } \\
\text { lightweight materials }\end{array}$ \\
\hline 2 & Product development & $\begin{array}{l}\text { Opportunities and limitations in the manufactur- } \\
\text { ing of body components in lightweight materials for } \\
\text { the automotive industry }\end{array}$ \\
\hline
\end{tabular}




\section{Objective - Case 1}

The objective of Case 1 was to investigate material selection in the automotive industry with a focus on production feasibility, and to evaluate how the project team would approach the introduction of a new material into an existing product.

Project process - Case 1

The project was set up to follow the Ulrich \& Eppinger model of product development [31], visualized in figure 46, with four main gates. The main restriction was that the assembly line would be as intact as possible, which was translated into a requirement of a possibility of implementing the solution with only one production cell added. Suggestions on how to improve the layout by making larger changes were encouraged.

This, along with a restriction on added cost (see excerpt below), set up the main framework for the requirements.

... design and construct a lightweight roof solution for [the company], and develop and demonstrate an assembly sequence that can be implemented with little to no increase in manufacturing cost"

Excerpt from project start-up documents, translated from Swedish to English.

The project team were given $\mathrm{CAD}$ data in the form of the body sides and roof of a mid-size station wagon for their project, along with basic requirements on the end product as well as study visits and filmed material of specific processes.

Information was gathered by the author via the four gates, the final project report, the four bachelor theses and an unstructured group interview at the end of the project.

Concepts were ranked and selected via concept screening [31] and concept scoring [31], as well as by discussions to cover aspects difficult to quantify. 


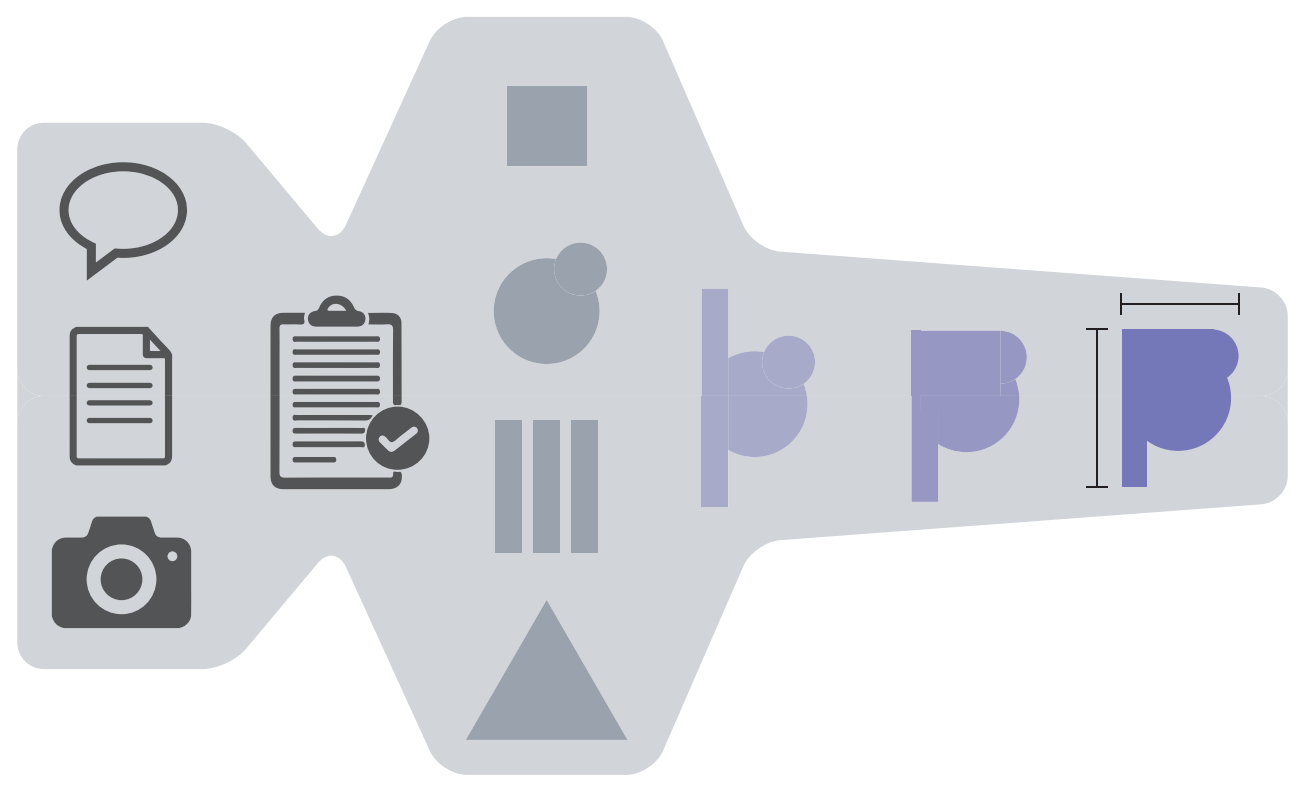

Figure 46. The product development process according to Ulrich and Eppinger [31], the model used in Case 1.

\section{Outcomes - Case 1}

In Case 1, the case team investigated and presented something they called the "material paradox". This was a way for the team to communicate a perceived understanding of the application time for different materials within the automotive industry. It also showed that developers perceive mass reduction, cost and environmental aspects as being in conflict with each other, as these three parameters were chosen for the Ternary plot explaining differences in material characteristics.

The resulting production process suggestion in Case 1 is a new sequencing joining the roof panel to the body late in the process, and using the opening in the body to assemble interior components by "dropping them" into the car rather than lifting components in through the door openings. This suggestion indicates a recursion effect between product changes and production process changes: a change in the product (in this case a new material) can trigger new production changes, 
which in turn trigger product changes, etc. This effect shows the importance of integrating product and production development projects, but also the risk of projects growing out of scope due to team members constantly finding more improvements if more redesign is done. 


\section{Case 2 - Aluminum roof panel}

The second case, Case 2, was set up in collaboration with a product-producing company within the automotive industry investigating new material solutions to reduce the mass of the roof panel in the Body-In-White. The case was set up as a student project course case, the project team consisting of five fifth-year students from the Master's programs in Mechanical Engineering and Design \& Product Development (see table 2). The design of the case was based on the experience from Case 1, adding further restrictions already from the start of the project. This case is also described in paper $\mathrm{C}$.

Table 2. Team setup within case 2 project.

\begin{tabular}{|r|l|}
\hline NO. OF STUDENTS & PROGRAM \\
\hline 4 & Design \& Product Development master's program \\
\hline 1 & Mechanical Engineering master's program \\
\hline
\end{tabular}

In Case 2, the project team was also set up to collaborate with another student team from another university focusing on production system changes and production system simulation [112].

\section{Objective - Case 2}

The objective in this case project was to investigate how an iterative product development methodology would affect material selection, and how decisions regarding materials were taken when material type and parts of the production system were clearly restricted.

\section{Project process - Case 2}

The project was set up to follow Cross' model of product development [113] (shown in figure 47), with eight main gates corresponding to two full iterations of the project. The project team were given CAD data (body sides, roof and roof structure) 
from a large SUV in order to recreate a real-world realistic project set up, along with basic requirements on the end product as well as study visits and filmed material of specific processes.

Information was gathered by the author via the eight main gate documents, as well as through two unstructured interviews (one at half-time and one at the end of the project) and individual reflection documents mandatory for the course grade. Concepts were ranked and selected via concept screening [31] and concept scoring [31].

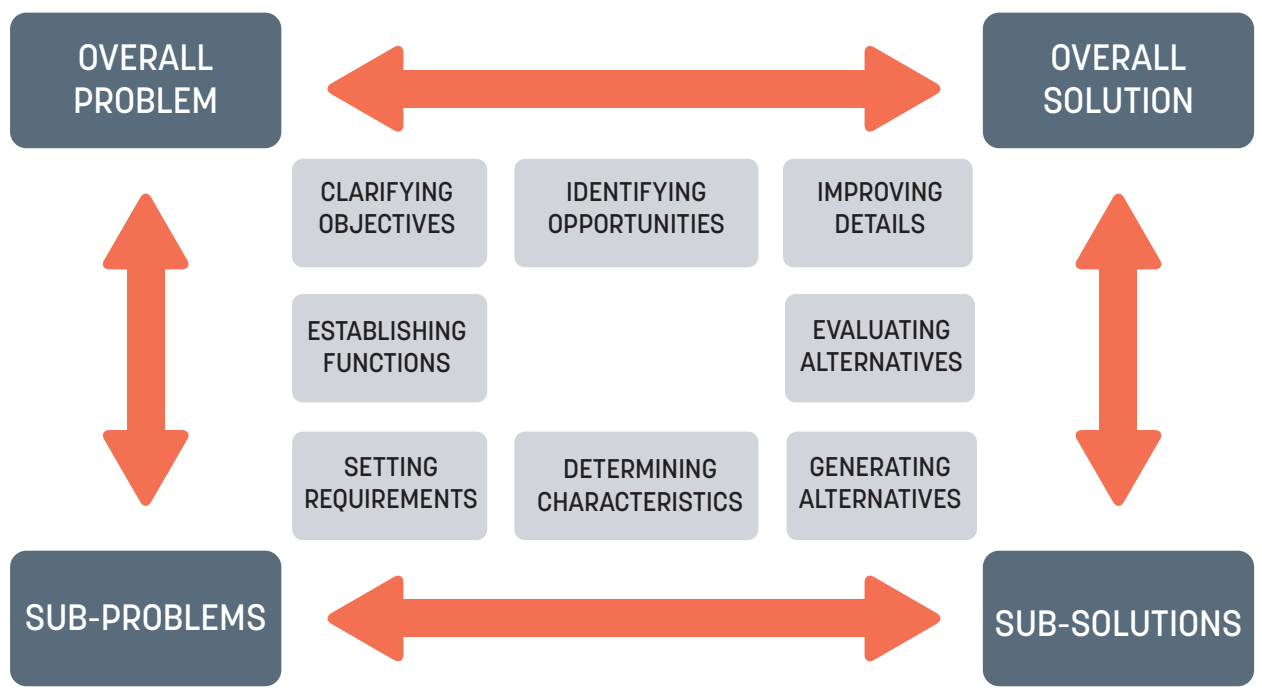

Figure 47. The product development process as described by Cross [113], the model used in case 2 .

\section{Outcomes - Case 2}

One outcome from Case 2 was an increased understanding of the need for production adaptions to new materials; the first restriction on no change in the production system meant that only one joining technology was possible from a production system standpoint (welding aluminum to steel), and this technology was not feasible from a product requirements standpoint (since the heat expansion difference will damage the welds in usage). These restrictions were revised in order to expand the design space for the case team. 
Case 2 also showed the need for implicit or contextual knowledge. A solution was developed that corresponded well to the requirements described but not all the requirements relevant to the system. Workstations downstream affected the product, and this set requirements outside of the normal operating window for the end product. This also showed that the requirements from the production system are sometimes more demanding than those in the product use phase, and that these requirements need to be identified and managed just as requirements from the use phase of the product. In this case, workstations downstream affected possible joining technologies upstream in the production system, excluding technologies that would work in the end product.

In Case 2, the project team evaluated several different solutions to multi-material designs based on sandwich materials, but refrained from using these due to a lack of information and knowledge regarding the material behavior. Also, since the project team identified material interfaces and interaction as a risk factor, the increased number of material interfaces in the sandwich material solutions became a liability in the concept selection. This pointed to an increased need of knowledge when introducing new materials, and the perception from product developers was that increasing the number of material interfaces increases the risk and uncertainty regarding functionality of the product. Specifically, production was mentioned as an unknown factor restricting too many material interfaces.

Case 2 showed the complexity of requirements definition of systems and components in systems, and specifically how this affects redesign activities. In the brief, the restriction was to not affect other components in the Body-In-White, while still fulfilling the requirements of the existing car. Team members explicitly commented on this requirement as restricting possible design solutions significantly, since the requirements of the component to redesign were ambiguous as well as clearly 
dependent on other components: there was a risk of the project becoming an exercise in duplicating a component (with regard to properties) in another material, a sort-of reverse engineering task. 


\section{Case 3 - Aluminum body side}

The third case was made in collaboration with a product-producing automotive company, and investigated a material substitution solution in the body side of an SUV. The case was set up as an evaluation project comparing different approaches to linear product development, with the researcher as a design engineer. This case is mentioned in paper $\mathrm{B}$.

\section{Objective - Case 3}

The objectives of Case 3 were to investigate how a material substitution task in a product system could be managed within a linear product development process model, and to investigate the effects of changing materials to one component in a product system without redesigning other components in the system.

\section{Project process - Case 3}

Case 3 was planned as a breadth-first development project, where a linear decision sequence was set up and followed, as shown in figure 48. No progress was allowed before a decision was made on the current level, and no diversion into multiple concepts was allowed.

\begin{tabular}{|l|lll|}
\hline \multicolumn{1}{|c|}{$\begin{array}{l}\text { PROJECT } \\
\text { INITIATION }\end{array}$} & $\begin{array}{l}\text { CONCEPT } \\
\text { DEVELOPMENT }\end{array}$ & $\begin{array}{l}\text { SYSTEM LEVEL } \\
\text { DEVELOPMENT }\end{array}$ & DETAIL DESIGN \\
\hline $\begin{array}{l}\text { Proposing solution } \\
\text { Identifying risk factors }\end{array}$ & $\begin{array}{l}\text { Proposing solution } \\
\text { Identifying risk factors }\end{array}$ & $\begin{array}{l}\text { Proposing solution } \\
\text { Identifying risk factors }\end{array}$ & $\begin{array}{l}\text { Proposing solution } \\
\text { Identifying risk factors }\end{array}$ \\
\hline $\begin{array}{l}\text { Mitigating risk factors } \\
\text { body shop }\end{array}$ & $\begin{array}{l}\text { Mitigating risk factors } \\
\text { body shop }\end{array}$ & $\begin{array}{l}\text { Mitigating risk factors } \\
\text { body shop }\end{array}$ & $\begin{array}{l}\text { Mitigating risk factors } \\
\text { body shop }\end{array}$ \\
\hline $\begin{array}{l}\text { Mitigating risk factors } \\
\text { paint shop }\end{array}$ & $\begin{array}{l}\text { Mitigating risk factors } \\
\text { paint shop }\end{array}$ & $\begin{array}{l}\text { Mitigating risk factors } \\
\text { paint shop }\end{array}$ & $\begin{array}{l}\text { Mitigating risk factors } \\
\text { paint shop }\end{array}$ \\
\hline $\begin{array}{l}\text { Mitigating risk factors } \\
\text { assembly shop }\end{array}$ & $\begin{array}{l}\text { Mitigating risk factors } \\
\text { assembly shop }\end{array}$ & $\begin{array}{l}\text { Mitigating risk factors } \\
\text { assembly shop }\end{array}$ & $\begin{array}{l}\text { Mitigating risk factors } \\
\text { assembly shop }\end{array}$ \\
\hline $\begin{array}{l}\text { Assesing costs } \\
\text { Assesing costs }\end{array}$ & Assesing costs & Assesing costs \\
\hline
\end{tabular}

Figure 48. The working process (starting at the top) of the Case 3 project. 


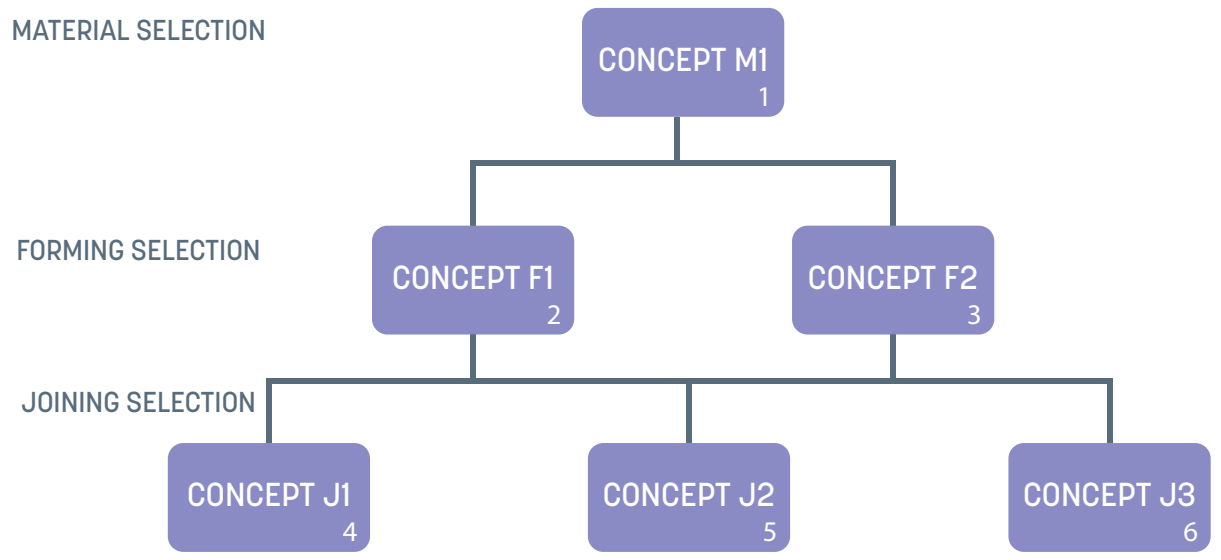

Figure 49. The principle of a breadth-first analysis, where concepts are evaluated in numerical order.

\section{Outcomes - Case 3}

Case 3 ended up in an abandoned project in system-level design, due to a lack of data guiding the decision on selecting joining technology. This meant that the decision would have been arbitrary, or that the fully sequential breadth-first approach (shown in figure 49) would have needed to be abandoned (thus allowing for more holistic concepts to be created and evaluated in parallel).

This shows that a fully sequential process is not preferable when developing components in new materials, as an iterative process could have solved some of the issues encountered by enabling knowledge needed for the concept selection. The fully linear or sequential process can be managed in two ways: either by the breadth-first analysis presented in this case, or through a depth-first analysis creating concepts for all possible solutions and making a cross-comparison of all possible concepts. This, on the other hand, results in a project with a very high budget and time consumption, which are described as qualities of bad product development projects according to Ulrich \& Eppinger [31]. 
Case 4 - Aluminum roof panel II

Case 4 was an industry-based action research project in collaboration with a product-producing company within the automotive industry, where the researcher was placed as the project coordinator in a production development investigation of the introduction of body panels in new materials.

\section{Objective - Case 4}

The objective of the study was to identify how an automotive industry company manages a material introduction project from a production development standpoint. The effects of a full-scale organization with multiple projects and on-site access to production was also of interest for investigation.

\section{Project Process - Case 4}

The project was set up as an investigation of manufacturability for a new body configuration of a passenger car with an aluminum roof panel. The researcher was set up as project coordinator, with contact points to all factory functions and in-house production process experts within the production development department. The process was iterative using a loop of proposing solutions, identifying risks, mitigating risks and cost assessment, as shown in figure 50 .

The project followed a linear but iterative process model, similar to the company's own models. This meant that risk factors were identified and addressed, typically working through each factory function before repeating with renewed risk factors and a more detailed conceptual solution. Once per week, a status meeting was held with the project coordinator, project owners and contact points within the company. 


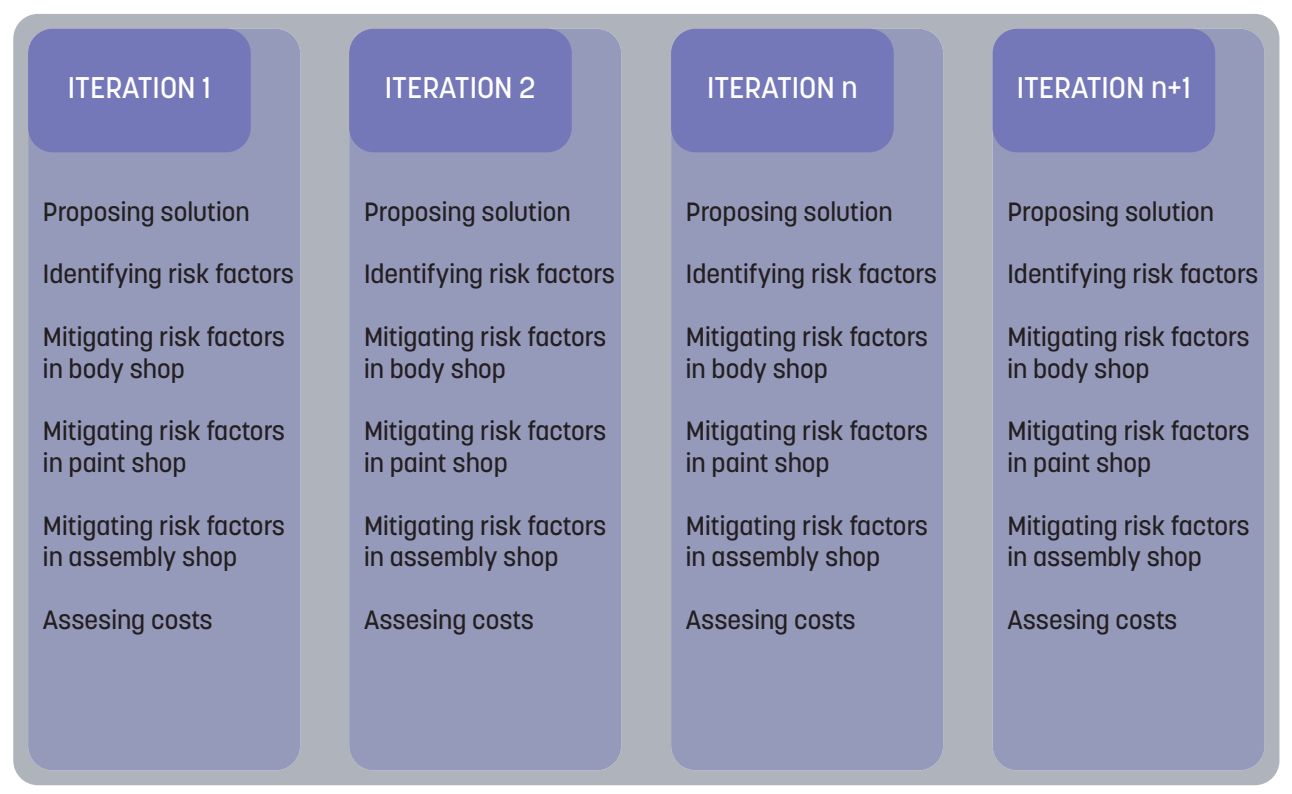

Figure 50. The working process for Case 4.

\section{Outcomes - Case 4}

In Case 4, the researcher identified some challenges with implementing change in industry when going from a known solution with detailed knowledge regarding several parameters to an unknown solution with low-fidelity or even contradicting data.

Questions raised during the project point toward the industry knowing that their production processes work, but not necessarily exactly how they work. This makes change of material in components complicated and a significant risk, since the knowledge acquired during existing work with steel could not be applied to a multi-material body. One instance of this was the investigation of forces acting on the BIW when sent through fluid baths as paint preparation. Since steel bodies have traditionally been welded and are therefore clearly strong enough, these forces have not been estimated; this created a risk factor for a new, non-welded design when going through these paint preparation baths with a lack of quantifiable requirements. 
Case 4 also gave an insight in that industry actors do not necessarily have the organizational structure to fully analyze the effects of a material change. The researcher found a need for technical simulation outside the regular scope within the production development, and identified the lack of an organizational structure to contact in-house experts in these specific simulations. While it was possible to contact inhouse experts, and said in-house experts estimated the task as manageable when inquired, there were no contact surfaces between the team led by the researcher and the in-house experts. This contact was instead taken via a combination of brute force contact seeking (the researcher simply went from desk to desk asking for a possible point of contact) and the researcher's personal contacts.

Since this project was mainly focused on production development, and given that there was a limited budget for product design and development, the resulting effect was that a very limited amount of design engineering was done. This affected the project by keeping a deceptively open design space. The design space was still open since no decisions on geometry were taken, but falsely open since it was obvious that latter decisions would constrict design space. This was repeatedly mentioned in communication with in-house experts, reporting that it is possible to produce a version of the proposed solution, but not any solution that might be proposed later in the project.

Case 4 reinforced the outcome from Case 2: that the most demanding requirements on a product or component can occur in production; assessing heat expansion, the highest temperature expected for the vehicle to experience is within the paint curing oven. This results in the product requirement specification specified for the use phase might obscure more demanding requirements. 
Case 4 highlighted the combination of introduction of new materials and mixed-model assembly lines as a challenge: Since multiple models use the same assembly line, solutions implemented for new materials and models need to fit with the existing solutions on other products in production without effecting cycle times in a significant manner. This creates design, material and process restrictions for the new material to be implemented. 


\section{Summary of the case studies}

In the four case studies presented, commonalities between insights can be seen both in topics and detailed insights. These have been visualized in table 3 :

Table 3. Insights from the case studies..

\begin{tabular}{|c|c|c|c|c|c|}
\hline INSIGHT & DESCRIPTION & CASE 1 & CASE 2 & CASE 3 & CASE 4 \\
\hline 1 & $\begin{array}{l}\text { Assembly system effects on the introduction of } \\
\text { new materials }\end{array}$ & $X$ & & & $X$ \\
\hline 2 & Need for iterative development processes & & $X$ & $X$ & $X$ \\
\hline 3 & $\begin{array}{l}\text { Communication between product and produc- } \\
\text { tion development }\end{array}$ & & $X$ & & X \\
\hline 4 & $\begin{array}{l}\text { Need for simulation tools when evaluating } \\
\text { multi-material design and new material intro- } \\
\text { duction }\end{array}$ & $X$ & X & & $X$ \\
\hline 5 & Manufacturing process selection challenges & $X$ & X & X & \\
\hline 6 & $\begin{array}{l}\text { Most demanding product requirements in pro- } \\
\text { duction }\end{array}$ & X & $X$ & & $X$ \\
\hline 7 & $\begin{array}{l}\text { Production and functional requirements sepa- } \\
\text { rated in development }\end{array}$ & $X$ & $X$ & $X$ & $X$ \\
\hline 8 & $\begin{array}{l}\text { Organizational needs for introducing new ma- } \\
\text { terials }\end{array}$ & & X & & $X$ \\
\hline 9 & $\begin{array}{l}\text { Product changes drive production system } \\
\text { change }\end{array}$ & $X$ & $X$ & & $X$ \\
\hline 10 & Joining multi-material bodies & X & & X & \\
\hline 11 & Backloading of assembly to later stages & $X$ & & & $X$ \\
\hline 12 & $\begin{array}{l}\text { Information, knowledge or requirements out- } \\
\text { side of scope affecting project }\end{array}$ & & $X$ & & $X$ \\
\hline 13 & $\begin{array}{l}\text { Process data and knowledge responsibility } \\
\text { within development }\end{array}$ & $X$ & $X$ & & $X$ \\
\hline 14 & Joining metals to metals & & X & X & $X$ \\
\hline 15 & Joining sandwich materials to metals & $X$ & $X$ & & \\
\hline 16 & Adhesive joining & & $X$ & & $X$ \\
\hline
\end{tabular}




\subsection{ANALYSIS AND DISCUSSION}

In the industry examples presented in the Part 3, "Technology Mapping", the materials used to reduce mass differ as well as the position, functionality and design of the non-steel panels. Some companies reduce weight within the load-bearing structure (BMW i3 and 7 Series), while some focus mainly on exterior panels (Cadillac CT6, Mercedes C-class). Some even have redesigned the body extensively to better suit the new materials (BMW i3, Chevrolet Corvette). While material selections are differentiated, high-strength steel and aluminum alloys are the most common replacements for regular steel in car bodies (Cadillac CT6, Mercedes C-class, Volvo XC90).

One trend that can be seen in several examples (BMW 7 Series, Cadillac CT6, Mercedes C-Class) is using higher-strength or lower-density materials at the top of the vehicle. In some cases (BMW 7 Series), regular steel crossbeams have been replaced by CFRP crossbeams, while in other cases (Mercedes C-Class) the roof panel has been made in aluminum instead of steel. This is probably due to a demand for a lower center of gravity in order to improve dynamic behavior.

The difference in which components are being subjected to material exchange, and which materials are being used, could be due to internal factors in product development processes, development capabilities or the production system itself. It could also indicate that this technology step is not yet matured within the automotive industry. If this is the case, it is not as of yet possible to present a generalized solution for how to design and produce a multi-material car body. This points to an industrial knowledge gap: a lack of knowledge on how new material introduction projects are performed, and which types of factors affect decisions when developing the product and production system.

In the theoretical analysis of existing product development processes presented in the organizational analysis, neither of the two main classes of processes (linear or 
quasi-linear, and non-linear models) are obviously suited for an integrated product and production development project introducing new materials into existing production infrastructure. While both have their clear benefits (for example, the clear progression in linear models and the explicit iterative process in non-linear models), there are also drawbacks or challenges with both (for example, the challenges with ambiguous data in linear models and the need for incremental progress in non-linear models).

This indicates that there is not a superior product development process that could be the panacea, solving all new material introductions. Instead, there is a need for investigating new material introduction projects in general, gathering knowledge about what type of questions that arise in this type of projects.

The combination of the industrial and theoretical knowledge gap indicates that research was needed on several aspects of introducing new materials in existing production systems within the automotive industry. Aggregating the case study insights from table 3 , several aspects of introducing new materials in existing production systems can be identified for further analysis:

-Efficient knowledge gathering

-Understanding the production system's effect on the product

-Understanding the product's effect on the production system

-Selecting technology

•Knowledge sharing and communication

-Managing requirements

-Methods and tools

-Modularity

These analysis aspects are derived from combining multiple case study insights according to table 4 . 
Table 4. Correlation between case study insights and analysis aspects.

\begin{tabular}{|l|l|}
\hline ASPECTS TO ANALYZE & INSIGHTS FROM CASE STUDIES \\
\hline Efficient knowledge gathering & $4,6,7,9,13,14$ \\
\hline $\begin{array}{l}\text { Understanding the production system's effect on } \\
\text { the product }\end{array}$ & $1,3,4,6,7,12$ \\
\hline $\begin{array}{l}\text { Understanding the product's effect on the produc- } \\
\text { tion system }\end{array}$ & $3,5,6,7,9,10,11,14,15,16$ \\
\hline Selecting technology & $5,10,14,15,16$ \\
\hline Knowledge sharing and communication & $3,7,8,12,13$ \\
\hline Managing requirements & $6,7,12,13$ \\
\hline Methods and tools & $2,6,9,10,11,14,15,16$ \\
\hline Modularity & $1,5,9,11$ \\
\hline
\end{tabular}

\section{Efficient knowledge gathering}

Efficient knowledge gathering regarding introducing new materials in existing production systems is vital, since industry is already implementing multi-material design, and the need for knowledge is thus already present in industry today.

The similarities in outcomes and insights between Case Studies 1, 2 and 4 show that for a clearly defined and delimited study and project, case studies on student engineering projects can provide useful and relevant insights regarding how problems are solved within a project setting. This means that student projects can be used to investigate certain aspects of integrated product and production development, given certain conditions: the project brief is industry relevant, the result is deemed reasonable from an industrial point of view, the accessible data and tools are industry relevant and the level of knowledge from the students is known.

An effort to incorporate student projects to a greater extent in research in manners like these could help both industry and academia by reducing cycle times for projects 
to observe, as well as enabling the parallelizing of observations. For example, multiple projects with different briefs or setups can be performed at the same time. This "university as a laboratory" principle should be beneficial for industry (industry will get relevant research insights while still reducing the risk of intellectual property being exposed to competitors), academia (academia will get the possibility to generate more data and insights quicker, being able to evaluate multiple project setups) and students (students will have relevant projects in courses, and supervisors with a clear interest in the project and outcome) in order to maximize the engagement from all parties, and thus maximize the possibility for useful results.

\section{Understanding the production system's effect on the product}

A central part of developing both products and production systems is to understand the relationship between them. One aspect of that is to evaluate the production system's effect on the product.

The production system could be explained as having primary, secondary and tertiary effects on the product throughout the system, as shown in figure 51. Primary effects would be the immediate and sought-after effects (the heat from a welded joint while the welding is being done), secondary effects would be immediate effects not sought after (the increased resistance of surrounding fluids in a solvent bath) and tertiary effects would be neither immediate nor sought-after effects (assembly workers applying a load to a panel while entering or exiting the vehicle to work with interior assembly, conveyor belt rattle when the product is transported, or weld spatter hitting body panels). While some secondary and tertiary effects can be mitigated or eliminated within the production system, others need to be taken into account when developing the product. This classification of production system effects could be used as a method for identifying suitability for the introduction of new technology; if there is a conflict between the requirements for introducing a new technology and 
a tertiary effect from the production system, there is a greater possibility of this being mitigated than if the conflict is between technology requirements and primary effects from the production system. On the other hand, primary effects will require significantly less effort to identify and quantify, which make them carry less risk into a project. This means that effort should be put into identifying secondary and tertiary production system effects, while primary production system effects are suitable for early-phase decisions on whether or not to further evaluate technology suitability.

\section{TERTIARY PRODUCTION SYSTEM EFFECTS}

\section{SECONDARY PRODUCTION SYSTEM EFFECTS}

\section{PRIMARY PRODUCTION SYSTEM EFFECTS}

Figure 51. Three different classes of production system effects on the product.

Case 4 even indicates that mixed-model assembly lines might be a hindering factor for the introduction of new materials; the reason for this could be that the flexibility in the system itself is required to manage multiple products, often in varying stages of a product life-cycle, which actually restricts the introduction of new solutions. If the solution requires flexibility outside the current range [15], the investment of implementing the new solution is significantly higher and the running costs increase due to the need to have two parallel technologies running in production. This results in a transition point for a set of design parameters, where the implementation costs increase drastically. 
Understanding the product's effect on the production system

Another aspect of understanding the relationship between product and production system (see "Understanding the production system's effect on the product") is to understand how the product affects the production system.

Since new materials can favor new joining technologies, it is possible that assembly should be sequenced differently depending on which material is used, and in which component, in order to get the best possible product-production compromise. This is due to a possible delay in the properties of components over time, which is due to joining technology (as seen in Figure 50). If this is the case, a new challenge arises in developing products for a mixed-model assembly line if the products have components in differing materials. Some joining technologies put limitations on loads and stresses for a certain time after the joining is made, something that will affect the setup of the production system if it is used.

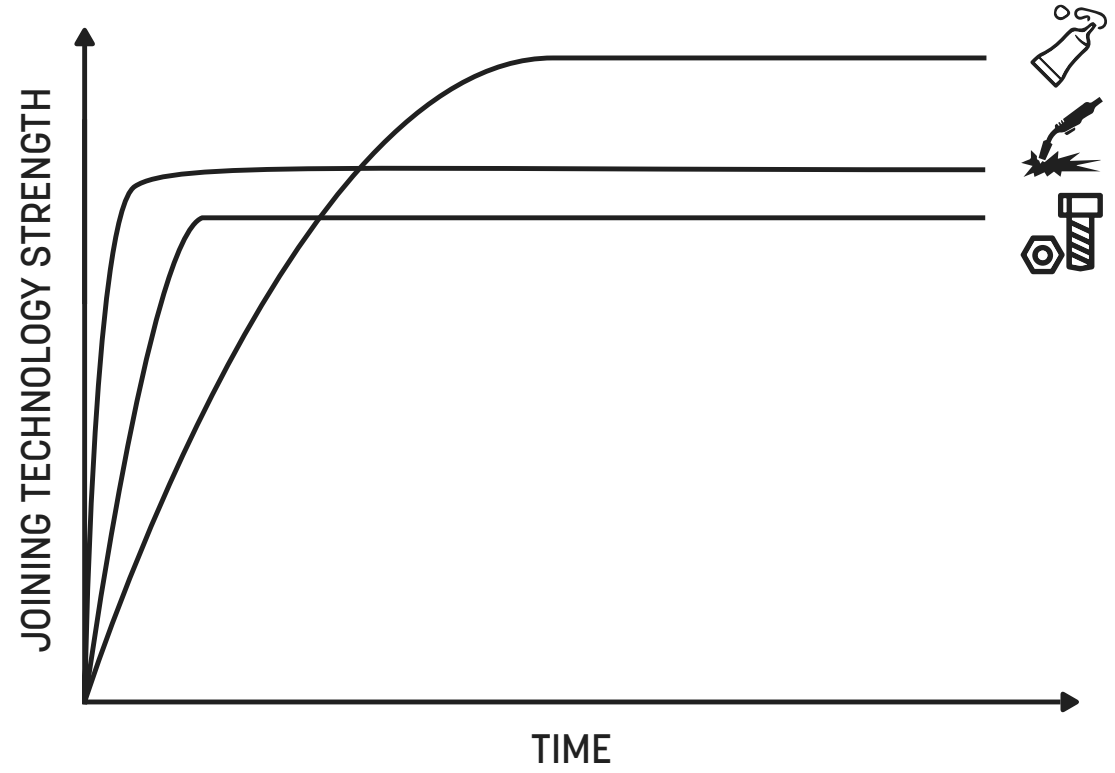

Figure 52. Graph showing delays in strength of different joining technologies over time. Adhesive joining can have a higher final strength, but due to curing times it takes a longer time to reach this higher value. 
This is further explained in two scenarios: one looking at material substitution in front fenders, and one looking at material substitution in roof panels.

\section{Scenario 1: Material substitution in front fenders}

An example of a component could be the front fender of a passenger vehicle. This component could be made in several different materials; we will look further into the consequences of four of them: steel, aluminum, CFRP and ABS plastic (shown in figure 53).

CONCEPT 1

STEEL

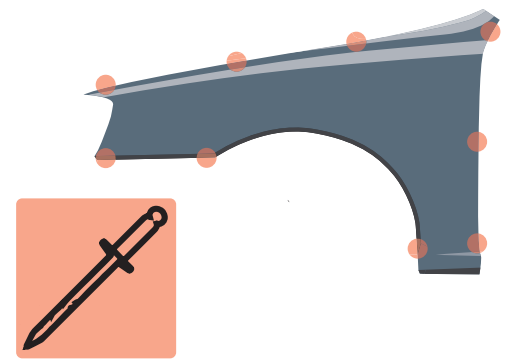

\section{CONCEPT 2}

ALUMINUM
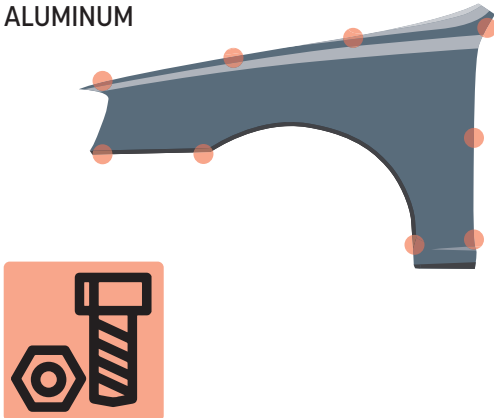

\section{CONCEPT 3 \\ CFRP}

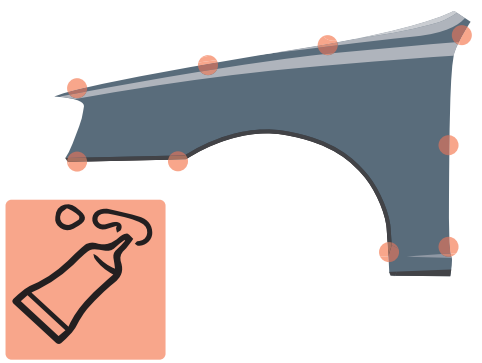

Figure 53. Four different material and joining concepts for a front fender of a passenger vehicle. The orange spots on the fenders indicate where the fender is joined to the vehicle body.. 
In this example, the best possible joining technology for the steel fender is riveting, for aluminum self-piercing screws, for CFRP adhesive bonding and for ABS a combination of snap joints and screws. When assembling the front fender to the body, all four technologies can be made to take the same time, but the curing time for the adhesive material is longer than the time taken for the other technologies to reach maximum strength. If the work station after the fender assembly is the assembly of fender linings or trim pieces, activities in this work station put pressure on the fender and might exceed the bonding strength of the adhesive at that time. This means that the CFRP fender should have a different assembly sequencing in order to reduce quality issues (as shown in figure 54). If products using the CFRP fender solution are produced alongside one or more products using any of the other solutions in parallel in a mixed-model assembly line, parts of the assembly line should have parallel tracks for different products. This could possibly explain the differentiation in technologies and solutions developed by different automotive companies and sometimes differences between models of the same brand; if companies have prioritized different components in different segment vehicles made in different production systems (both organizationally and architecturally), the end result in terms of material selection, geometry and production process should vary.

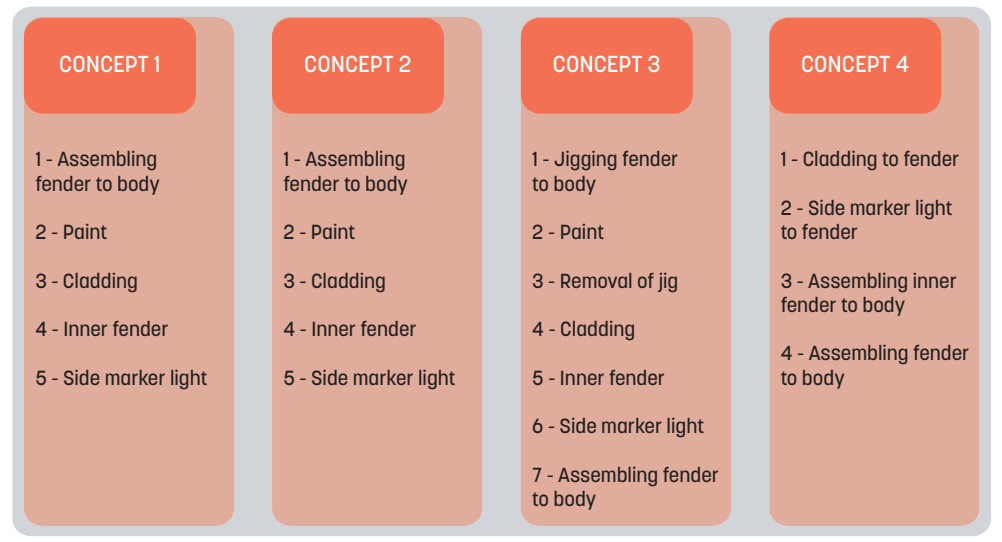

Figure 54. The suitable production process sequences corresponding to the concepts from figure 53. 


\section{Scenario 2: Material substitution in roof panels}

Another example would be the roof panel of a station wagon. The panel could be made in several different materials: steel alloys, aluminum alloys, CFRP, thermoplastics, or natural composites. All these materials are viable solutions, but since the painting process (which occurs after the work station where the roof is joined to the BIW in a traditional flow) requires a higher temperature and a chemical resistance that some of the viable materials cannot manage, some selections of material require the introduction of a new work station joining the roof to the BIW after the paint curing. In a mixed model assembly-line flow, this creates unused work stations for all products: that is, older, steel-based products that pass through a work station in final assembly and newer products that leave the body and welding shop without a roof.

\section{Selecting technology}

Both the use of technology in the assembly system and the principal layout of how the assembly process is organized will affect which type of geometries and materials are preferred by the production system.

In the papers A and $\mathrm{B}$, as well as in Case 2, joining technology is mentioned as a technology change when introducing new materials. Some joining technologies are unsuitable or impossible for some materials, and therefore the selection of material and the selection of joining technology is therefore a coupled system of decisions. If the component material and joining technology is changed, this creates new requirements in assembly. This is especially the case if mixed-model assembly lines are in use, as assembly cells need to be reconfigured to manage multiple joining technologies in different materials with the same cell time as before. If this is not solved, solutions like partly parallel lines could possibly be implemented, but require space to put additional assembly cells in close proximity. 
In the technological mapping, it was shown that material properties in certain production system-relevant parameters can differ widely between steel alloys, aluminum alloys, polymers and polymer composites. Using the thermal expansion rate and maximum service temperature as an example, the difference in thermal expansion results in technological challenges when introducing multi-material body panels before the paint curing station, which is described in the generalized production system model for vehicle manufacturing. Different materials will expand at different rates, resulting in stress and tension within the body. This stress risks reducing quality or increasing scrap rates. The subject of value engineering within the DFMA work [53] also becomes increasingly complicated, since a combination of products and materials needs to be taken into account, and the risk for sub-optimization of specific components increases.

\section{Knowledge sharing and communication}

All the cases studied, especially Case 3, indicate the need to work iteratively and integratively in order to manage the introduction of new materials. The integrated and iterative approach both reduces risk and increases the possibility of finding new business opportunities. This also correlates with product development theory on linear product development process models. While the integrated and iterative approach have significant positive aspects, it may demand more from a project management standpoint, since Case 1 highlights a risk with integrated projects in the form of "mission creep". Mission creep is the phenomenon where the project scope grows in a recursive manner due to the project team constantly finding ripple-down effects from changes in the product or production system. Project management needs to set up clear boundaries for the project, and adhere to these even if there might be positive side effects from going outside the delimitations. 
When transitioning from separate or parallel to integrated product and production development, both product developers and production developers can and must learn from each other. Production developers could learn from the early phases of product development (as described in, for example, Ulrich and Eppinger [31]), with its broad data collection and high level of abstraction, in order to identify core challenges and issues. Product developers, on the other hand, could benefit from learning what data and information to gather regarding production from production developers. Production developers could also incorporate simulation and analysis tools connected to product development, while product developers could incorporate production development knowledge earlier in the process in order to develop concepts that are possible to produce.

\section{Managing requirements}

All the cases indicate that production requirements are expressed and managed differently than functional requirements, and the product development process theory reinforces this by separating the formulation of functional requirements and production analysis (especially in [31]). Some of the observations in the projects indicate that product developers view production requirements as a framework of limitations rather than functional requirements. When looking at introducing new material, this risks resulting in product developers not understanding what is actually happening in the production process. This means that developers have two options for analyzing production requirements: accepting them as is and working accordingly, or dismissing them and ignoring the requirements completely. Managing requirements like this differs from how user requirements are managed, where the analysis phase of formulating requirements both includes an abstraction of one or multiple use cases, and an acceptance for manipulating the use case scenario via the product itself (some behaviors are encouraged and some are discouraged via the design itself). 
The black-and-white view of production requirements also restricts the design space, since no compromise is possible. The "wiggle room" or negotiation on qualities is restricted, and thus fewer solutions are possible.

\section{Methods and tools}

Findings from the case projects indicate that there is an interplay between people, organizations, work processes and methods and tools when working in integrated product and production development projects. One way of viewing this can be seen in Figure 55, with these four factors described based on a people or functionality focus on the one hand, and a number of entities focus on the other. This describes how decisions can be affected mainly by organizations, individuals, work processes or methods and tools factors. The especially interesting part is the interface between the factors and their effect on resulting design decisions.

PEOPLE

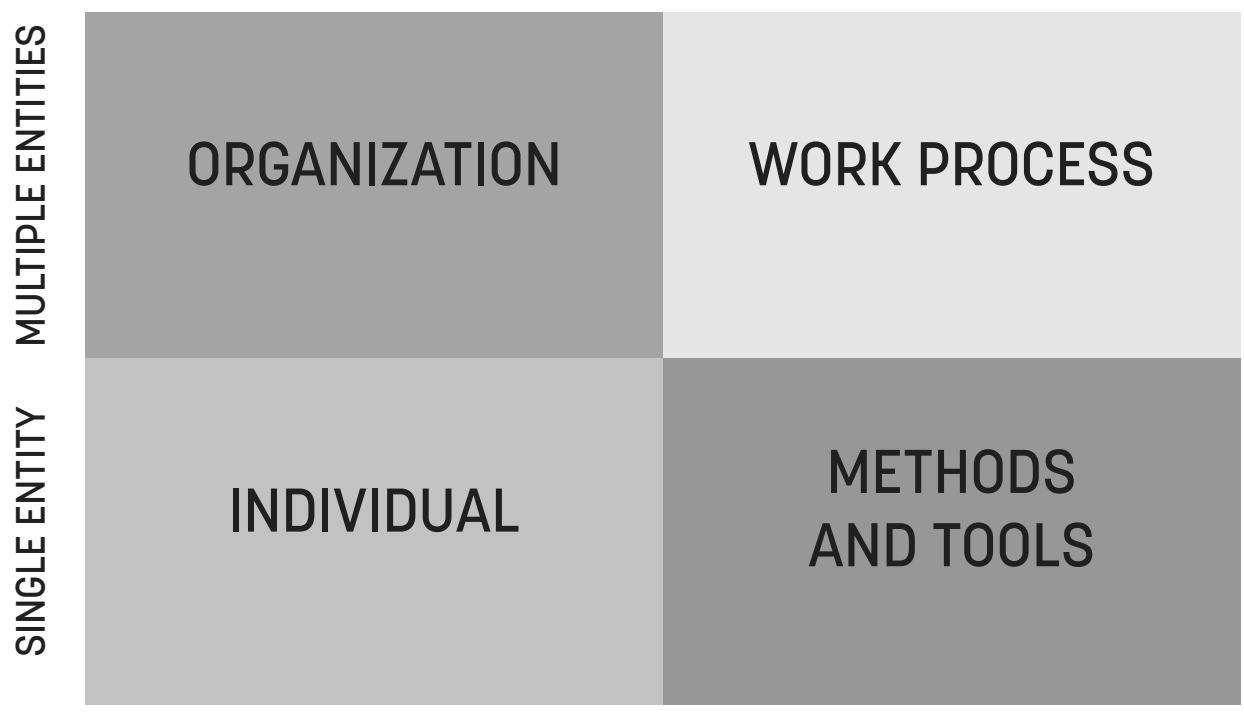

Figure 55. A preliminary description of the interplay of decision factors in integrated product and production development.
TECHNICAL FUNCTIONALITY

\section{METHODS} AND TOOLS 
From Case 1, the assumed conflict between cost, sustainability and mass reduction from a material change can be attributed to individual factors (stemming from team members' knowledge and previous experience). From Case 2, the team members' identification of material interfaces as a risk factor can be attributed to individual factors (stemming from team members' knowledge and previous experience) and factors regarding tools and methods (a lack of tools investigating the effects of material interfaces). From Case 3, the abandonment of the project due to a need for arbitrary decisions can be attributed to work process factors (the completely sequential work process forcing a decision without "looking forward"). From Case 4, the lack of points of contact to in-house experts can be attributed to organizational factors (organizational divide between functions in the company), while the lack of ability to simulate effects of the changes to the system can be attributed to individual factors and factors regarding methods and tools.

Common to all the case projects is that the combination of material, geometry and production processes is changed from previous products. There is a relationship between these three parameters of a product or component, and the optimum solution is found where these three factors intersect [63].

With changes in the relationship between the three factors visualized in Figure 52, a new optimum solution is found in the intersection of the three factors. This reasoning could also explain the material differences in the industrial examples, since production processes (in terms of infrastructure, machine availability, supply chain and assembly strategy and sequence) and geometry differ between companies giving different optimum solutions. 


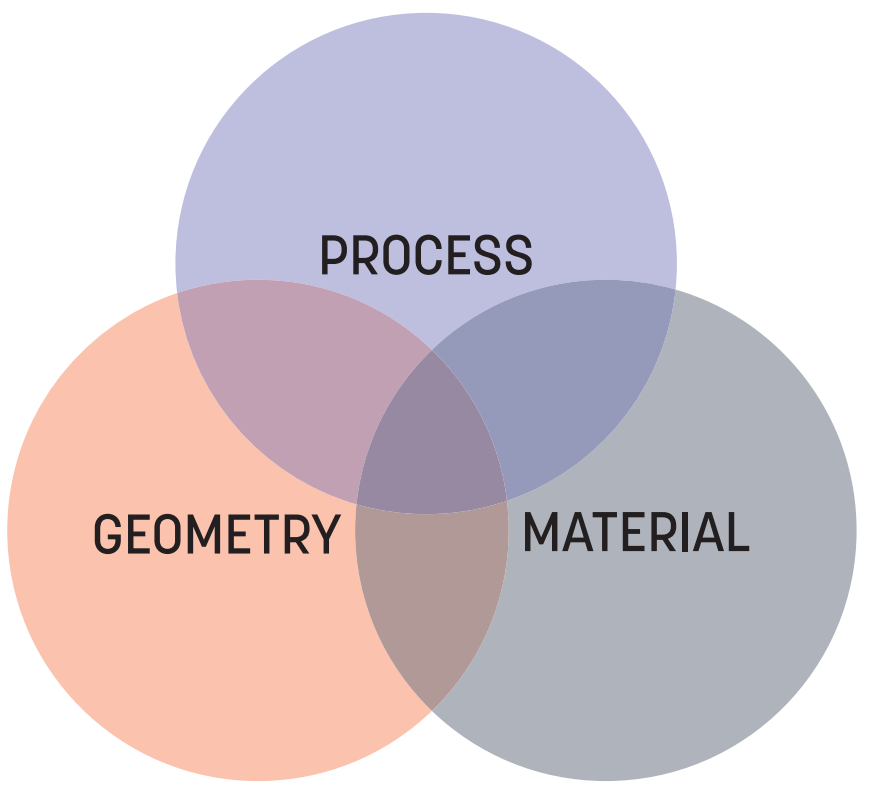

Figure 56. The interlinked relationship between process, geometry and material, adapted from [63].

\section{Modularity}

For each product-producing company, product range and platforms/modularity need to be managed within the introduction of new materials into existing production infrastructure. This could be seen in where (in terms of components or systems) materials are introduced, in which type of materials are introduced and in which product in the range that is the first to have new materials introduced.

While the effect of manufacturing technology on material selection might be more easily understood (as an example, most polymers cannot be joined using traditional welding, and different polymers cannot necessarily be welded together), the assembly system also seems to have a significant effect on the product, and there are indications that the assembly system affects the design space. Both these effects from the manufacturing technologies and assembly systems point towards a need for including material selection and possible material change in future products when defining the product modularity. This is partly in line with Andersson's [48] work on 


\section{INTERFACES}

ASSEMBLY

INTRODUCTION

MATERIAL

SELECTION

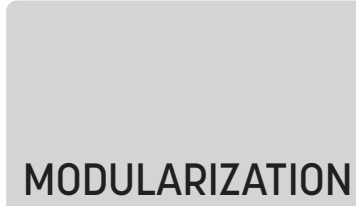

STANDARDIZATION

\section{MANUFACTURING}

\section{FUNCTIONALITY}

Figure 57. A visualization of factors affecting modularization decisions in products, with a suggestion for adding "new material introduction" as a complementing factor.

flexibility and the need for modularization efforts to take product redesign into account. In the case of new materials, factors such as susceptibility to adapt new materials, module size and assembly, module generality within the product range and expected life span of the technology in the module should be taken into account when evaluating whether or not a module is suitable for new material introduction. In the modularization work, the possibility for the introduction of new materials should be added as a factor when reevaluating module composition; components with a high level of probability for introduction of new materials could perhaps be excluded from the platform in order to reduce the risk of new material introduction. This is also in some way supported by Krishnan and Gupta [49], though on an intra-product level. 



\subsection{CONCLUSIONS}

In order to introduce new materials in the automotive industry, there needs to be an organization, technological knowledge, theoretical knowledge and tools available to enable:

-Efficient knowledge gathering

-Understanding the production system's effect on the product

-Understanding the product's effect on the production system

-Selecting technology

-Knowledge sharing and communication

•Managing requirements

-Methods and tools

-Modularity

These aspects, further discussed in the analysis chapter, correspond to the research questions and conclusions as follows.

RQ1: How does the production system affect the introduction of new materials in products?

Material properties affect almost every aspect of production. The production system and production development, therefore, have a significant effect on the introduction of new materials, and the introduction of new materials affects the need for production development in terms of pace and direction. A significant contributor to the complexity and risk of introducing new materials and technologies is the secondary and tertiary effects from the production system on the product. The layout of the assembly system also has an effect on the risk and cost of introducing new materials. Studies performed indicate that the mixed-model assembly line can be a restricting factor when looking at the introduction of new materials, due to the need for compatibility between new and old technology in the same work station. 
Important factors here are the understanding of the production system's effect on the product, the product's effect on the production system and the selection of technology.

RQ2: How well suited are current product development processes to manage the introduction of new materials?

Current product development methodology has issues with managing production system development and managing ambiguous input into complex systems with a lack of relevant data to analyze. While there are initiatives to either manage development with a minimal amount of data available or manage parallel and integrated development, most methodology struggles with managing both these aspects. As of yet, integrated development is assumed to require detailed data on a level not suitable for the introduction of new materials in existing production systems. With new additions to both product development and production development methodology, these issues should be manageable. Important factors here are the understanding of the production system's effect on the product, knowledge sharing, communication and the management of requirements.

RQ3: How could product and production development processes be altered to ease the introduction of new materials?

One possible way of resolving the issues could be to view production as a user of the product it is producing. This gives a more dynamic management of requirements and expects development both in the product and production system. Another way would be to view the product and production system as a combined system of systems, and develop them jointly. This would require some additional work on what to decide at which point, and how to manage the low level of data and low fidelity of data that could affect this approach. 
In general, both product and production development processes need to be improved in order to enable integrated product and production development, something that will be of importance when introducing new materials in existing production systems. Product development processes could be improved by improving and understanding the actual needs and requirements from production, as more abstraction and analysis could be beneficial before developing towards the requirements. Production development processes could be improved by adapting the broad data collection from the early stages of product development in order to further understand the secondary and tertiary effects of the production system on the product. Important factors here are knowledge sharing, communication, the management of requirements and product modularity. 


\subsection{FUTURE RESEARCH}

During the span of the work presented in this thesis, a number of future research possibilities have been identified. In this section, some ideas for future work are presented and discussed.

1. Generalization to other product genres

2. Combining existing design methodologies

3. Assembly system effects on the product design space

4. Further development of requirements management

5. Expansion to "smart materials"

6. Developing the research methodology

Firstly, it is of great interest to evaluate the possibility to generalize the findings from this thesis to other product genres, and not just passenger vehicles. While there is nothing obviously limiting the conclusions to the automotive industry, but instead to certain aspects of the product (market demands, complexity) and production system (complexity, investment level, OEM/supplier network), the conclusions have not been tested for other industries.

Future research efforts should investigate possibilities of combining existing methodologies to manage the challenges of introducing new material in existing production systems. Both material-focused and production-focused methodologies exist; material-driven design is an example of the former, and design for manufacturing and assembly is an example of the latter. Combining methods like these could help create more efficient methods for introducing new materials.

Parts of the analysis in this thesis point towards an influence from the assembly system configuration on the success of introducing new materials in existing production systems. This can be seen in the analysis sections about understanding the production system's effect on the product and the selection of technology. 
Interesting parameters to investigate would be the configuration of the assembly system, tact time and physical layout of the assembly system.

One recurring theme in this thesis is the management of requirements when introducing new materials. Production requirements seem to be managed in a different way from other requirements, both in terms of collection and development towards these requirements.

This thesis is strictly focused on the introduction of new materials in existing production systems. With the introduction of sensor technology and microprocessors integrated into components, so-called "smart products", new technology should also be introduced into existing production systems. Whether this introduction of new technology and the use of integrated sensor and processing capabilities creates the same challenges as the introduction of new materials is not yet investigated. Can "smart materials" or "smart components" be treated as any material and introduced into the production system using the knowledge gathered in the work presented in this thesis? This should be further investigated, and the knowledge presented in this thesis should be amended to further expand the knowledge on how to implement new technology in products when utilizing an existing production system.

Lastly, the methodology of using well-designed student case projects as case studies for data gathering should be further developed. This method is promising, but similarities should be quantified and the difference in insights between industry and student case projects should be further investigated in order to use different cases in the most efficient way for research. This should be done to make knowledge gathering more efficient. 



\section{REFERENCES}

[1] United Nations, "The Global Goals," United Nations, [Online]. Available: http://www.globalgoals.org/. [Accessed 10 October 2017].

[2] United Nations General Assembly, "Resolution Adopted by the General Assembly on 25 September 2015," United Nations, 2015.

[3] W. Swenson Jr. och R. Traficante, "The Influence of Aluminum Properties on the Design, Manufacturability and Economics of an Automotive Body Panel," i Society of Automotive Engineers International Congress and Exposition, Detroit, Michigan, 1982.

[4] J. V. Busch och J. R. Dieffenbach, "Economic Criteria for Sensible Selection of Body Panel Materials," SAE Technical Paper Series, 1991.

[5] D. M. Baskin, S. Dinda och T. S. Moore, "A Simple Approach to Selecting Automotive Body-in-White Primary-Structural Materials," SAE Technical Paper Series, 2002.

[6] A. Airoldi, S. Bertoli, L. Lanzi, M. Sirna och G. Sala, ”Design of a Motorcycle Composite Swing-Arm by Means of Multi-Objective Optimization," Applied Composite Materials, nr 19, pp. 599-618, 2012.

[7] A. Björnsson, Enabling Automation of Composite Manufacturing Through the Use of Off-The-Shelf-Solutions, Linköping: Division of Manufacturing Engineering, Linköping University, 2014.

[8] Naturvårdsverket, "National Inventory Report Sweden 2016 - Greenhouse Gas Emission Inventories 1990-2014," Naturvårdsverket, Stockholm, 2016.

[9] H. Kharas, "The Emerging Middle Class in Developing Countries," OECD Development Centre, France, 2010. 
[10] H. Koo, ”The Global Middle Class: How Is It Made, What Does It Represent?," Globalizations, vol. 13, nr 4, pp. 440-453, 2016.

[11] Trafikanalys, "The Swedish National Travel Survey 2011," Trafikanalys, 2011.

[12] Trafikanalys, "The Swedish National Travel Survey 2015-2016," Trafikanalys, 2017 .

[13] S. D. Davis, S. W. Diegel and R. G. Boundy, Transportation Energy Data Book, edition 28, Oak Ridge: U.S. Department of Energy, 2009.

[14] S. C. Davis, S. W. Diegel and R. G. Boundy, Transportation Energy Data Book - Edition 31, Oak Ridge: U.S. Department of Energy, 2012.

[15] M. P. Groover, Automation, Production Systems and Computer-Integrated Manufacturing, USA: Pearson Education Inc., 2008.

[16] V. Krishnan och K. Ulrich, "Product Development Decisions: A Review Of The Literature," Management Science, vol. 47, nr 1, pp. 1-21, 2001.

[17] D. Unger och S. Eppinger, ”Improving Product Development Process Design - A Method For Managing Information Flow, Risks and Iterations,” Journal of Engineering Design, vol. 22, nr 10, pp. 689-699, 2011.

[18] T. R. Browning, J. J. Deyst, S. D. Eppinger och D. E. Whitney, ”Adding Value in Product Development by Creating Information and Reducing Risk, IEEE Transactions on Engineering Management, vol. 49, nr 4, pp. 443-457, 2002.

[19] M. Rabe, "Volvo Torslandaverken fyller 50 år,” Teknikens Värld, 2 April 2014. [Online]. Available: http://teknikensvarld.se/volvo-torslandaverken-fyller-50-ar-116434/?_ga=1.50004709.276116223.1453217176. [Accessed 26 April $2017]$.

[20] C. Lee och G. Vairaktarakis, "Workforce planning in mixed model assembly systems,” Operations Research, pp. 553-567, 1997. 
[21] Volvo Car Group, "All-new XC90 the first Volvo built on the company's new Scalable Product Architecture,” 12 August 2014. [Online]. Available: https://www. media.volvocars.com/global/en-gb/media/pressreleases/148966/all-new-xc90-willbe-the-first-volvo-built-on-the-companys-new-scalable-product-architecture. [Accessed 5 May 2017].

[22] Volvo Car Group, "The new Volvo V90 will benefit from over 60 years of estate heritage," 9 February 2016. [Online]. Available: https://www.media.volvocars. com/global/en-gb/media/pressreleases/173558/the-new-volvo-v90-will-benefitfrom-over-60-years-of-estate-heritage. [Accessed 5 May 2017].

[23] Volvo Car Group , "The first new Volvo XC60 rolls off the production line in Torslanda, Sweden," 26 April 2017. [Online]. Available: https://www.media.volvocars.com/global/en-gb/media/pressreleases/207630/the-first-new-volvo-xc60rolls-off-the-production-line-in-torslanda-sweden. [Accessed 5 May 2017].

[24] K. T. Ulrich, D. Sartorius, S. Pearson och M. Jakiela, "Including the Value of Time in Design-For-Manufacturing Decision Making,” Management Science, vol. 39, nr 4, pp. 429-447, 1993.

[25] R. G. Cooper, ”Stage-Gate Systems: A New Tool For Managing New Products," Business Horizons, Vol. 1 /2 May-June, pp. 44-54, 1990.

[26] G. Pahl och W. Beitz, Engineering Design - A Systematic Approach, Great Britain: Springer-Verlag, 1996.

[27] T. E. Jensen och M. M. Andreasen, ”Design Methods in Practice - Beyond The "Systematic" Approach of Pahl \& Beitz," i Proceedings of the 11th International Design Conference DESIGN 2010, Dubrovnik, Croatia, 2010.

[28] D. L. Parnas och P. C. Clements, "A Rational Design Process: How And Why To Fake It," IEEE Transactions on Software Engineering, Vol. 1/2 SE-12, nr 2, pp. 251-257, 1986. 
[29] D. Gerwin och N. J. Barrowman, ”An Evaluation of Research on Integrated Product Development," Management Science, vol. 48, nr 7, pp. 938-953, 2002.

[30] R. Dekkers, C. Chang och J. Kreutzfeldt, "The Interface Between "Product Design and Engineering” and Manufacturing: A Review of the Literature and Empirical Evidence,” International Journal of Production Economics, vol. 144, pp. 316333, 2013.

[31] K. T. Ulrich och S. D. Eppinger, Product design and development, Singapore: McGraw-Hill, 2008.

[32] D. G. Ullman, The Mechanical Design Process, Singapore: McGraw-Hill , 2010.

[33] R. G. Cooper, "What's Next? After Stage-Gate," Research-Technology Management, Vol. 1/2 January-February, pp. 20-31, 2014.

[34] R. G. Cooper, S. J. Edgett och E. J. Kleinschmidt, ”Optimizing The Stage-Gate Process: What Best-Practice Companies Do - I,” Research Technology Management, Vol. 1/2 September-October, pp. 21-27, 2002.

[35] R. G. Cooper, S. J. Edgett och E. J. Kleinschmidt, ”Optimizing The Stage-Gate Process: What Best-Practice Companies Do: II,” Research Technology Management, Vol. 1/2 November-December, pp. 43-49, 2002.

[36] V. Hubka och W. Ernst Eder, Engineering Design - General Procedural Model of Engineering Design, Zürich: Heurista, 1992.

[37] B. Prasad, Concurrent Engineering Fundamentals - Integrated Product and Process Organization, USA: Prentice Hall LTD, 1996.

[38] S. Gedell, M. T. Michaelis och H. Johannesson, "Integrated Model for Co-Development of Products and Production Systems - A Systems Theory Approach," Concurrent Engineering: Research and Applications, vol. 19, pp. 139-156, 2011. 
[39] Department of Defense, Systems Engineering Fundamentals, Fort Belvoir, Virginia: Defense Acquisition University Press, 2001.

[40] R. G. Cooper och A. F. Sommer, "From Experience: The Agile-Stage-Gate Hybrid Model: A Promising New Approach and a New Research Opportunity, Journal of Product Innovation Management, vol. 33, nr 5, pp. 513-526, 2016.

[41] B. Davis, Agile Practices for Waterfall Projects - Shifting Processes for Competitive Advantage, USA: J.Ross Publishing, 2013.

[42] N. Worren, K. Moore och P. Cardona, "Modularity, Strategic Flexibility, and Firm Performance: A Study of the Home Appliance Industry, Strategic Management Journal, vol. 23, pp. 1123-1140, 2002.

[43] S. Lorenzi och A. Di Lello, ”Product Modularity Theory and Practice: The Benefits and Difficulties in Implementation Within a Company," International Journal of Automotive Technology and Management, vol. 1, nr 4, pp. 425-448, 2001.

[44] R. Sanchez, "Using Modularity to Manage the Interactions of Technical and Industrial Design,” Design Management Journal, vol. 2, nr 1, pp. 8-19, 2002.

[45] K. Ulrich, "The Role of Product Architecture in the Manufacturing Firm," Research Policy, vol. 24, pp. 419-440, 1995.

[46] T. Magnusson och N. Lakemond, "Evolving Schemes of Interpretation: Investigating the Dual Role of Architectures in New Product Development," R\&D Management, vol. 47, nr 1, pp. 36-46, 2015.

[47] T. Shibata, M. Yano och F. Kodama, "Empirical Analysis of Evolution of Product Architecture - Fanuc Numerical Controllers from 1962 to 1997,” Research Policy, vol. 34, pp. 13-31, 2005.

[48] T. Anderson, Aesthetic Flexibility - Modularity of Visual Form in Product Portfolios and Branded Products, Linköping: Linköping University, 2016.

[49] V. Krishnan och S. Gupta, "Appropriateness and Impact of Platform-Based Development," Management Science, vol. 47, nr 1, pp. 52-68, 2001. 
[50] T. W. Simpson, "Product Platform Design and Customization: Status and Promise," Artificial Intelligence for Engineering Design, Analysis and Manufacturing, vol. 18, pp. 3-20, 2004.

[51] J. Jiao, T. W. Simpson och Z. Siddique, "Product Family Design and Platform-Based Product Development: A State-Of-The-Art Review, Journal of Intelligent Manufacturing, vol. 18, pp. 5-29, 2007.

[52] J. Herbertsson, Holistic Design for Manufacture - A Theoretical Analysis, Linköping: Linköping University, 1995.

[53] D. E. Whitney, "Manufacturing By Design," i Design for Manufacture - Strategies, Principles and Techniques, Great Britain, Addison-Wesley Publishing Company, 1991, pp. 37-49.

[54] G. Boothroyd, P. Dewhurst och W. A. Knight, Product Design for Manufacture and Assembly, USA: Taylor \& Francis, 2011.

[55] S. Kalpakjian och S. Schmid, Manufacturing Engineering and Technology, USA: Prentice-Hall, 2001.

[56] Merriam-Webster, "Production | Definition of Production by Merriam-Webster," Merriam-Webster, [Online]. Available: https://www.merriam-webster.com/ dictionary/production. [Accessed 15 September 2017].

[57] Merriam-Webster, "Manufacturing | Definition of Manufacturing by Merriam-Webster," Merriam-Webster, [Online]. Available: https://www.merriam-webster.com/dictionary/manufacturing. [Accessed 15 September 2017].

[58] A. E. W. Jarfors, T. Carlsson, A. Eliasson, H. Keife, C.-M. Nicolescu, B. Rundqvist, M. Bejhem och B. Sandberg, Tillverkningsteknologi, Hungary: Studentlitteratur, 2010.

[59] P. Beardmore och C. F. Johnson, "The Potential for Composites in Structural Automotive Applications," Composites Science and Technology, vol. 26, pp. 251-281, 1986. 
[60] E. Tempelman, H. Shercliff och B. Ninaber van Eyben, Manufacturing and Design - Understanding the Principles of How Things are Made, Elsevier Ltd., 2014. [61] M. Bellgran, Systematic Design of Assembly Systems - Preconditions and Design Process Planning, Linköping: Department of Mechanical Engineering, Linköping University, 1998.

[62] M. Groover, Automation Production Systems, And Computer-Integrated Manufacturing, 3rd red., USA: Pearson Education, 2008.

[63] F. Henriksson och K. Johansen, "An outlook on multi material body solutions in the automotive industry - possibilities and manufacturing challenges," i SAE World Congress 2016, Detroit, Michigan, USA, 2016.

[64] M. Vielhaber och P. Stoffels, "Product Development vs. Production Development," i 24th CIRP Design Conference, Milan, Italy, 2014.

[65] C. Schätz, A Methodology for Production Development - The Body of Knowledge Approach, Trondheim: Norwegian University of Science and Technology, 2006.

[66] A. Bryan, J. Ko, S. J. Hu och Y. Koren, ”Co-Evolution of Product Families and Assembly Systems," Annals of the CIRP, nr 56, pp. 41-44, 2007.

[67] Y. P. Gupta och S. Goyal, ”Flexibility of Manufacturing Systems: Concepts and Measurements," European Journal of Operational Research, nr 43, pp. 119-135, 1989.

[68] M. Mandelbaum, Flexibility in Decision Making - An Exploration and Unification, Toronto: University of Toronto, 19781.

[69] D. M. Upton, ”The Management of Manufacturing Flexibility”, California Management Review, vol. Winter, pp. 72-89, 1994.

[70] D. E. D’Souza och F. P. Williams, "Toward a Taxonomy of Manufacturing Flexibility Dimensions,” Journal of Operations Management, nr 18, pp. 577-593, 2000.

[71] N. Slack, "The Flexibility of Manufacturing Systems," International Journal of Operations and Production Management, vol. 12, nr 25, pp. 1190-1200, 2005. 
[72] J. Browne, D. Dubois, K. Rathmill, S. P. Sethi och K. E. Stecke, ”Types of Flexibility and Classification of Flexible Manufacturing Systems," University of Michigan, 1984.

[73] R. Beach, A. Muhlemann, D. Price, A. Paterson och J. Sharp, ”A Review of Manufacturing Flexibility, European Journal of Operational Research, vol. 122, pp. 41-57, 2000.

[74] R. Yin, Case Study Research - Design and Methods, Sage, 2014.

[75] J. Trevelyan, ”Reconstructing Engineering From Practice," Engineering Studies, vol. 2, nr 3, pp. 175-195, 2010.

[76] S. Timpf, "Abstraction, Levels of Details, and Hierarchies in Map Series," i Spatial Information Theory - Cognitive and Computational Foundations of Geographic Information Science, C. Freksa och D. Mark, Red., London, Springer, 1999, pp. 125-140.

[77] C. Potts, "Software-Engineering Research Revisited," IEEE Software, nr September, pp. 19-28, 1993.

[78] A. Björnsson, Automated Layup and Forming of Prepreg Laminates, Linköping : Linköping University, 2017.

[79] S. Ottosson och E. Björk, "Research on Dynamic Systems - Some Considerations," Technovation, nr 24, pp. 863-869, 2004.

[80] A. Harrison, "Case Study Research,” i Essential Skills for Management Research, Beverly Hills, Sage, 2002, pp. 158-180.

[81] B. Diffner, Combining Flexibility and Efficiency in Automotive Assembly Preparing for New Powertrain Vehicles, Linköping: Linköping University, 2001.

[82] P. Tuli och R. Shankar, "Collaborative and lean new product development approach: a case study in the automotive product design," International Journal of Production Research, vol. 53, nr 8, pp. 2457-2471, 2015. 
[83] M. Tarkian, ”Design Automation for Multidisciplinary Optimization - A High Level CAD Template Approach,” Linköping University, Linköping, 2012.

[84] S. Shahbazi och M. Kurdve, "Material Efficiency in Manufacturing," i Swedish Production Symposium, Gothenburg, 2014.

[85] V. Gopinath, K. Johansen och Å. Gustafsson, ”Design Criteria for a Conceptual End Effector for Physical Human Robot Production Cell," i Swedish Production Symposium, Gothenburg, 2014.

[86] H. Skipworth och A. Harrison, "Implications of form postponement to manufacturing: a case study, International Journal of Production Research, vol. 10, nr 42, pp. 2063-2081, 2004.

[87] C. Soosay, B. Nunes, D. J. Bennett, A. Sohal, J. Jabar och M. Winroth, ”Strategies for sustaining manufacturing competitiveness," Journal of Manufacturing Technology Management, vol. 27, nr 1, pp. 6-37, 2016.

[88] E. Stringer, Action Research, Sage, 2007.

[89] S. André, Supporting the Utilization of a Platform Approach in the Engineer-to-Order Supplier Industry, Jönköping: Jönköping University - School of Engineering, 2017.

[90] M. Ström, Improving Engineering Change Processes by Using Lean Principles, Göteborg: Chalmers University of Technology, 2013.

[91] K. Williamson, Learning to See, Wagga Wagga, NSW, Australia: Center for Information Studies, 2002.

[92] D. Kickett, D. McCauley och E. Stringer, Community Development Processes: An Introductory Handbook, Perth, Western Australia, Australia: Curtin University of Technology, 1986.

[93] S. Ottosson, "Participation Action Research - A Key to Improved Knowledge of Management," Technovation, nr 23, pp. 87-94, 2003. 
[94] G. E. Dieter, Mechanical Metallurgy, USA: McGraw-Hill, Inc., 1976.

[95] R. R. Craig Jr., Mechanics of Materials, USA: John Wiley \& Sons, Inc, 2000.

[96] A. M. Lovatt, H. R. Shercliff och P. J. Withers, "Material selection and processing," www-materials.eng.cam.ac.uk/mpsite, data courtesy of Granta Design Ltd, Cambridge, UK, 2000.

[97] Granta, "Maximum and Minimum Service Temperatures - Definition and Measurement," [Online]. Available: http://inventor.grantadesign.com/en/notes/science/material/S12b\%20Use\%20temperature.htm. [Accessed 17 July 2017].

[98] R. Tucker, "Trends in Automotive Lightweighting," Metal Finishing, March/ April 2013.

[99] J. Lanfranchini, "The Role Of The Automobile In The Development Of The Plastics And Composite Materials Industry," SAE International, pp. 1.76-1.85, 1988.

[100] M. Pfestorf och J. van Rensburg, "Improving the Functional Properties of the Body-In-White with Lightweight Solutions Applying Multiphase Steel, Aluminium and Composites," SAE Technical Paper Series, 2006.

[101] SAE International, "Altair Enlighten Awards: 2017's best mass-cutting innovations," 3107 2017. [Online]. Available: http://articles.sae.org/15545/. [Accessed 15 August 2017].

[102] G. Gardiner, "Class A Composites: A History," Composites World, 19012017. [Online]. Available: https://www.compositesworld.com/articles/class-a-composites-a-history. [Accessed 02 October 2017].

[103] T. Falconer, Original Corvette 1953-1962, China: MBI Publishing Company, 1997.

[104] M. Vale, Lotus Elan - The complete Story, The Crowood Press Ltd., 2013.

[105] BBC Technology, 2014. [Online]. Available: http://www.bbc.co.uk/news/ technology-12691062. [Accessed 02 June 2014]. 
[106] BMW Sweden, "BMW 7 series Carbon Core," [Online]. Available: http:// www.bmw.se/_common/shared/newvehicles/7series/sedan/2015/showroom/highlights/carbonslider/img/7-series-sedan-carbon.jpg . [Accessed 13 August 2015].

[107] SAE, "Cadillac pursues aluminum/steel mix for new CT6 luxury sedan," 01 04 2015. [Online]. Available: http://articles.sae.org/13986/ . [Accessed 13 August 2015].

[108] SAE International, "2017 Pacifica is first hybrid minivan, rides on all-new FCA platform," [Online]. Available: http://articles.sae.org/14557/. [Accessed 14 August 2017].

[109] L. W. Cheah, "Cars on a Diet: The Material and Energy Impacts of Passenger Vehicle Weight Reduction in the U.S.," Massachusetts Institure of Technology, Cambridge, 2010 .

[110] W.-H. Hucho, Aerodynamics of Road Vehicles - Fourth Edition, USA: SAE, 1998.

[111] K. T. Ulrich och D. J. Ellison, "Holistic Customer Requirements and the Design-Select Decision," Management Science, vol. 45, nr 5, pp. 641-658, 1999.

[112] P. Denzler och M. Wiktorsson, "Maximizing product possibilities while Minimizing process change: A case of introducing Light Weight Material in Automotive Manufacturing," i 26th CIRP Design Conference, Stockholm, 2016.

[113] N. Cross, Engineering Design Methods - Strategies for Product Design (third edition), Wiltshire, Great Britain: John Wiley \& Sons Ltd., 2003. 


\section{Papers}

The papers associated with this thesis have been removed for copyright reasons. For more details about these see:

http:// urn.kb.se/ resolve?urn=urn:nbn:se:liu:diva-142873 